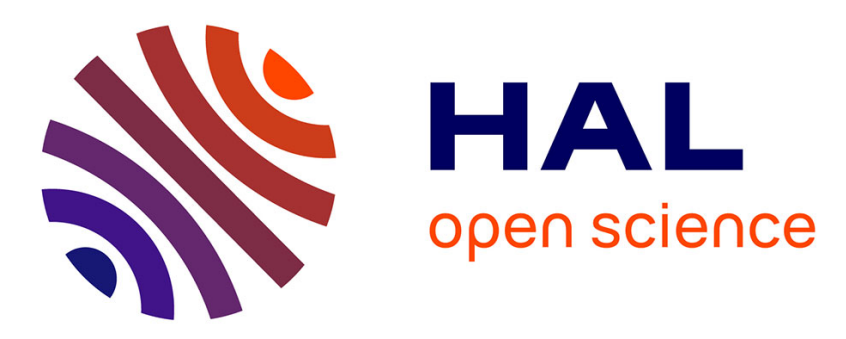

\title{
From bumblebee to bioeconomy: Recent developments and perspectives for sophorolipid biosynthesis
}

Sven Dierickx, Martijn Castelein, Jelle Remmery, Veerle de Clercq, Sofie Lodens, Niki Baccile, Sofie L de Maeseneire, Sophie L.K.W. Roelants, Wim K Soetaert

\section{To cite this version:}

Sven Dierickx, Martijn Castelein, Jelle Remmery, Veerle de Clercq, Sofie Lodens, et al.. From bumblebee to bioeconomy: Recent developments and perspectives for sophorolipid biosynthesis. Biotechnology Advances, 2021, pp.107788. 10.1016/j.biotechadv.2021.107788 . hal-03273220

\section{HAL Id: hal-03273220 \\ https://hal.sorbonne-universite.fr/hal-03273220}

Submitted on 29 Jun 2021

HAL is a multi-disciplinary open access archive for the deposit and dissemination of scientific research documents, whether they are published or not. The documents may come from teaching and research institutions in France or abroad, or from public or private research centers.
L'archive ouverte pluridisciplinaire HAL, est destinée au dépôt et à la diffusion de documents scientifiques de niveau recherche, publiés ou non, émanant des établissements d'enseignement et de recherche français ou étrangers, des laboratoires publics ou privés. 


\section{From bumblebee to bioeconomy: recent 2 developments and perspectives for 3 sophorolipid biosynthesis \\ 4}

\section{Author names and affiliations}

Sven Dierickx 1, Martijn Castelein 1, Jelle Remmery 1, Veerle De Clercq 1, Sofie Lodens 1, Niki Baccile $_{2}$, Sofie L. De Maeseneire ${ }_{1}$, Sophie L. K. W. Roelants ${ }_{1,3, a}$, Wim K. Soetaert ${ }_{1,3}$

${ }^{1}$ Centre for Industrial Biotechnology and Biocatalysis (InBio.be), Department of Biotechnology, Faculty of Bioscience Engineering, Ghent University, Coupure Links 653, 9000 Ghent, Belgium

${ }^{2}$ Centre National de la Recherche Scientifique, Laboratoire de Chimie de la Matière Condensée de Paris, Sorbonne Université, Place Jussieu 4, 75005 Paris, France

${ }^{3}$ Bio Base Europe Pilot Plant, Rodenhuizenkaai 1, 9042 Ghent, Belgium

${ }^{a}$ corresponding author

E-mail (in order of authorship): sven.dierickx@ugent.be, martijn.castelein@ugent.be, jelle.remmery@ugent.be, veedcler.declercq@ugent.be, sofie.lodens@ugent.be, niki.baccile@sorbonne-universite.fr, sofie.demaeseneire@ugent.be, sophie.roelants@ugent.be, wim.soetaert@ugent.be

\section{Abstract}

Sophorolipids are biobased compounds produced by the genera Starmerella and Pseudohyphozyma that gain exponential interest from academic and industrial stakeholders due to their mild and environmental friendly characteristics. Currently, industrially relevant sophorolipid productivities are reached up to $3.7 \mathrm{~g} \cdot \mathrm{L}^{-1} \cdot \mathrm{h}^{-1}$ and sophorolipids are used in the personal care and cleaning industry at small scale. Moreover, applications in crop protection, food, bioflotation and medical fields are being extensively researched. The research and development of sophorolipids is at a crucial stage. Therefore, this work presents an overview of the state-of-the-art on sophorolipid research and their applications, while providing a critical assessment of scientific techniques and standardisation in reporting. In this review, the genuine sophorolipid producing organisms and the natural role of sophorolipids are discussed. Subsequently, an evaluation is made of innovations in production processes and the relevance of in-situ product recovery for process performance is discussed. Furthermore, a critical assessment of application research and its future perspectives are portrayed with a focus on the self- 
assembly of sophorolipid molecules. Following, genetic engineering strategies that affect the sophorolipid physiochemical properties are summarised. Finally, the impact of sophorolipids on the bioeconomy are uncovered, along with relevant future perspectives.

\section{Keywords}

Sophorolipid, biosurfactants, Starmerella, process engineering, genetic engineering, natural role, application research, self-assembly, bioeconomy

\section{Introduction}

In solving worldwide problems caused by human activity, like global warming or the looming loss of biodiversity (Cardinale et al., 2012; Masson-Delmotte et al., 2019), help can come from unexpected places. Indeed, the smallest organisms will help to make big impact, as micro-organisms produce biochemicals with applications in a plethora of domains like human health, agriculture, waste processing and even transport; and these production processes are much more eco-friendly compared to their chemical counterparts and start from renewable resources (Khoo et al., 2016). Particularly interesting biochemicals are the secondary metabolites, as these compounds have an extensive structural variety resulting in a broad spectrum of properties and activities and therefore can substitute or extend the current markets. Academic and industrial interest in a specific type of secondary metabolites is increasing exponentially, namely sophorolipids (SLs). Sophorolipids consist of a hydrophilic sophorose moiety linked by a glycosidic binding to a fatty acid tail (figure 1). The sophorose head can have up to two acetylation groups while the tail commonly consists of 16 to 20 carbon atoms and is saturated to polyunsaturated. SLs can be lactonised due to a condensation reaction between the fatty acid carboxyl group and the sophorose 4" hydroxyl group (figure 1A). A second sophorose moiety can be linked to the fatty acid tail via an ester binding. The resulting molecules are then referred to as bolaform sophorolipids (figure 1B). It should be noted that SLs are predominantly produced in varying mixtures of different congeners, depending on culture conditions and producing organisms (see section 2). As SLs are amphiphilic molecules consisting of a hydrophilic 'head' and aliphatic 'tail', SL application studies and their commercialisation currently focus on their role as a biosurfactant.

Figure 1: Chemical structures of sophorolipid congeners. $R_{1}$ and $R_{2}=H$ or OAcl A) Lactonic SL $\left(C_{18: 1}, \omega-1\right)$ B) Bolaform $\left.S L\left(C_{18: 1}, \omega-1\right) C\right)$ Acidic $\left.S L\left(C_{18: 1}, \omega-1\right) D\right)$ "branched” $S L\left(C_{22: 0,} \omega-10\right)$

The increasing (industrial) interest in SLs can be illustrated by the exponential increase in patents on SLs published from 2010 till now (figure 2A). To gain more insight in the interested industrial fields, an analysis of the top 10 patent classes according to the international patent classification (IPC) over time was performed. Per time period, the top 10 IPC classes were grouped in 
six fields, four according to the applications they claim (biocide, medical, cosmetic or detergent applications) and two regarding production methods (organic chemistry or industrial biotechnology) (figure 2B). Regarding production, the top 10 IPC classes are located mainly in the field of fermentation processes, while for the applications cosmetics and detergents predominate. In the period of 2011-2015, IPC classes concerning biocide applications were positioned in the top 10 but they dropped out in 2016-2019. As one patent can belong to multiple IPC classes and only the top 10 is analysed, it should be noted that figure 2 only shows a trend of the most frequently occurring IPC classes. Moreover, this analysis does not take in to account the impact on the sophorolipid development per single patent. Hence, important fields can be neglected (e.g. genetic engineering).

Figure 2: Average annual counts were collected in the Lens patent database with the search term "sophorolipid*" A) Average annual count of published patents per time period B) Average annual count of top 10 IPC patent codes per time period. IPC codes classified per parent class: biocide application (A01N25/30, A01N43/16, A01P3/00), medical application (A61K31/70, A61K31/7016, A61K31/7024, A61K31/739), cosmetic application (A61K8/00, A61K8/60, A61K8/73, A61Q19/00, A61Q19/10, A61Q5/02), organic chemistry (C07H15/04, C07H15/06, C07H1510), detergent application (C11D1/66, C11D11/00, C11D3/00, C11D3/20, C11D3/22, C11D3/30, C11D3/37, C11D3/386, C11D3/42), fermentation process (C12P19/12, C12P19/44, C12P7/62) (Cambia, 2020)

Sophorolipids are industrially relevant molecules and are clearly the subject of a large number of recent research papers and patent applications. However, an expanding field can suffer from success as incorrect methodologies and the lack of a complete overview can propagate to persistent academic and industrial misunderstandings and failures. Furthermore, the link between academic research and industrial developments is often ignored or incorrect information on industrial developments and requirements is presented. Therefore, this review provides the reader a complete overview and critical assessment of research and industrial development. Moreover, important aspects that are neglected in previous sophorolipid concerning reviews are tackled in this work. More specifically, the selfassembly of sophorolipid molecules which is the main driver for its application potential and the natural role of sophorolipids.

This work is structured to guide the expanding sophorolipid community towards efficient research and commercialisation. To aid researchers, this review provides a critical assessment of scientific techniques used in the field of SLs and proposes a standardisation for reporting. Both academic and industrial stakeholders will benefit from the state-of-the art overviews on producing micro-organisms and their respective SL production spectrum (section 1), unravelled biological functions (section 2), advances in SL production process development (section 3), SL applications (section 4), genetic engineering strategies (section 5) and insights on the industrial potential of SLs and their impact on the bioeconomy (section 6). 


\section{Producing micro-organisms}

Although otherwise reported in the past, all sophorolipid producing organisms are members of the Starmerella clade (genera Starmerella), except Pseudohyphozyma bogoriensis. Though closely related, except $P$. bogoriensis, these yeasts differ in SL production spectrum.

\subsection{Acknowledged sophorolipid producers}

The very first observation of SL production was reported by Gorin et al. (Gorin et al., 1961) in 1961 with the ascomycetous yeast Starmerella apicola, which was originally isolated from sow thistle petals. This yeast was formerly known as Torulopsis magnoliae, T. apicola and Candida apicola (Santos et al., 2018; Tulloch and Spencer, 1968) and produces a heterogeneous SL mixture which mainly consists of lactonic SLs of which the mono- and non-acetylated forms are abundant, and which contains minor amounts of the acidic congeners (Kurtzman et al., 2010). The $\left(\mathrm{C}_{18: 1}\right)$ hydroxy fatty acid group is mainly $\omega-1$ linked to the sophorose head group (Price et al., 2012).

In 1968, Tulloch et al. first described the production of a specific type of acidic sophorolipids by Candida bogoriensis, namely 13-[(2'-0-13-D-glucopyranosyl-8-n-glucopyranosyl)- oxy] docosanoic acid 6',6"-diacetate (figure 1D) (Tulloch et al., 1968). Later on, this yeasts' name was altered to Rhodotorula bogoriensis (Nuñez et al., 2004), and recently it was changed again, to Pseudohyphozyma bogoriensis (Wang et al., 2015). P. bogoriensis was first isolated from the leaf surface of the Randia malleifera shrub in Indonesia. The SLs produced by P. bogoriensis contain 13hydroxydocosanoic acid (13-OH- $\mathrm{C}_{22}$ ) as the lipid moiety (Solaiman et al., 2015) and are also called 'branched $\mathrm{C}_{22}$ SLs'. Also, minor amounts of $\mathrm{C}_{24}$ branched SLs are present in the mixture (Ribeiro et al., 2012a). Both the 'branched' structure and the length of the incorporated fatty acids is unique among SL-producing organisms.

Starmerella bombicola (initially referred to as Torulopsis bombicola or Candida bombicola) was first isolated from the nectar of a bumblebee in 1970 (Spencer et al., 1970). It became the best known and the most intensively studied SL producing yeast species, due to its naturally high production titres (> $200 \mathrm{~g} \cdot \mathrm{L}^{-1}$ ) (Davila et al., 1997; Gao et al., 2013; Van Bogaert et al., 2015; Zhang et al., 2018) and high overall productivities (up to $3.7 \mathrm{~g} \cdot \mathrm{L}^{-1} \cdot \mathrm{h}^{-1}$ ) (Gao et al., 2013). Indeed, S. bombicola is the only SL producing yeast of which the (entire) SL production pathway has been elucidated (figure 5 and described in section 6) (Ciesielska et al., 2014; Saerens et al., 2010; K. M. Saerens et al., 2011b; K. M. J. Saerens et al., 2011c; Van Bogaert et al., 2013). Typically, SLs produced by $S$. bombicola, but also by other strains of the Starmerella clade, contain a hydrophobic hydroxy fatty acid moiety that is $\omega$-1 hydroxystearate $\left(\mathrm{C}_{18: 0}\right), \omega / \omega-1$ hydroxyoleate $\left(\mathrm{C}_{18: 1}\right)$ or hydroxylinoleate $\left(\mathrm{C}_{18: 2}\right)$, but $\omega / \omega-1$ intermediates with $16 \mathrm{C}$-atoms $\left(\mathrm{C}_{16: 0}\right.$ and $\left.\mathrm{C}_{16: 1}\right)$ have also been detected (Ashby et al., 2008; Tulloch et al., 1962). These hydroxy fatty acid moieties are linked to a sophorose moiety. The SLs may be acetylated at the 6' and/or 6" positions of the sophorose moiety (Tulloch et al., 1967) and a 
macrocyclic lactone structure may form between the 4" hydroxyl group of the sophorose molecule and the carboxyl group of the hydroxy fatty acid moiety (Tulloch et al., 1967). In contrast to other species within the Starmerella clade, S. bombicola predominantly produces a di-acetylated $\mathrm{C}_{18: 1}$ lactone form in addition to a minor fraction of the free acid form, but this ratio is susceptible to variation based on culture conditions (see below). Although the SLs of S. bombicola mainly consist of a $\mathrm{C}_{18: 1}$ hydroxy fatty acid, (sub)terminally ( $\omega-1)$ linked to a sophorose molecule, a clear structural diversity in the produced SL mixtures has been demonstrated. Kurtzman et al. (2010) proved this to be the case for the whole Starmerella clade.

In 1987, another SL producing yeast strain was reported, namely Starmerella floricola (formerly known as Candida floricola), which was isolated from dandelion and azalea flowers (Tokuoka et al., 1987). In 2010, Imura et al. (2010) described its ability to produce SLs. These SLs are predominantly di-acetylated $\mathrm{C}_{18: 1}$ acidic SLs. This was confirmed in recent papers by Konishi et al. (2017, 2018), as new $S$. floricola isolates were reported to primarily produce $\omega-1 \mathrm{C}_{18: 1}$ di-acetylated acidic SLs at a concentration of approximately $36.1 \mathrm{~g} \cdot \mathrm{L}^{-1}$ and with a productivity of $0.21 \mathrm{~g} \cdot \mathrm{L}^{-1} \cdot \mathrm{h}^{-1}$ in shake flask experiments when glucose and oleic acid were fed simultaneously.

Starmerella batistae (formerly known as Candida batistae) was first described in 1999. It was isolated from larval provisions, larvae, and pupae of the solitary bees Diadasina distincta and Ptilotrix plumata (Apidae) in Minas Gerais, Brazil (Rosa et al., 1999). The SLs produced by S. batistae consist of $75 \% \omega$-hydroxy fatty acids (mostly $\mathrm{C}_{18: 1}$ and to a very small extent some $\mathrm{C}_{18: 0}$ and $\mathrm{C}_{18: 2}$ congeners), which is different from the SLs produced by S. bombicola, consisting of 65\% - 72\% ( $\omega-1)$-hydroxy fatty acids (Konishi et al., 2008; Inge N A Van Bogaert et al., 2009). Also, S. batistae typically produces more than $60 \%$ acidic SLs, in contrast to S. bombicola, which produces more than $65 \%$ lactonic SLs. It can thus be concluded that $S$. batistae primarily produces $C_{18: 1}$ terminally linked $(\omega)$ diacetylated acidic SLs (Konishi et al., 2008).

In 2010, Kurtzman et al. (2010) evaluated several strains of the Starmerella clade for SL production, including S. stellata, S. riodocensis and Candida. sp. Y-27208, later identified as Starmerella kuoi (Kurtzman, 2012). S. stellata is a common isolate from grape must and can be used in a co-fermentation with S. cerevisiae for wine production (Soden et al., 2000). S. riodocensis was isolated from pollen-nectar provisions, larvae and faecal pellets of Megachile sp. bees (Pimentel et al., 2005), whereas S. kuoi was isolated from concentrated grape juice in Cape Province, South Africa (Kurtzman, 2012). These three strains produce very little lactonised SLs compared to S. bombicola and S. apicola. The major SL produced by these three species is the di-acetylated acidic $\mathrm{C}_{18: 1}$ congener, along with smaller amounts of mono- and non-acetylated acidic $\mathrm{C}_{18: 1}$ SLs (Kurtzman et al., 2010; Kurtzman et al., 2011; Price et al., 2012). S. kuoi and S. riodocensis produce $\omega$ linked SLs, 
while for S. stellata it was not specified whether the hydroxy fatty acid was $\omega$ or $\omega-1$ linked to the sophorose molecule.

\subsection{Controversial sophorolipid producers}

Besides the eight SL producing species mentioned above, which are thoroughly identified and for which the structure of the SLs they produce is thoroughly studied, also some other, more doubtful reports of SL producers were reported, which are critically discussed below.

In 2006, Chen et al. first reported SL-production by the yeast Wickerhamiella domercqiae, which was isolated from oil containing wastewater (not further defined) (Chen et al., 2006). Subsequently, the same group investigated the influence of several nitrogen $(\mathrm{N})$ sources on growth and SL production and composition (Ma et al., 2012, 2011). The formation of acidic SLs was stimulated when inorganic $\mathrm{N}$-sources such as ammonium sulphate were used, whereas the use of organic $\mathrm{N}$ sources promoted the formation of lactonic SLs. Later, they also investigated the influence of metal ions on SL production: addition of $\mathrm{Mg}^{2+}$ ions promoted the production of lactonic SLs, whereas $\mathrm{Fe}^{2+}$ ions promoted the production of acidic SLs (Chen et al., 2014). A patent application for this selective production of either acidic either lactonic SLs was filed in 2014 (Chen and Zhang, 2014; Song, 2013). Several other papers were published about the effects of different factors on the SL production with this species ( $\mathrm{Li}$ et al., 2013, 2012; Liu et al., 2016). However, in the beginning of 2016, strain W. domercqiae Y2A CGMCC 3798, reported in the articles and patent, was reclassified as S. bombicola based on sequence analysis, meaning the conclusions apply to $S$. bombicola instead of $W$. domercqiae (Li et al., 2016). This clearly underlines the importance of thorough strain characterisation.

SL production was reported in 2008 for Wickerhamomyces anomalus, formerly known as Pichia anomala PY1 (Punrata et al., 2020; Thaniyavarn et al., 2008). LC-MS analysis of the product revealed molar mass peaks that could be correlated to $\mathrm{C}_{20: 0}$ and $\mathrm{C}_{18: 1}$ SLs. Yet, Souza et al. (2017) concluded from NMR analysis that the molecules produced by this strain cannot contain a sophorose moiety. However, a full identification was not accomplished. Nevertheless, W. anomalus might not produce SLs, since the molecules claimed to be SLs might not contain a sophorose moiety, as described by Souza et al. (2017).

Candida rugosa and Rhodotorula mucilaginosa, isolated from hydrocarbon contaminated sites, were shown to produce biosurfactants in the presence of $2 \%(v / v)$ diesel as sole carbon- and energy source (Chandran and Das, 2011). It was claimed that C. rugosa produces mono-acetylated lactonic $\mathrm{C}_{18: 1}$ SLs and that $R$. mucilaginosa produces di-acetylated acidic $\mathrm{C}_{18: 1}$ SLs. It was not specified whether the hydroxy fatty acid chains are coupled via the $\omega$ or the $\omega-1$ position. However, the proposed structures should be reconsidered as the reported mass to charge ratios of $\mathrm{m} / z 728$ and $\mathrm{m} / \mathrm{z} 668$ do not correspond to those of the $\mathrm{C}_{18: 1}$ SLs. Though the reported molar masses might be consistent with sodium adducts of $\mathrm{C}_{18: 1}$ congeners (Ribeiro et al., 2012b), this should be checked 
before conclusions can be drawn. In addition, the identification of these two yeasts is doubtful, as it was done using a Vitek yeast card reader, which is not particularly accurate. Chandran and Das (2012) described SL production by Candida tropicalis in 2012. The yeast was isolated from contaminated soil in India and reported to produce SLs in the presence of diesel oil, making it an interesting and efficient diesel oil degrader. However, the same remarks as to their study on C. rugosa and R. mucilaginosa can be made. Strain identification is doubtful and though the reported mass to charge ratio $\mathrm{m} / \mathrm{z}$ of 668 could correspond to the sodium adduct of lactonic $\mathrm{C}_{18: 1}$ SL (Ribeiro et al., 2012b), they claim it corresponds to $\mathrm{C}_{20: 4}$ mono-acetylated lactonic SLs, which is doubtful. Moreover, the reported titre and productivity only amount to $1 \mathrm{~g} \cdot \mathrm{L}^{-1}$ and $0.003 \mathrm{~g} \cdot \mathrm{L}^{-1} \cdot \mathrm{h}^{-1}$, respectively, rendering this strain not particularly interesting for SL production at industrial scale.

The production of SLs by Cyberlindnera samutprakarnensis was first reported in 2013 (Poomtien et al., 2013). The strain was isolated from cosmetic industrial waste in Thailand. In the presence of $2 \%$ glucose and $2 \%$ palm oil it produced $1.89 \mathrm{~g} \cdot \mathrm{L}^{-1}$ crude SLs with a mean volumetric productivity of $0.0113 \mathrm{~g} \cdot \mathrm{L}^{-1} \cdot \mathrm{h}^{-1}$ at shake flask level. The authors claimed production of non-acetylated lactonic $\omega-1 \mathrm{C}_{18: 0} \mathrm{SL}$ and di-acetylated lactonic $\omega-1 \mathrm{C}_{16: 0}$ SLs linked to mass over charge ratios of 574 and 662 in a MALDI-TOF-MS analysis. However, a mass over charge ratio of 574 does not correspond to non-acetylated lactonic $\mathrm{C}_{18: 0} \mathrm{SLs}(\mathrm{m} / \mathrm{z} 606.3604$ [M-H]), so what is actually produced should be further investigated. It could be suggested that they are $\mathrm{C}_{16: 2}$ non-acetylated lactonic SLs. Furthermore, the chromatogram shows a mass of 664 instead of 662. The $m / z$ of 664 might correspond to $\mathrm{C}_{18: 1}$ mono-acetylated acidic SLs instead of the claimed di-acetylated lactonic $\mathrm{C}_{16: 0}$ SLs.

Candida albicans 0-13-1 was described for the first time as a SL-producing yeast in 2012 (Yang et al., 2012). A high titre of $108 \mathrm{~g} \cdot \mathrm{L}^{-1}$ was reported. In the reported mixture mostly $\mathrm{C}_{18: 1}$ diacetylated lactonic SLs were detected, although also the $\mathrm{C}_{18: 2}$ and $\mathrm{C}_{18: 0}$ variants were found. Later, the same research group published a new bioreactor design, enabling integrated SL production using $C$. albicans 0-13-1 (Zhang et al., 2018). However, as there are no other reports claiming SL production by $C$. albicans, it is possible that these authors are actually dealing with another strain as it was in neither of the two publications mentioned how the producing strain was identified.

In 2014, Basak et al. found that Cryptococcus sp. VITGBN2 is a potent producer of SLs in mineral salt media containing vegetable oil as additional carbon source to glucose. The chemical structure of the purified biosurfactant was proposed to be di-acetylated acidic $\mathrm{C}_{18: 1} \mathrm{SL}$. It was not mentioned whether the $\mathrm{C}_{18: 1}$ chain is $\omega$ or $\omega-1$ linked to the sophorose head. This study lacks thorough structure identification analysis by e.g. NMR or MS fragmentation. For example, the MW of the extracted biosurfactant is ambiguous as a $\mathrm{m} / \mathrm{z}$ value of 706 is reported while the unionised monoisotopic mass of a di-acetylated acidic $\mathrm{C}_{18: 1} \mathrm{SL}$ is $706.3776 \mathrm{Da}$. Though the information of the ionisation mode is lacking, it is highly unlikely that this biosurfactant is a di-acetylated acidic $\mathrm{C}_{18: 1} \mathrm{SL}$. 
Sen et. al. (2017) reported on SL production in a novel yeast strain, Rhodotorula babjevae YS3, which was isolated from an agricultural field in Assam, Northeast India. A SL titre and a mean volumetric productivity of $19.0 \mathrm{~g} \cdot \mathrm{L}^{-1}$ and $0.26 \mathrm{~g} \cdot \mathrm{L}^{-1} \cdot \mathrm{h}^{-1}$ were observed, respectively. The production performance might be further increased by optimisation of the process parameters. The product was characterised as a heterogeneous SL product containing lactonic and acidic congeners after analysis through TLC, FTIR and LC-MS. The produced mixture was claimed to contain non-acetylated acidic $\mathrm{C}_{11: 0}$ and $\mathrm{C}_{13: 1} \mathrm{SLs}$, as well as non-acetylated lactonic $\mathrm{C}_{13: 1}, \mathrm{C}_{15: 3}, \mathrm{C}_{16: 0}, \mathrm{C}_{18: 2} \mathrm{SL}$ and di-acetylated lactonic $\mathrm{C}_{18: 0}$ SLs (Sen et al., 2017). However, these conclusions should be treated very critically, as a recent publication of another group claims production of extracellular polyol esters of fatty acids (PEFA) by this microorganism R. babjevae. (Garay et al., 2017), which they also concluded earlier (Cajka et al., 2016). In the latter publication, Garay et al. claim that the masses of the polar functions of the studied molecules point towards sugar alcohols (polyols) instead of hexoses, which were observed in the SL control they used. It is thus doubtful that this species is a SL-producer.

Recently, a new SL-producing microorganism Lachancea thermotolerans BBMCZ7FA20 was isolated from the gut of honeybee, Apis melifera (Mousavi et al., 2015). The authors report the production of both acidic and lactonic SLs, but their conclusions are based solely on FTIR analysis. Production titres went up to $24 \mathrm{~g} \cdot \mathrm{L}^{-1}$ in a shake flask experiment when adding $100 \mathrm{~g} \cdot \mathrm{L}^{-1}$ glucose and $100 \mathrm{~g} \cdot \mathrm{L}^{-1}$ canola oil as substrates; however, more detailed analyses are vital in order to unequivocally confirm the identity of these SLs.

Specifications on the products produced by all above mentioned organisms are given in table 1. It is clear that several alleged SL producing organisms were doubtfully identified, or the structural analysis of the SLs was not sufficiently in depth, thus, most likely not al claimed SL producers are actual SL producers. This illustrates that both proper strain identification and proper SL structure identification is of uttermost importance (Claus and Van Bogaert, 2017). "In the perspective of stringent strain identification, we recommend the use of PCR amplification of reference sequences followed by DNA sequencing and subsequent use of Basic Local Alignment Search Tools (BLAST) to nucleotide sequence databases. Hitherto, all described sophorolipid producers are yeast species and therefore, we recommend the analysis of the internal transcribed spacer (ITS) region in the $18 \mathrm{~S}$ subunit of ribosomal RNA as reference sequence for species identification. However, when strain identification is aimed, we recommend whole genome sequencing and subsequent sequence alignment (Twigg et al., 2020). Our recommendations for standardisation of sophorolipid structure identification are described in section 4."

Table 1: Overview of fully acknowledged SL producers and produced SL variants. DiAc $=$ diacetylated, $M A c=$ mono-acetylated, $N A c=$ non-acetylated, $I D=$ identification $;$ Purple hexagon $=$ glucose, red filled circle $=\mathrm{COOH}$, red open circle $=\mathrm{COO}$, green line $=$ glycosidic bound (cfr. figure 

sophorolipids. a: C18:0, Sls with C16:0 and C16:1 backbones, b: small amounts of SLs with C18:0 and C18:2, c: Mac and DiAc C22:0 hydroxylated at C13. Black square = acknowledged, $\boldsymbol{X}=$ not acknowledged, $\pm=$ more information is necessary.

277

278

279

280

281

282

283

\section{Natural role(s)}

Many yeasts of the Starmerella clade are associated with (bumble)bees or with substrates that are often visited by (bumble)bees. It is thus believed that there is a mutually beneficial relationship between (bumble)bees and various yeast species from the Starmerella clade (Rosa et al., 2003). Although many papers and patents deal with production and application of sophorolipids and their producing microorganisms, the natural role of these secondary metabolites for their natural producers remains elusive. Why do these yeasts, found in a very specific niche, produce these non-essential secondary metabolites?

The fact that SLs are secondary metabolites indicates they do not fulfil (an) essential function(s) in cell growth and/or -maintenance, but that their presence favours the producing organism in specific conditions, resulting in an evolutionary benefit which sustains production (Hommel and Ratledge, 1993). The elucidation of the natural role(s) of SLs thus leads back to the question about the evolutionary benefit of these molecules for the producing organism. The benefits associated with the production of other biosurfactants are as diverse as the comprising chemical structures and the microorganisms producing them: e.g. the cyclic lipopeptide surfactin shows antimicrobial properties and is believed to be involved in the sporulation of B. subtilis; rhamnolipids are linked to the virulence of $P$. aeruginosa by playing a role in biofilm formation and cell motility; and flocculosin, produced by the fungus $P$. flocculosa, was postulated to serve as a storage compound besides being an antifungal agent (Abdel-Mawgoud et al., 2010; Grossman, 1995; Kitamoto et al., 2002; Mimee et al., 2009; Ron and Rosenberg, 2001; Van Hamme et al., 2006).

For SLs in particular, the hypotheses that have been postulated since their discovery 60 years ago can be summarised in five theories, but unambiguously supporting evidence is sparse (Roberto De Oliveira et al., 2014; Van Bogaert et al., 2007): (1) SLs improve the uptake of hydrophobic substrates; (2) SL production constitutes an overflow metabolism; (3) SLs exert antimicrobial activity, thereby inhibiting the growth of competing microorganisms; (4) SL production is a protection mechanism against high osmotic pressure in their natural environment; and (5) SLs serve as an extracellular storage compound for carbon and energy.

All but one SL producing organisms are members of the Starmerella clade: S. apicola, S. bombicola, S. floricola, S. batistae, S. stellata, S. riodocensis and S. kuoi (Konishi et al., 2016; Kurtzman et al., 2010). In nature, these ascomycetous yeasts are found, as some names suggest, in 
close relation with (bumble)bees and flowers, environments rich in sugars (e.g. honey and nectar) and lipids (e.g. beeswax and plant oils) (De Graeve et al., 2018; Rosa et al., 2003). Most research papers that deal with the elucidation of the natural role of SLs are focussing on S. bombicola, as it is the most investigated SL producing organism. However, it can be assumed that the SLs produced by the other species of the Starmerella clade have similar natural functions, due to a shared ecological niche. The exception to the rule is the basidiomycete P. bogoriensis - not only aberrant in its produced SL structures, but also in phylogeny and habitat. Although only being isolated twice (from the leaf surfaces of an unidentified Schefflera species and Randia malleifera in the same botanical garden in Bogor, Indonesia), it is very likely that the natural habitat of $P$. bogoriensis, presumably the phylloplane (the leaf surface of a plant, an oligotrophic environment characterised by the presence of lipids in the cuticle), is different from that of the Starmerella species. This is confirmed by the fact that basidiomycetes present in nectar samples were unable to reproduce and were believed to be occasionally present there due to carry-over from the phylloplane (Brysch-Herzberg, 2004; Deinema, 1961; Lindow and Brandl, 2003; Ruinen, 1963). Accordingly, the SLs produced by P. bogoriensis might have a (slightly) different natural function.

\subsection{Uptake of hydrophobic substrates}

The oldest hypothesis on the natural role of SLs dates back to 1982 (Ito and Inoue, 1982). It presumed the involvement of SLs in the uptake of water-insoluble alkanes, because the addition of e.g. octadecane to the S. bombicola culture medium 'induced' SL production. For hexadecane improved growth was observed when a wildtype SL mixture (termed 'safflower-SL') was added to the culture medium, seemingly by shortening the lag phase with several days (roughly estimated from about 8 to 2 days). Later on, it turned out that S. bombicola not only produces SLs in the presence of hydrophobic substrates, but also when grown solely on glucose as C-source (Hommel et al., 1994). Hence, if the natural function of SLs is enhancing the uptake of hydrophobic substrates, the yeast would waste energy in unrequired SL production in the absence of alkanes. On top, the previously reported shortened lag phase for growth on hexadecane could not be repeated by De Clercq et al. (2021); on the contrary: growth on hexadecane declined for both the wildtype and the $\Delta$ cyp52M1 strain (non SL producing S. bombicola strain) when SLs were supplemented to medium with hexadecane as sole carbon source (De Clercq et al., 2021). On the other hand, the addition of SLs to $\Delta$ cyp52M1 cultures promoted growth (significantly increased growth rates compared to $\Delta c y p 52 M 1$ cultures without SLs addition) on triglycerides (rapeseed oil), which thus indicates that SLs could confer their producing microorganism with a competitive benefit as TGAs are hydrophobic substrates that are present in the natural habitat of $S$. bombicola (De Clercq et al., 2021).

Aside from improving growth, the presence of SLs could also enhance the uptake of hydrophobic substrates like triglycerides, which can be incorporated as fatty acids in newly produced 
substrates results in more efficient SL production. With SLs having additional benefits as described below thus resulting in a competitive advantage. Although many researchers have shown that SLs have emulsifying/solubilising properties, which can enhance the contact of the cells with waterinsoluble hydrophobic substrates, the fact that S. bombicola produces SLs in the absence of hydrophobic substrates, mainly in the stationary phase and in rather high concentrations, indicates that improved uptake of hydrophobic substrates for growth may not be the main natural role of SLs, which might be different for P. bogoriensis. However, the progeny of SL producing cells (which typically arise in the neighbourhood of the original SL producing cells) could benefit from the SLs produced and secreted in the extracellular space by their mother cells i.e. allowing them to grow faster and produce SLs more efficiently on hydrophobic substrates compared to the progeny of non-SL producing cells. This could thus give rise to an evolutionary benefit for SL producing cells over nonSL producing cells.

\subsection{Overflow metabolism}

A second posed natural role is that SL production constitutes an overflow metabolism in order to regulate the intracellular energy level and redox balances. Davila et al. (1997) proposed this theory to clarify the observation that SLs are excreted upon nitrogen starvation. However, overflow metabolism relates to a deficit in the cofactor $\mathrm{NAD}^{+}$, caused by excessive NADH formation during glycolysis in fast growing cells, and results to incomplete oxidation of substrates (e.g. glucose), even in the presence of oxygen (Szenk et al., 2017). To restore the NAD cofactor balance, overflow metabolites such as lactate, acetate and ethanol are excreted. Several reasons can be alleged why SL production does not fit with this hypothesis. First of all, SLs are typically produced in the stationary phase where the growth rate declines and secondly, the overall biosynthesis reaction of SLs generates NADH instead of recycling it back to NAD+ (see biosynthetic reaction 1, which is concurrent with the calculations of Linton as 1 NADPH corresponds to 4 ATP (Linton, 1991)). When generalising the trigger of overflow metabolism to overall redox balances, the oxidation of NADPH to NADP+ during (sub)terminal hydroxylation of the fatty acid (the first step in the SL pathway, see figure 5) could help to restore a deficit in NADP+. However, NADP+ can easily be recovered via reactions in the central metabolism with formation of mannitol (NADP+ recycling) - together with ethanol and glycerol (NAD+ recycling) - the true end product(s) of the overflow metabolism in S. bombicola (Gonçalves et al., 2018).

Biosynthetic reaction 1: overall reaction of the formation of di-acetylated acidic $S L s\left(C_{18: 1}\right)$ starting from glucose and fatty acid $\left(C_{18: 1}\right)$ :

fatty acid $+\mathrm{O}_{2}+\mathrm{NADPH}+3$ glucose $+2 \mathrm{ATP}+4 \mathrm{NAD}^{+}$

$$
\rightarrow \text { diacetylated acidic SL }+\mathrm{NADP}^{+}+4 \mathrm{NADH}+2 \mathrm{ADP}+2 \mathrm{CO}_{2}+3 \mathrm{H}_{2} \mathrm{O}
$$




\subsection{Antimicrobial activity}

In a third hypothesis, the natural role of SLs is linked to their antimicrobial activity, inhibiting the growth of microorganisms occupying the same ecological niche as the producing organisms. Antimicrobial activity was first reported for lactonic SLs of S. bombicola, inhibiting growth of some alkane utilising yeasts such as Y. lipolytica and C.albicans (Ito et al., 1980). Other studies substantiated this inhibiting effect not only for yeasts, but also for bacteria (e.g. B. subtilis and $P$. aeruginosa) and fungi (e.g. U. maydis) (De Clercq et al., 2021; Díaz De Rienzo et al., 2016; Gross and Shah, 2003; Haque et al., 2016; Kim et al., 2002; Lydon et al., 2017; Tran, 2012). More recently, also antifungal activity of $\mathrm{C}_{22}$ SLs of $P$. bogoriensis was observed for the first time, in a plate assay with $P$. acnes (Solaiman et al., 2015). Important to note is that these antimicrobial experiments were performed with eye on application potential of SLs and therefore, the examined strains lack relevance with the ecological niche of SL producing strains. Nevertheless, SLs indeed exert antimicrobial activity by changing or rupturing cellular membranes through similar effects exerted by detergents and hence target a fundamental and universal prerequisite for survival of cells (Akemi et al., 2018). In this way, the microorganisms populating the natural habitat are likely also inhibited by the presence of SLs, giving the SL producing microorganism a competitive advantage and thus resulting in a niche protection role of SLs.

\subsection{Protection against osmotic pressure}

A theory far less examined, stated by Hommel et al. (1994), proposes that SLs are produced as an adaptation to osmotic stress, arising from the prevalence of sugars in honey and nectar, present in the natural habitat of SL producing microorganisms (with exception of $P$. bogoriensis). Hommel et al. noted parallels in the biosynthesis of the sophorose moiety of SLs in S. apicola and trehalose synthesis in S. cerevisiae (Hommel et al., 1994). The latter is known to act as a compatible solute under (osmotic) stress conditions (Babazadeh et al., 2017). Yet, compatible solutes are defined as highly water soluble and low molecular weight molecules that accumulate to high intracellular concentrations; three conditions that are not fulfilled for SLs (Sleator and Hill, 2002). Inverting this rationale on the other hand, could theoretically imply a relief of osmotic stress: the osmotically active, small sugars outside the cell are converted into higher molecular and less soluble SLs, thereby alleviating the osmotic pressure on the microbial cell. If this process represents the natural function of SLs, it should entail enhanced growth in high sugar concentrations of a strain capable of making SLs compared to a SL deficient strain (e.g. $\Delta c y p 52 M 1$ (Van Bogaert et al., 2013) or AugtA1 (K. M. J. Saerens et al., 2011c)). However, no significant differences in growth (neither in lag, $\mu$ max or maximal cell concentration) of the wild type SL producing strain compared to the mutant $\Delta c y p 52 M 1$ non-SL producing S. bombicola strain were observed when cultured (under laboratory conditions) on glucose or fructose concentrations up to $600 \mathrm{~g} \cdot \mathrm{L}^{-1}$ (De Clercq et al., 2021). 


\subsection{Exclusive storage compound}

A fifth and last hypothesis is that SLs serve as an extracellular storage compound of carbon and energy. This was also first stated by Hommel et al., (1994) as trehalose not only functions as a compatible solute but can also act as a storage compound for S. cerevisiae (Hommel et al., 1994; Jules et al., 2008). This implies that S. bombicola can use its own SLs as carbon source, as was also already suggested by Garcia-Ochoa et al. (1996), who filed a patent claiming SLs were degraded from 5 to 1 g.L $\mathrm{L}^{-1}$ when used as sole carbon source, followed by the formation of sophorose (Garcia-Ochoa and Casas, 1996). Although later on some other reports stated that $S$. bombicola cannot dissimilate SLs (Hu, 2000; Lo and Ju, 2009), Li et al. (2016) recently identified a monooxygenase enzyme MoA that could be involved in the metabolism of acidic SLs. They found specificity of MoA towards $\mathrm{C}_{18: 2}$ diacetylated acidic SLs, as overexpression or deletion of $m o A$ only affected the peak area of that compound, with a decrease or increase, respectively. Unfortunately, they used UV absorbance as a detection method, thereby missing the effect of MoA on SLs comprised of saturated fatty acids. The activity and specificity of MoA was confirmed by a heterologous enzyme test with purified MoA enzyme and $\mathrm{C}_{18: 2}$ di-acetylated acidic SLs as substrate (no activity was found towards $\mathrm{C}_{18: 1}$ diacetylated acidic SLs or $\mathrm{C}_{18: 2}$ di-acetylated lactonic SLs). The authors believe MoA is involved in the catabolism of SLs as they claim the detection of (acetylated) sophorose and hydroxylated fatty acids in the final reaction mixture of the MoA enzyme with $\mathrm{C}_{18: 2}$ di-acetylated acidic SLs. The latter results need thorough reinvestigation as the data show some inconsistencies (varying mass differences for loss of water, no standards included in the analyses, no negative control as reference, ...). Still, to invigorate the hypothesis that S. bombicola is able to catabolise its own produced SLs, our research group found that SLs disappear from the medium during prolonged incubation upon starvation. It was shown that the predominantly produced di-acetylated lactonic SLs are 1. deacetylated and 2. that ring opening occurred, resulting in the extracellular accumulation of non-acetylated acidic SLs. Further experimental evidence indicates subsequent uptake of non-acetylated acidic SLs by the yeast cells and further intracellular degradation thereof into glucose and hydroxylated fatty acids. It was also proven that these reactions are not due to 'spontaneous' hydrolysis, but that certain yet unidentified extracellular and intracellular enzymes of S. bombicola are responsible for the observed conversions. This mechanism allowed yeast cells to remain viable in submerged 'starved' conditions for over 3 months. Furthermore, our lab confirmed that SLs can also sustain growth when used as sole carbon source (De Clercq et al., 2021).

The theory of SLs as extracellular storage compound can also hold for P. bogoriensis, as the disappearance of its branched SLs from old culture medium was already reported in 1961 (Deinema, 1961). In agreement with our findings, gradual disappearance of di-acetylated SLs occurred after 3 or 6 days of cultivation of $P$. bogoriensis and simultaneous appearance of mono- and non-acetylated derivatives was observed (Esders and Light, 1972; Ribeiro et al., 2012a). An acetylesterase capable of performing these deacetylation reactions was identified some years later by Bucholtz et al. (Bucholtz 
and Light, 1976). They presumed a preference for initial deacetylation of the outer 6" C of sophorose, which was also noted in more recent research, but further elucidation of the degradation mechanism of SLs in P. bogoriensis is still lacking (Bucholtz and Light, 1976; Solaiman et al., 2015).

\subsection{Sophorolipids: an exclusive storage compound with antimicrobial properties}

To summarise, the most coherent and proven theory on the main natural function of SLs is that they encompass a dual function resulting in an evolutionary benefit to competing microorganisms, i.e. as extracellular storage compound with inherent antimicrobial activity. SLs do not protect the microorganism in unfavourable conditions ( $c f r$. overflow metabolism and osmotic pressure) and are not primarily produced to enhance growth on hydrophobic substrates, but SLs aid the producing organism to compete against other microorganisms in the ecological niche ( $c f r$. antimicrobial activity and storage compound). Valuable and easily degradable carbon sources, such as sugars and/or fatty acids, are claimed by converting them into more inert compounds: SLs. By that, microorganisms create a 'personal hoard' that can be addressed under starvation conditions while minimising nutrient competition with other microorganisms. For Starmerella species, these starvation conditions could arise during the hibernation of bumblebee queens, as was speculated by De Clercq et al. (2021). By catabolising the previously produced and exclusive SLs, the yeast can keep up its cell numbers, entailing a benefit towards other bumblebee associated microorganisms. Additionally, the antimicrobial activity of SLs could pertain to a possible mutualistic relation between (bumble)bees and SL producing yeasts by inhibiting pathogens.

Figure 3. Overview of the confirmed (in green), refuted (in red) and precarious (in orange) theories on the physiological role of sophorolipids for S. bombicola. In nature, this yeast can be found in close association with flowers and (bumble)bees. The prevailing theories aroused from environmental factors characterising/present in this habitat: high sugar concentrations, a wide variety of hydrophobic substrates and the presence of other microorganisms (De Clercq et al., 2021).

\section{Advances in production process optimisation}

Apart from being produced by Starmerella in its natural environment, SLs are also produced in bioreactors to obtain them as industrially interesting compounds. There is a large abundance of research describing methods towards increasing sophorolipid titres and productivities in submerged bioprocesses. Prior to reviewing the published research regarding this topic, we would like to stress that it is very difficult to compare research outcomes because multiple parameters typically differ between manuscripts and in the authors long-lasting experience, small differences in parameters can make a dramatic difference in production outcomes (productivity/titre related, but also on the distribution of the different congeners). Moreover, the lack of standardisation of the declared production parameters and erroneous quantification and qualification results of the produced SLs often gives rise to more questions than answers. 
Specifically, as a first issue we would like to address terminology, typical parameters to measure and compare production process outcomes are amounts $(\mathrm{g})$, endpoint titre $\left(\mathrm{g} \cdot \mathrm{L}^{-1}\right)$, substrate yield $\left(\mathrm{g}_{\mathrm{SL}} \cdot \mathrm{g}_{\text {substrate }}{ }^{-1}\right)$, productivity $\left(\mathrm{g} \cdot \mathrm{h}^{-1}\right)$ and volumetric productivity $\left(\mathrm{g} \cdot \mathrm{L}^{-1} \cdot \mathrm{h}^{-1}\right)$. Some research articles solely report an endpoint titre. Yet, mean volumetric productivities and substrate yields can easily be calculated and hence should be declared in addition to the endpoint titre. A high production titre obtained in a very lengthy process for example will be a lot less industrially relevant compared to a lower titre obtained in a short process time. Furthermore, 'titre' or 'concentration' is often referred to as 'yield', which should be avoided. Standardisation in the terminology will allow more straightforward comparison between production processes.

A second issue is the use of erroneous quantification techniques, as also critically reviewed recently by Twigg et al. (2020). Crude techniques like gravimetrical or colorimetric methods are often used (Hans-J. Daniel et al., 1998; Hans-Joachim Daniel et al., 1998; Pekin et al., 2005), but result in an overestimation of produced SLs. The so-called gravimetrical methods consist of heating the bioprocess broth, resulting in gravimetrical sedimentation of the heavy SL containing phase, followed by collection and determination of the weight of this phase. However, this crude, viscous SL product typically still contains between 40 to $60 \%$ residual water and other impurities such as fatty acids, salts, residual sugar, glycerol etc. (Roelants et al., 2019), giving rise to a significant overestimation of the SL titres (calculating back to the broth volume). A variation consists of solvent extraction followed by evaporation, which suffers from similar bottlenecks, although often the error will be smaller. In the colorimetric methods, anthrone reacts with carbohydrates, which results in a green product with an absorption maximum at $630 \mathrm{~nm}$. Hence, a rough SL titre estimate can be made by calculating back the obtained carbohydrate value to glucose molecules present in SL molecules, which requires the researchers to make an 'educated guess' of the mean molecular weight of the produced SLs as they are -as mentioned- produced as a mixture. The 'choice' of the molecular weight of SLs in this calculation gives rise to variations in the deduced titre of up to $17 \%$. Moreover, any residual carbohydrates/sugars (e.g. glucose used as a substrate) in the sample should be considered and should be measured independently and subtracted from the detected 'carbohydrates' (de Bruyn et al., 1968). Such methods can be used for screening purposes but should be avoided to report titres in further scaled-up processes (shake flask and bioreactor scale). Other methods for quantification are more advanced analytical methods such as (U)HPLC-UV, (U)HPLC-ELSD, GC-MS, (U)HPLC-MS ${ }^{\mathrm{N}}$, ESI-MS ${ }^{\mathrm{n}}$, MALDI-TOF and NMR; but the limitation there is that quite a lot of effort is required to develop a solid and efficient quantification method. Smyth et al. (2014) published standard methods for purification, identification and quantification of glycolipids, which should definitely be considered in future reporting. An adequate method for SL analysis and quantification is the use of (U)HPLC-ELSD in combination with pure standards $(>98 \%)$. A drawback of this method is that pure standards are not commercially available and should thus be made in-house. Each quantitative SL analysis should be accompanied 
with a qualitative analysis e.g. using MS and/or NMR analysis. This is necessary because some SL congeners share retention times. NMR or $\mathrm{MS}^{\mathrm{n}}$ analysis is also required to thoroughly characterise the glycolipid mixture produced by newly developed or -discovered SL production strains.

The abovementioned aspects should be considered when performing and reporting on process optimisation efforts. Process development typically consists of three interconnected modules: medium- and substrate- optimisation, bioreactor- and downstream processing development.

\subsection{Medium- and substrate development and-optimisation}

Medium development and -optimisation are of utmost importance when developing novel bioprocesses. The thorough investigation thereof for SLs was often overlooked in the past as the evaluation of different substrates and medium components at varying concentrations and the examination of potential interactions requires many replicates. To decrease labour intensity, a number of 'high' throughput screening methods based on deep well plates have been described. Van Renterghem et al., (2019) evaluated the effect of different yeast extracts on SL production with an optimised deep-well method. High throughput screening was combined with $\mathrm{Cu}(\mathrm{OH})_{2}$ and $\mathrm{I}_{2}$ assisted detection of, respectively, carbohydrates and sophorolipids (Lin et al., 2019; Zhou et al., 2019). Though such colorimetric methods can be used in combination with a (fractional) factorial or centroid experimental design to perform a cost-effective screening (Jiménez-Peñalver et al., 2018, 2016; Ribeiro et al., 2012b; Rispoli et al., 2010), an accurate final quantification and qualification is still necessary, as discussed above. It is very important to validate a high throughput screening method, i.e. it should simulate a larger scale set up (i.e. bioreactor scale) allowing the generation of results relevant towards upscaling.

As mentioned above, SLs are secondary metabolites, which indicates that the production onset occurs when cells switch from the growth phase to the stationary phase. Therefore, a distinction should be made between base 'batch' medium and fed-batch substrates. The former is optimised for growth and stimulate production onset while the latter is fed to optimise SL production in the stationary phase.

\subsubsection{Base 'batch' medium for biomass generation and SL production onset}

Though SL production is almost exclusively occurring in the stationary phase, increased biomass levels give rise to increased SL productivity (until a plateau is reached (Gao et al., 2013)). A costefficient growth phase is favoured, as short as possible and resulting in increased biomass at the start of the stationary phase (Ciesielska et al., 2013; Gao et al., 2013). Both scenarios can be accomplished by tailoring the batch medium components.

The transition from growth to stationary phase is usually triggered by a limitation of nitrogen and/or phosphorous resources in combination with an excess of carbon, more specifically, a high $\mathrm{C} / \mathrm{N}$ 
ratio (Albrecht et al., 1996; Davila et al., 1992). This limitation does not equal an absence, as SL production occurs while nitrogen and phosphorous are still present in sufficient amounts (Ciesielska et al., 2013). Nitrogen limitation remains the most preferred strategy to trigger the stationary phase.

The nitrogen source and its relative concentration is therefore highly important as it will greatly influence the efficiency of the growth phase. Although the Starmerella clade is known for its limited range of nitrogen sources that can be assimilated (Gonçalves et al., 2020; Shen et al., 2018), several were evaluated: $\mathrm{NH}_{4} \mathrm{Cl}$ (Lang et al., 2000), urea (Vedaraman and Venkatesh, 2010), yeast extract (YE) (Casas and Garcia-Ochoa, 1999), $\mathrm{NaNO}_{3}$ (Konishi et al., 2015), $\mathrm{NH}_{4} \mathrm{SO}_{4}$ (Ribeiro et al., 2012a), malt extract (Rispoli et al., 2010), peptone extract (Rispoli et al., 2010), soytone (Rispoli et al., 2010), corn steep liquor (Develter and Fleurackers, 2012), ... As there are multiple synergistic effects between medium components and SL producing organisms differ in nutritional requirements, it is difficult to make hard conclusions, but some trends can be observed:

1) Organic nitrogen sources like YE are predominantly used, as they are also a source of vitamins and metal ions (Casas and Garcia-Ochoa, 1999; Göbbert et al., 1984; Hommel et al., 1994; Lang et al., 2000; Van Renterghem et al., 2019).

2) The $\mathrm{C} / \mathrm{N}$ ratio is of utmost importance as a high $\mathrm{C} / \mathrm{N}$ ratio (8-9) results in a higher specific production but a lower biomass, while a low $\mathrm{C} / \mathrm{N}$ ratio (3.5-4) results in lower production but higher biomass. A balanced $\mathrm{C} / \mathrm{N}$ ratio (4.5-5) results in an optimal SL and biomass production (Van Renterghem et al., 2019).

3) Industrial scale sophorolipid production has made reference to the use of corn steep liquor (Develter, D.; Fleurackers 2012); while it has been noticed that this results in lower biomass and lower SL production in comparison to YE in a deep well scale screening experiment (Van Renterghem et al. 2019).

\subsubsection{Metals}

In addition to carbon $(\mathrm{C})$ and nitrogen $(\mathrm{N})$ resources, some metal ions have been described to have a profound effect on S. bombicola's growth and/or SL production. The influence of several ions $\left(\mathrm{Mg}^{2+}\right.$, $\left.\mathrm{Zn}^{2+}, \mathrm{Fe}^{3+}, \mathrm{Fe}^{2+}, \mathrm{Ni}^{2+}, \mathrm{Mn}^{2+}, \mathrm{Cu}^{2+}, \mathrm{Co}^{2+}\right)$ as sulphate salt additives was investigated. $\mathrm{MgSO}_{4}$ favours the production of lactonic SLs, $\mathrm{Fe}^{2+}$ favours acidic SL production and addition of $\mathrm{Cu}^{2+}$ increased the total SL content 2.16 fold (Chen et al., 2014). Rispoli et al. (2010) on the other hand observed a negative effect of $\mathrm{MgCl}_{2}$ on SL production. These different results probably originate from two reasons: the use of two different counterions and the use of another base medium (glucose, YE and ureum (Rispoli et al., 2010) vs glucose, $\mathrm{YE}, \mathrm{KH}_{2} \mathrm{PO}_{4}, \mathrm{Na}_{2} \mathrm{HPO}_{4}$ and oleic acid (Chen et al., 2014)). It is thus advised to the effect of the counterions and the interaction effect between the substrates. 


\subsubsection{Fed batch substrates}

587 Besides medium components and cofactors necessary to produce biomass and to induce SL 588 production, also the substrates which are used (in)directly towards conversion into SLs are important 589 factors of the medium. Typically, a combination of hydrophilic and aliphatic carbon substrates is fed 590 towards increasing SL productivity. While the SL producers of the Starmerella clade have a limited 591 range of hydrophilic carbon molecules they can metabolise (on average $10 \pm 5$ out of 47 tested carbon 592 sources), Pseudohyphozyma bogoriensis can assimilate a wider variety of hydrophilic molecules (33 593 out of 47 tested carbon sources), including $\alpha, \alpha$-trehalose, D-xylose and D-arabinose (Centraal bureau voor Schimmelculturen, 2020; Kurtzman, 2012; Pimentel et al., 2005). SL producing organisms can typically also assimilate a high variety of aliphatic substrates: oils (Daverey and Pakshirajan, 2009), fatty acids (Li et al., 2016), alkanes (Ito et al., 1980), fatty alcohols (Brakemeier et al., 1998a; Van Renterghem et al., 2018), fatty acid methyl esters (Konishi et al., 2018), .... Most literature describing SL production processes focusses on glucose (Lang et al., 2000; Solaiman et al., 2015), sucrose (Klekner et al., 1991) or glycerol (Konishi et al., 2017; Lin et al., 2019) as hydrophilic substrates. While for the aliphatic substrate, $\mathrm{C}_{18: 1}$ containing sources such as rapeseed oil, high oleic sunflower oil (HOSO) or oleic acid are preferred (Cavalero and Cooper, 2003; Van Bogaert et al., 2011; Van Renterghem et al., 2018; Zhang et al., 2011). The substrate selection will depend on a trade-off between the substrate cost and the associated SL productivity. Some cheaper substrates (e.g. waste streams) can result in a dramatic decrease in SL productivities and therefore an associated higher production cost, although the substrate cost is substantially lower. This is an important aspect to keep in mind, certainly so because substrate cost only becomes an important denominator of the production costs at the very large industrial scale (multiple 1000 tonnes level) (Roelants et al., 2018) and the use of waste substrates might complicate registration and commercialisation of derived SLs (certainly for some markets).

\subsubsection{Second generation resources and waste streams}

611 Baccile et al. (2017a) observed in a life cycle analysis that glucose and rapeseed oil contributed for $61241 \%$ and $47 \%$ to the total environmental impact of an investigated SL production process, 613 respectively, in total representing $87 \%$ of the impact. Moreover, these first generation substrates are 614 resources which compete with the food industry (plant oil, starch derived food grade glucose, sucrose, 615 etc.). Thus, to increase sustainability, to reduce the ecological footprint, to avoid the competition with 616 food production and to promote a circular economy, the use of $2^{\text {nd }}$ generation substrates and waste streams is under investigation. Waste streams are also cheaper than $1^{\text {st }}$ generation substrates, which do

618 account for 10\%-30\% of the total cost of a bioprocess (Mnif and Ghribi, 2016). Potential pretreatment 619 costs, higher downstream processing (DSP) costs (medium containing more impurities), quality issues 620 towards registration of derived products and lower productivities hampers the breakthrough of $2^{\text {nd }}$ generation economic viable industrial processes (Bhangale et al., 2014; Shah et al., 2017; Takahashi et 
al., 2011). Further strain and process engineering towards the more efficient use of these types of substrates and the robustness against medium inhibitors is necessary to increase the economic competitiveness of these processes. Recently, an economical viable SL production process was established using hydrolysed food waste as batch medium combined with fed glucose and oleic acid (Kaur et al., 2019; Wang et al., 2020a). Comprehensive and complete overviews of the utilisation of $2^{\text {nd }}$ generation resources and waste streams towards SL production were recently provided by JiménezPeñalver et al., (2019), Wang et al., (2019) and Ma et al., (2020) and the reader is referred to these reviews for more in depth information.

\subsection{Bioreactor optimisation}

631 Generally, three bioreactor methods have been evaluated for SL production: fed-batch production, continuous production with in situ product removal and solid-state production.

\subsubsection{Fed-Batch production}

634 Fed-batch production is the most applied towards SL production. The process starts typically with a \pm 6352 days cell-growth phase resulting in biomass production with a typical end-titre of 7 to $30 \mathrm{~g} \cdot \mathrm{L}^{-1}$ cell 636 dry weight (CDW). Subsequently, an 8-14 days SL production phase is conducted where hydrophilic and aliphatic substrates are fed semi- or non-continuously. Common mean SL productivities are in the range of $0.51-2.1 \mathrm{~g} \cdot \mathrm{L}^{-1} \cdot \mathrm{h}^{-1}$ (Roelants et al., 2019). Gao et al. (2013) described a high cell density process which reached $80 \mathrm{~g} \cdot \mathrm{L}^{-1} \mathrm{CDW}$ and a mean volumetric productivity of $3.7 \mathrm{~g} \cdot \mathrm{L}^{-1} \cdot \mathrm{h}^{-1}$. However, production levels could not be maintained due to the rapidly increasing required working volume caused by the high production rate requiring fast feeding of the substrates (Gao et al., 2013). When SL concentrations increase above about $200 \mathrm{~g} \cdot \mathrm{L}^{-1}$ (typically after 8-14 days), the viscosity of the broth increases and oxygen transfer decreases, which negatively impacts SL productivity (Zhang et al.,

644 2018). Examples of fed-batch processes are described in detail by Roelants et al. (Roelants et al., 645 2019), Van Bogaert and Soetaert (Van Bogaert and Soetaert, 2011), Jiménez-Peñalver et al. (Jiménez646 Peñalver et al., 2019) and Wang et al. (Wang et al., 2019)

\subsubsection{In situ product removal}

648 Fed-batch production is hindered by maximum volumetric capacity of fed substrates at high 649 production rates and reduced productivities caused by limited oxygen transfer over time. These issues urged researchers to develop integrated processes such as in situ product removal (ISPR) coupled to a fed-batch or (semi-) continuous bioprocess set-up. Such systems are also developed aiming to decrease 652 down-time and simplify DSP. There are different ISPR methods possible depending on the specific SL 653 congener produced (figure 4). If the product has low water solubility such as lactonic SLs (Hu and Ju, 654 2001), ISPR can be obtained through a gravimetric settling set-up. Dolman et al. (2017) described a 655 semi-continuous set-up with a 'separator' coupled to the bioreactor for the production of wild type 
conditions), the broth is constantly pumped through the separator, where the SLs precipitate and the broth with a reduced SL content is pumped back into the bioreactor, resulting in a lower viscosity. The latter separation is performed in a cyclical set-up. Depending on the glucose concentration being lower or higher than $50 \mathrm{~g} \cdot \mathrm{L}^{-1}$, the SLs will situate respectively in the bottom or top layer in the separator (figure 4C and 4D). Hence, six cycles were performed using a top layer separator which resulted in a relatively long cultivation time of $1023 \mathrm{~h}$ with a mean productivity of $0.61 \mathrm{~g} \cdot \mathrm{L}^{-1} \cdot \mathrm{h}^{-1}$, substrate yield of $0.47 \mathrm{~g} \cdot \mathrm{g}^{-1}$ and a total separation efficiency of $65 \%$. Nevertheless, higher total separation efficiencies were reached in shorter cultivation times. Utilising a top separation set-up amounted to $86 \%$ for a process of 3 cycles and 305 hours. While, a bottom separation set-up resulted in a total separation efficiency of $74 \%$ for a process of 4 and 379 hours. The reason for this lower separation efficiency for the longer process time was described by the authors to be due to variation in SL concentration present in the bioreactor before the separation.

A similar but batch operated gravimetrical ISPR for wild type SLs was described by Liu et al. (2019) (figure 4B). The authors altered the rheological conditions by adjusting the rapeseed oil/SL ratio to $0.08-0.12$ by oil addition prior to pumping the broth into a pre-separator to remove excess air. The latter was coupled to a gravimetrical separator of which the top layer was pumped to a washing tank where the SLs could settle. The broth was recycled and pumped back into the bioreactor for further production. This procedure was performed three times and a mean productivity of $1.55 \mathrm{~g} \cdot \mathrm{L} \cdot \mathrm{h}^{-1}$, a substrate yield of $0.43 \mathrm{~g} \cdot \mathrm{g}^{-1}$ was achieved. An overall separation efficiency of $91 \%$ was reached, but this did not take into account the SL loss in the final separation step upon termination of the bioprocess. The system has the drawback of being operated in batch mode and therefore the process is idle while performing the separation step.

Aforementioned ISPR systems provide some clear benefits, such as smaller reactor size required towards the production of a certain SL production volume, which decreases capital expenditures (CAPEX). However, the constant removal of SLs will require adequate feeding regimes of hydrophilic and especially hydrophobic substrates as these are removed together with the SLs. For hydrophilic substrates, this will result only in reduced yields on substrate and thus negatively affect cost-efficiency (substrate lost), while for the hydrophobic substrates, in addition, it is notoriously difficult to separate them from the SLs, which will require further purification steps. This increases costs and negatively impacts the environmental impact of the overall process as determined through life cycle analysis (LCA).

To mitigate the hydrophobic substrate loss, Zhang et al. (2018) developed another ISPR design for wild type SLs which utilises dual sieve plates inside the bioreactor coupled to two semicontinuous separation units, one for the separation of SLs from bioreactor broth by applying soybean 
These authors did not mention the separation efficiency of the reported processes. As the working volume of the reactors was also not reported, the separation efficiency cannot be calculated either. Based on the dimensions of the reactor, the separation efficiency can be estimated between $70 \%$ and $80 \%$. A mean volumetric SL productivity of $1.59 \mathrm{~g} \cdot \mathrm{L}^{-1} \cdot \mathrm{h}^{-1}$ and a substrate yield of $0.59 \mathrm{~g} \cdot \mathrm{g}^{-1}$ was reached with a final titre of $477 \mathrm{~g} \cdot \mathrm{L}^{-1}$ by using Candida albicans $\mathrm{O}-13-1$. As mentioned before, $C$. albicans has never been described in literature to produce SLs, so this study most probably concerns $S$. bombicola. Moreover, the SL quantification was done by using the anthrone method, which can be inaccurate, as described in the introduction of section 4. Moreover, the specific role of the sieve plates was not well explained, and it is thus not clear if these sieve plates actually represent a benefit compared to the more straightforward ISPR systems described above and below or even to a regular bioreactor system without sieve plates applied towards a cyclic process of production and sedimentation. Moreover, the separation set up is quite complex and would not be easily scalable. Also, no information about the residual soybean oil in the SL fraction was reported, which is expected to be substantial when using soybean oil as a process aid to enhance separation of SLs from process broth.

707

Figure 4: Schematic representation of ISPR production processes reported for SLs. A) Process by (Wang et al., 2020a), B) Froth separation by Liu et al. (2019), Gravity separation by Dolman et al. (2017) with C) SL in upper phase \& D) SL in lower phase, E) Dual sieve-plates and dual ventilation pipes bioreactor by Zhang et al. (2018) F) Cell recycle process for bolaform sophorolipids (Roelants et al., 2018). I) batch separator, II) continuous separator, III) continuous tangential microfilter $(0.2 \mu \mathrm{m}) \mathrm{IV})$ washing tank. Blue lines represent feed, red lines sophorolipid depleted flows and orange lines sophorolipid enriched flows.

Recently, Wang et al. (2020a) described another ISPR process which uses a batch separator process optimised for low hydrophobic substrate loss (figure 4A). Though having the same drawback as the system of Liu et al. (2019), being that the system is operated in batch mode, a mean volumetric productivity of $2.39 \mathrm{~g} \cdot \mathrm{L}^{-1} \cdot \mathrm{h}^{-1}$ and a substrate yield of $0.73 \mathrm{~g} \cdot \mathrm{g}^{-1}$ over $480 \mathrm{~h}$ of production time was achieved while utilising a restaurant left over waste stream as batch medium fed with glucose and oleic acid in the fed batch phase. The overall separation efficiency over 6 cycles and final separation step amounted to $93 \%$. A techno-economic analysis was performed for a full-scale SL production plant based on this process. Multiple scenarios indicate lower minimum selling prices in comparison to the market price (13.87 euro $\mathrm{kg}^{-1}$ vs. 21.62 euro $\mathrm{kg}^{-1}$, respectively) (Wang et al., 2020b).

A different type of ISPR was developed for bolaform SLs, which are, in contrast to lactonic SLs, highly water soluble (Van Renterghem et al., 2018). This process couples a $0.2 \mu \mathrm{m}$ filter to the bioreactor and a continuous microfiltration is performed where broth enriched in cells is pumped back to the bioreactor, whereas filtrate containing medium components, substrates and bolaform SLs is constantly removed (figure 4F). A mean volumetric productivity of $0.63 \mathrm{~g} \cdot \mathrm{L}^{-1} \cdot \mathrm{h}^{-1}$ was reached and could be maintained for 240 hours, after which it slowly declined (Roelants et al., 2018). Like for the 
set up described by Dolman et al. (2017), it can be remarked that the substrates are 'lost' in the filtrate. However, a subsequent purification step on the filtrate e.g. ultrafiltration can be imagined where the bolaform SLs are separated from the remaining medium components, which can then be pumped back into the bioreactor (Roelants et al., 2016). The way the set up was now described a separation efficiency of about $100 \%$ was achieved as the concentration bolaform SLs pumped out of the reactor was the same as the concentration bolaform SLs in the bioreactor. It should be noted that such set up can only be applied with compounds with high water solubility, while the set ups described above for lactonic SLs on the contrary can only be applied with compounds with low water solubility.

ISPR proved to be an efficient and economical viable technique to increase SL productivity at lab-scale. However, higher operational expenses can be predicted because ISPR systems in general require more follow-up (Palme et al., 2010). Therefore, an economic analysis should be performed to determine if an ISPR design has an economical beneficial effect. Also, attention should be given to the feasibility of scaling-up ISPR procedures which can be particularly challenging. However, two companies are currently applying ISPR techniques for SL production at the larger scale, which confirms the industrial relevance. Holiferm (Manchester, UK) communicated that they started with the construction of a pilot plant (300L) based on the ISPR set-up described by Dolman et al. (2017). Also, Locus (Solon, Ohio) is utilizing a similar ISPR technique for SLs production (Sean et al., 2020). They filed a patent that describes a large-scale apparatus that includes a bioreactor vessel and a directly connected collector vessel. The main challenges associated with these systems are residual hydrophobic substrates remaining together with the collected SLs as they are required for optimal SL production.

\subsubsection{Solid state production}

Solid state production is a process that takes place in a solid matrix in absence or near absence of free water (Thomas et al., 2013). The advantage is that (cheaper) solid substrates can be used while no foam control is necessary (Jiménez-Peñalver et al., 2016). Jiménez-Peñalver et al. (2018) used a foam of polyurethane with sugar beet molasses and stearic acid $(1.17: 1 \mathrm{w} / \mathrm{w})$ as substrates to obtain a yield of $0.211 \mathrm{~g}$ SLs per $\mathrm{g}$ of substrates. The use of solid waste streams in a solid state production set-up has also been evaluated, e.g. mango kernel (Parekh et al., n.d.), safflower cake (Nooman et al., 2017), motor oil waste and sunflower oil cake (Rashad et al., 2014). The effect of mixing steps of a solid state consisting out of winterisation oil cake and sugar beet molasses was profound and resulted in an increase from $0.179 \mathrm{~g} \mathrm{SL} / \mathrm{g}$ dry mass (DM) to $0.235 \mathrm{~g} \mathrm{SL} / \mathrm{g}$ DM. A correlation was observed between the oxygen uptake rate (OUR), cumulative oxygen uptake rate (COC) and the SL substrate yield (Jiménez-Peñalver et al., 2016).

Solid state production can reach industrial standards for waste stream processing but needs to resolve its key issues: the lack of heat dissipation, minimal process monitoring and down-stream 
processing. The latter is currently only possible with solvent extraction methods, which are not preferred, mainly due to environmental reasons (Jiménez-Peñalver et al., 2019).

765

766

767

768

769

770

771

772

773

774

775

776

777

778

779

780

\subsection{Downstream processing optimisation}

The downstream processing (DSP) cost for many processes can contribute up to $60-80 \%$ of the total production cost, therefore the development of cost-effective DSP processes is of high interest (Fleurackers, 2013). A common lab scale approach for SL purification is solvent extraction with ethanol (Van Bogaert et al., 2016), ethylacetate (Kurtzman et al., 2010) or pentanol (Baccile et al., 2013). These methods are often accompanied by hexane washing steps to remove residual fatty acids (Baccile et al., 2013). Moreover, silica gel chromatography (Gross et al., 2013) methods have been described. However, all above mentioned methods use organic solvents, which is not the preferred method for industrial production of SLs, because it conflicts with the green nature of microbial biosurfactants (Jessop, 2011; Thavasi and Banat, 2018). Therefore, different DSP methods are described, mitigating the use of solvents, e.g. the use of filtration techniques (Baccile et al., 2017a; Roelants et al., 2016; Van Renterghem et al., 2018) or separation based on melting at $55^{\circ} \mathrm{C}$ of SLs followed by a sedimentation, separation and water washing (Roelants et al., 2016). A possible subsequent phase can be the crystallisation and drying of SLs crystals, but this can result in increased costs, so a trade-off should be made between purity and cost. More information concerning DSP methods is described by Thavasi and Banat (2018).

It should be considered that when using waste streams as substrates, the USP (upstream processing) and DSP can become more elaborate. There is a higher market tolerance for increased impurities for low-end applications (e.g. detergents) compared to high-end applications (e.g. food, nanotechnology). The final product of a WT SL mixture production process is either a SL syrup (78\% dry matter) or SL crystals (97\% dry matter) (Roelants et al., 2016; Wang et al., 2020b). A technoeconomical study determined the CAPEX of a crystalliser and a freeze-dryer, both necessary to create SL crystals, equals $68.5 \%$ of the CAPEX cost of the bioreactor (Wang et al., 2020b). Furthermore, freeze-dryers are known to have a high energy demand. In contrast, SL crystals are more stable and have a longer shelf life in comparison to a syrup (Van Bogaert and Soetaert, 2015). Moreover, the impact of transportation of SL crystals is less as it contains less 'dead weight', i.e. water. Therefore, an economical and environmental trade-off should be made while taking the aimed final product in mind.

\section{Multipurpose compounds with a broad application potential}

The applications of SLs have extensively been reviewed elsewhere (de Oliveira, 2015; Develter and Lauryssen, 2010; Hayes et al., 2019; Santos et al., 2016; Van Bogaert et al., 2007). The aim of this section is to complement these reviews and to focus on recent (2015-2020) and most promising proceedings in terms of SL applications. 
SLs can be applied for their bio-active properties and/or for their surface-active properties. These properties can vary significantly in function of purity (e.g. residual presence of hydrophobic substrate(s)), uniformity (e.g. ratio lactonic versus acidic SLs) and formulation matrix (water-, oil- or solvent based), so it is of utmost importance to keep these in mind when evaluating application literature. For example, the reported bioactive properties reported for (wild type) SLs vary a lot. such as anti-microbial properties can reach very diverse values. However, this can clearly be attributed to the fact that the ratio between lactonic and acidic SLs and their acetylation degree in a (wild type) SL mixture depends on the culture conditions and the fact that lactonic and acidic SLs differ in bioactivity (Ciesielska et al., 2016). Information on purity and SL congener ratios should thus be included in future publications to avoid further confusion on the potential application areas of 'sophorolipids' (Twigg et al., 2020).

As many applications of SLs relate to the self-assembly properties of SLs in water, the latter will be discussed first, followed by the literature review of specific SL application areas. These areas not surprisingly are to a great extent in line with the surfactant market and the use of classic surfactants over a range of markets with varying market volumes. These include, from large to smallest: household detergents, personal care, textile, industrial and institutional (I\&I) cleaning, elastomers and plastics, oilfield chemicals, food \& beverages, crop protection and smaller scale use markets such as pharma, construction, paints and inks, etc.

\subsection{Self-assembly properties of sophorolipids}

\section{$816 \quad 5.1 .1$ General principles of surfactant self-assembly in solution}

817 Surfactant self-assembly in solution generally refers to an equilibrium process driven by the so-called hydrophobic effect, involving non-specific interactions between aliphatic chains of surfactants. This attractive force is counterbalanced by a number of repulsive contributions to the free energy, including, but not limited to, steric, electrostatic and interfacial components. The first two contributions occur at the level of the hydrophilic headgroup while the latter occurs at the micellewater interface (Israelachvili et al., 1976; Tanford, 1973). The simplest self-assembled morphology of a surfactant in solution is a micelle, spheroidal object forming above a critical concentration of the surfactant in solution. The shape of micelles can evolve towards cylinders, vesicles or lamellae, according to concertation and in relationship to the shape of the surfactant's molecule (Israelachvili et al., 1976). The critical micelle concentration $(\mathrm{cmc})$ in water is commonly measured for all surfactants (Holmberg et al., 2002) and cmc values for sophorolipids were reported before (Daverey and Pakshirajan, 2010; Hirata et al., 2009; Kim et al., 2005; Mnif et al., 2018; Solaiman et al., 2004). On the other hand, knowledge of the molecular structure (tail length and volume, headgroup surface area)

830 helps understanding the shape of the self-assembled aggregates in solution. This last aspect has been rationalised long ago in the so-called critical packing parameter (PP): the lower the $\mathrm{PP}$, the stronger 
tendency for the surfactant to assemble into spheroidal micelles; the higher the PP, the stronger its tendency to assemble into flat bilayer membranes (Holmberg et al., 2002; Israelachvili et al., 1976). It goes without saying that, although the PP approach has been verified over the years, it still constitutes an oversimplified way to understand self-assembly and it has been shown to fail in many cases, due to which more recent general theories have been proposed (Bergström, 2000a, 2000b). We have recently revised the PP theory and discussed it within the context of biosurfactants' self-assembly (Baccile et al., 2021b).

\subsubsection{Self-assembly of sophorolipids in solution}

Sophorolipids, compared to classical head-tail chemical surfactants, have a triple level of complexity: 1) structural., because they are asymmetric bolas, instead of common head-tail, amphiphiles; 2) chemical, because they contain chemically-reactive and physicochemically-active groups $(\mathrm{C}=\mathrm{C}$, carboxylic acid); 3) compositional, because sophorolipids are rarely pure molecules but generally a mixtures of similar congeners with different properties. Speaking of sophorolipid self-assembly is then highly imprecise, and one should state which SL are concerned and the $\mathrm{pH}$ at which self-assembly is studied. In this regard, it is not surprising that the critical micelle concentration (cmc) of sophorolipids reported over the years in the literature vary from 6 to about $700 \mathrm{mg} / \mathrm{mL}$ (Daverey and Pakshirajan, 2010; Hirata et al., 2009; Kim et al., 2005; Mnif et al., 2018; Solaiman et al., 2004). Table 2 summarises the up-to-date work published on the solution (water) self-assembly properties (concentrations below $10 \mathrm{wt} \%$ ) of a number of sophorolipids and their derivatives and recently reviewed in Ref. (Baccile et al., 2021b). We present below a short comment for each specific phase. Please note that appropriate references are given in Table 2.

Micellar phase (L1). This phase is by far the most representative for a large number of sophorolipids, except lactonic SLs, at concentration below $10 \mathrm{wt} \%$ (Table 2, Micellar column). The L1 phase is systematically observed for the charged, $\mathrm{COO}^{-}$or $\mathrm{NH}_{3}^{+}$, forms of SLs at $\mathrm{pH}$ respectively above and below neutrality. This can be explained by the repulsive electrostatic contribution to the intermolecular forces as well as by the bulky sophorose headgroup. For specific SL derivatives (e.g., alkynyl, peracetylated phorphyrin), the micellar phase is controlled by temperature, instead. The L1 phase is found for a broad $\mathrm{pH}$ range, from acidic to basic, for both the acidic (R-COOH) and aminyl ( $\mathrm{R}-\mathrm{NH}_{2}$ ) forms of $\mathrm{C} 18: 1-$ cis nonacetylated SLs, the former being the most common form of SLs, easily obtained by hydrolysis of acetylated lactonic SLs. It cannot be excluded that stabilization of the micellar phase in a broad $\mathrm{pH}$ range may be due to the presence of spurious amounts $(<10 \%)$ of SL congeners, naturally present in the raw mixture and hard to remove (Dhasaiyan et al., 2017). The structure of SL micelles has been studied in depth using a combination of small angle X-ray scattering (SAXS) and numerical modelling. The localization of the $\mathrm{COO}^{-}$groups has been probed through the 
hydrophobic core through contrast-matched small angle neutron scattering. The bolaform nature of SLs produces a spheroidal (prolate ellipsoid) micelle with a small hydrophobic core and an asymmetric hydrophilic shell (coffee-bean like model) (Manet et al., 2015). The micellar phase has also been reported for a number of asymmetrical, symmetrical, divalent and Y-shaped SL derivatives (N. Baccile et al., 2019a).

Micelles of C18:1-cis nonacetylated SLs (COOH or $\mathrm{NH}_{2}$ end-groups) are neutral or charged according to the ionization state of the end-group and, in this regard, they can interact with other molecular species, like polyelectrolytes (Ben Messaoud et al., 2018; Seyrig et al., 2020) or proteins and enzymes (Andersen et al., 2016; Madsen et al., 2017). Strong electrostatically-driven SLspolyelectrolyte complexes present interesting possibilities in emulsion stabilization through soft colloids, (Laquerbe et al., 2021) whereas acidic SLs were shown to be poor emulsion stabilizers. In this regard, acidic-lactonic SL mixtures and alkyl-modified SLs were shown to have better emulsion stabilization properties than acidic SLs (Koh et al., 2017a, 2016; Koh and Gross, 2016a, 2016b). On the contrary, interactions between SLs and proteins and enzymes were shown to be relatively mild, if compared to other ionic surfactants, thus limiting their denaturation (Andersen et al., 2016; Madsen et al., 2017).

Vesicle phase. This phase is relatively rare for SLs, probably due to their bulky sophorose headgroup. Multilamellar vesicles (MLV) have been reported mainly for behenic $\left(\mathrm{C} 22: 0_{13}\right)$ and linolenic (C18:3-cis) derivatives of SLs at neutral/acidic pH (Table 2, Vesicle column) while single unilamellar vesicles (SUV) have been reported for lactonic SLs.

Lamellar phase. This phase (Table 2, Lamellar column) is particularly rare, and it has been most likely observed as a precipitate for behenic derivative of SL (C22:0 $\left.0_{13}\right)$ at acidic $\mathrm{pH}$, upon full protonation of the $\mathrm{COOH}$ group.

Columnar phase. This unique phase has been reported for hydroxylated porphyrin dimers of SLs, and it is strictly related to the presence of the porphyrin group, but also to the presence of residual OH groups (Table 2, Columnar column). Such compounds could serve to develop new biocompatible exciton-coupled chromophores.

Fibre phase. This phase, in the morphology of twisted ribbons, has been surprisingly observed for a large number of SL derivatives, thus demonstrating the complexity of the self-assembly process of this compound. Initially reported for deacetylated C18:1-cis sophorolipids under acidic conditions (Zhou et al., 2004) (Dhasaiyan et al., 2013), this result was questioned years later by others, showing that such compound rather forms a micellar phase (Baccile et al., 2016a, 2012, 2011; Penfold et al., 
2011). The presence of a mixture of congeners (one of which forms twisted ribbons of its own) in the analysed samples partially explained such discrepancy (Dhasaiyan et al., 2017). The fibre phase has been otherwise observed for the neutral form of C18:0 SL derivatives, may they have an end-COOH (acidic $\mathrm{pH}$ ) or $-\mathrm{NH}_{2}$ (basic $\mathrm{pH}$ ) group, but also for C18:1 alkynyl SLs, C18:1-trans (acidic pH), C16:0 (acidic pH) SLs bolaform, di-sophorose, sophorosides and SL derivatives. (Table 2, Fibre column). Interestingly, the $\mathrm{C} 18: 1$-trans $\mathrm{SL}$ derivative in its ionic form at basic $\mathrm{pH}$ also shows the formation of a fibre phase in the order of hours.

The reason according to which this phase is so often observed for a broad set of SL derivatives is still unclear. It does not seem to be related to a specificity of the sophorose headgroup itself, as cellobioselipids display a similar phase (Baccile et al., 2016b). It could be related to the all-trans configuration of the SL fatty acid backbone, but the C18:1-cis alkynyl derivative also shows this phase. It could be related to the chiral centres of the sophorose headgroup, but no specific enantiomeric excess could be detected in the fibre twist (Cuvier et al., 2015a). Following the hypotheses formulated by others (Barclay et al., 2014), fibre formation could be a kinetic phenomenon related to the poor solubility in water of the above-cited molecules and in combination with the bulkiness of the sophorose headgroup, which could drive the twist though steric hindrance and limit later crystal growth during the nucleation and growth of the fibres. The kinetic aspect seems to be justified by the fact that the C18:0 SL derivative forms flat crystals upon dispersion in water (Dhasaiyan et al., 2013) but twisted fibres through a fast pH-jump process (Cuvier et al., 2014). In the latter, fibres can be homogeneous or in the shape of spherulites, according to the rate of $\mathrm{pH}$ variation (Ben Messaoud et al., 2019), whereas the presence of salt seems to play an important role in the fibrillation process (Ben Messaoud et al., 2019; Cuvier et al., 2015a). It goes without saying that fibrillation of SLs should be studied further for a better understanding.

Despite the above, homogeneous fibrillation induces hydrogel formation at concentrations as low as $1 \mathrm{wt} \%$ of SL in water (Baccile et al., 2021a, 2018; Ben Messaoud et al., 2019). Controlled variation of $\mathrm{pH}$ and temperature directly controls the nucleation and growth of the SL fibres, thus providing not only $\mathrm{pH}$-responsive, but also tough, hydrogels, with elastic modulus as high as $10 \mathrm{kPa}$, thus paving the way to the development of biosurfactant-based soft materials (Baccile et al., 2019b).

Other (minor) phases. Platelet aggregates or ill-defined phases, mainly detected in SAXS profiles and in cryogenic transmission electron microscopy, are often observed for the ionic form of SLs. They generally involve a small fraction of the compound and to date, neither their origins nor their full control are understood. In some occasions, such phases result in a flocculate visible with bare eye.

In summary, SLs display a rich phase behaviour, which depends on their structure, physicochemical conditions in solution and purity. The take-home message is that nonacetylated 
acidic C18:1-cis SL, the most accessible compound through alkaline hydrolysis of a raw acidiclactonic SL mixture, is water soluble and mainly forms a micellar phase in a broad $\mathrm{pH}$ range, and of which the surface charge (neutral/negative) depends on $\mathrm{pH}$. This compound is then interesting to develop further formulations with other surfactants and (bio)macromolecules. The fibre phase, on the contrary, is very interesting to develop strong hydrogels and it can be mainly obtained from saturated derivatives of SL under acidic conditions.

Table 2: Self-assembled structures of sophorolipids and derivatives reported at room temperature (unless otherwise stated). SUV: single unilamellar vesicles; MLV: multilamellar vesicles. \#time $>1 \mathrm{~h}$ (minor fraction) \#\#: $1 \mathrm{i}, 1 \mathrm{~h}, 1 \mathrm{f}, 1 \mathrm{k}, 1 \mathrm{j}, 1 \mathrm{l}, 1 \mathrm{~g}, 2 \mathrm{~g}$ (Ammonium- and amine oxide derivatives of $S L$ ) and $3 b, 3 c, 3 d, 4 d, 5 c, 5 d, 6 a, 6 d$ (Symmetrical amine SL derivatives) in Ref. (Baccile et al., 2019a) as neutral form at basic $\mathrm{pH}$.

\subsection{Cleaning/washing}

The biggest part of the annual production volume of surfactants $(46.3 \%)$ is produced for household detergents (Ranji et al., 2019). Sophorolipids can be used as readily biodegradable, non-toxic, biobased, non-irritable, 'green' formulation agents in detergents and cleaning applications. Research papers and patents describe the use of SLs in hard surface cleaners (Develter et al., 2003; Develter and Fleurackers, 2007; Karsten et al., 2010); anti-scaling, rinse aid, (low-)foaming, wetting, degreasing agents (Hillion et al., 1995; Van Renterghem et al., 2018; Xiaoming et al., 2005) and biosolubilisers (Ernenwein et al., 2013). Besides for their purely physicochemical traits, SLs have been extensively examined for their antimicrobial, antifungal and antiviral properties for disinfectant and/or germicide purposes in cleaning formulations for the medical, food, agricultural and cosmetic industry. Besides direct inhibition of micro-organisms, SLs have been shown to inhibit biofilm formation and disrupt biofilms. Unlike in other application fields, SLs have been applied in B2C products like cleaning products for some years and the Belgian company Ecover (Malle, Belgium) was one of the pioneers. Since the B2B commercialisation of SLs under the name of Rewoferm ${ }^{\circledR}$ SL by Evonik (Essen, Germany), a product honoured with the SEPAWA Innovation Award 2016 for its excellent ecological profile, the application field is expected to open up for more B2C companies. Future commitments in this context should include the further elucidation of the formulative potential of these compounds and the continuous efforts to evaluate for functioning bioactive formulations.

\subsection{Personal care and cosmetics}

974 The personal care and cosmetics surfactants market segment is the second largest segment of the surfactant market after detergents, corresponding to a yearly production/use of about 3 million tonnes, and is also the fastest-growing segment of the surfactants market and projected to register a CAGR of 5.5\%, in terms of volume, between 2016 and 2021 (Markets and markets, 2016). Because this is a very 
consumer receptive market, it has been clearly redirecting itself the past 5 to 10 years towards more sustainable, green, bio-based and mild products which also do not contribute to deforestation, a clear issue in a market using a lot of palm oil derived products. Due to higher acceptable costs, this is an ideal entry market for new types of (typically more expensive) bio-based surfactants such as SLs. Already in the late 80 's the first reports on the use of SLs in such products were published, which ultimately resulted in the commercialisation of SLs in personal care products in the early 2000's. For example, the antibacterial and sebum control agent Sopholiance ${ }^{\circledR}$ used in deodorants (Soliance, now Givaudan (Vernier, Switzerland)) or the Sopholin Acne Soap (MG Intobio Co LTD, Icheon, Republic of Korea) both make use of the bacteriostatic and bactericidal properties of SLs to fight odour-, acneand/or infection inducing bacteria such as Bacillus subtilis, Staphylococcus epidermidis, Staphylococcus aureus, Streptococcus faecium, Propionibacterium acnes and Corynebacterium xerosis (Lang and Wagner, 1993; Yatim et al., 2010) or fungi such as Candida albicans and Trychophyton spp. (Haque et al., 2017; Sanada et al., 2014; Sen et al., 2017). The use of sophorolipids in cosmetic and dermatological compositions was already patented in 1994 (Hillion et al., 1994). Patents describing the use as a mild, foaming detergent and the use in hair and skin cleaning compositions are assigned to, respectively, Unilever (London, United Kingdom) (Cox et al., 2011) and Evonik (Essen, Germany) (Allef et al., 2012). Their use in sulphate-free cleansing agents for their prebiotic activity is also patented (Heike et al., 2016). However, according to publications and other granted patents, interesting properties include more than only formulation aiding or bacterial control agents, as they have been suggested as cellulite reducers through leptin synthesis stimulation in adipocytes (Pellicier and Andre, 2004), and as skin penetration or transdermal release enhancers for active ingredients such as mogroside V (Imura et al., 2014), bovine lactoferrin (Ishii et al., 2012; Matsumiya et al., 2017) and lignans (Naik et al., 2019). Other patents describe their use to provide free radical formation inhibiting activity, elastase inhibiting activity and anti-inflammatory activity (Hillion et al., 1995) or as activator of macrophages, as fibrinolytic agent, as healing agent, as desquamation agent and as depigmentation agent (Maingault, 1996). The further expansion of the use of SLs in cosmetic- and personal care products would allow their price to drop, which will result in turn in even more opportunities and eventually possibly in the mainstream use of SLs and other (microbial) biosurfactants in personal care and other products, as 'cost' is one of the main bottlenecks.

\subsection{Oilfield chemicals and microbial enhanced oil recovery}

Due to their amphiphilic properties, SLs are able to adsorb at hydrophobic surfaces such as crude oil, resulting in a reduced surface- and interphase tension, increasing specific surface area and reducing viscosity (de Oliveira, 2015). These traits can be used in so-called microbial enhanced oil recovery (MEOR) in which residual oil, accounting for approximately $50 \%$ of the oil reserves after primary and secondary extraction, can be partially recovered from oil wells (Geetha et al., 2018). For in-situ MEOR microorganisms or nutrients are injected into the oil well, while ex-situ MEOR uses a purified 
product for extraction purposes, both circumventing the use of traditional non-biodegradable and sometimes unstable chemical counterparts. Although interesting results were seen in core-flooding experiments in which up to $27.27 \%$ of the residual oil was recovered through the use of SLs (Elshafie et al., 2015), only limited patents or publications are available describing the use thereof for such applications (Duran 2015; Koral, Weers and Campbell 2014; Elshafie et al. 2015; Gunawan, Vorderbruggen and Armstrong 2017). The need for facultative (an)aerobic bacteria and tricky growth

1020 control for in-situ MEOR and the high cost of SLs in the case of ex-situ MEOR impedes the elaboration of SL-MEOR, but also for microbial biosurfactants in general. Another challenge is the execution of field-scale experiments, which sometimes gives rise to deviating results compared to labscale experiments (Geetha et al., 2018). As long as the scale of industrial SL production remains relatively small and prices thus remain high, utilisation for high volume, bulk commodities such as MEOR will not be possible. Geetha, Banat, and Joshi (2018) have summarised the status of the use of biosurfactants in oil recovery in a very concise way, including issued patents on the matter. Oilfield chemicals in general represent a market share of about 1 million tonnes or about $5 \%$ of the total surfactant volumes produced (Markets and markets 2016). Decreasing the cost of raw materials, often an important factor governing the price of the product on the very large industrial scale, by using nutrient rich industrial wastes as displayed by Joshi et al. (2019) or (Wang et al., 2020a) could be an important step to increase the economic viability of these applications at least at large industrial scale as discussed in section 7 (Felse et al., 2007; Roelants et al., 2018). Nevertheless, the use of microbial biosurfactants, which have amongst others been created as an alternative to petroleum-based surfactants, in the petroleum industry seems contradictory and should be critically considered.

\subsection{Food and beverages}

The food $\&$ beverage industry covers meats, processed foods, beverages, dairy products, baked goods, candy, snack foods, frozen foods, and fats \& oils. Surfactants are used in this industry, with a total annual market of about 0.9 million tonnes (Markets and markets, 2016), for different purposes linked with both physicochemical and anti-microbial properties. They have always been an important formulation component of foodstuffs because of their stabilising, anti-adhesive, emulsion forming or breaking and foam forming activity (Kralova and Sjoblom, 2009; Sharma, 2016; Tadros, 2013). At present, SLs have not yet found their way into the food sector, however, due to their non-toxic nature (Develter and Lauryssen, 2010), their green image and production from renewable resources such as glucose and sunflower oil, SLs are highly compatible with foodstuffs and thus increasingly gain interest in this field (Campos et al., 2013). SLs are able to form oil/water (O/W) emulsions with a range of hydrocarbon and triglyceride oils, suggesting their food applicability (Gross et al., 2013; Koh et al., 2017b; Sałek and Euston, 2019). Xue et al. (2013) demonstrated that the stabilisation of O/W emulsions containing structured lipids using SLs was equally effective as compared to Polysorbate 20, a commonly used food emulsifier. Other studies determined the interfacial surface tension of a series 
of alkyl esters of SLs added to mixtures of paraffin and water, almond oil and water and lemon oil and water to form $\mathrm{O} / \mathrm{W}$ emulsions, demonstrating optimal SL-ethyl ester concentrations to stabilise the emulsions (Koh et al., 2016; Koh and Gross, 2016a, 2016b). Besides these tests based on purely physicochemical characteristics, a number of studies have demonstrated the antibacterial and/or antifungal effects of SLs against food spoiling and opportunistic pathogenic microbial species (Baccile et al., 2019a; Díaz De Rienzo et al., 2016; Olanya et al., 2018; Zhang et al., 2016). The potential application of SLs as emulsifiers and/or preservatives in food products requires studying the tastesensory properties of SLs. According to Ozdener et al. 2019 and Solaiman et al. 2019, the addition of SLs into foodstuffs could have an effect on taste responses as they could ameliorate bitter tastes in foods and drugs through t1R3 mediated HBO cell response. As mentioned, implementation of SLs into food stuffs is not a reality yet. The lack of complete and decisive toxicological studies, and the rather high prices for SLs account for this stasis. A breakthrough could be their added value e.g. their use in high value food products such as dietary supplements and/or nutraceuticals or functional foods. For example, acidic SLs have been shown to solubilise and nano-encapsulate curcumin, improving its water solubility, stability and bioavailability and hence enhancing its therapeutic activity. The exploitation of the multifunctionality of SLs, combining quality improvement through formulation, prolonging shelf-life and improving therapeutic properties of high value foodstuffs, reduces the need for other additives, making its application cheaper, more attractive and worth the investment.

\subsection{Crop protection}

About 0,8 million tonnes of surfactants are used every year for the formulation of agrochemicals that are used for crop protection (Markets and markets 2016). Surfactants are used here for their dispersing, suspending, wetting, foaming and penetration properties and also help to improve the shelf life of the products due to their anti-microbial properties. Also, in this sector the demand for bio-based surfactants is increasing due to a growing use of environmentally friendly chemicals in agriculture. One might thus exploit the biodegradable and non-toxic character of SLs and hence the use of SLs has been quite thoroughly investigated for multiple purposes in this sector. The main advantage of using SLs here is the reduction or total elimination of the need for (chemical) pesticides and fungicides, limiting the overall costs while maintaining the pesticide or herbicide emulsifying function (Vaughn et al., 2014) and increasing production yields (Sieverding, 2015). Through the reduction of the surface tension of herbicides, SLs will aid in the formation of smaller droplets and have a softening effect on the plant's crystalline waxes, resulting in improved retention on the leaves and thus lower dissipation. Also increased foliar uptake was described due to better penetration and increased spread (Schönherr et al., 2000; Vaughn et al., 2014). When using SLs as adjuvant to the commonly used herbicides glufosinate ammonium (GLA) and lemongrass oil (LGO), the herbicide Cato ${ }^{\circledR}$ (DuPont ${ }^{\mathrm{TM}}$, Wilmington, USA) and the systemic fungicide Opus ${ }^{\circledR}$ (BASF, Ludwigshafen am Rhein, Germany), increased effects have been described in comparison to the formulation without SLs (Vaughn et al. 

antifungal effects for plant pathogenic fungi and bacteria such as Phytophtora sp., Phytium sp., Alternaria solani, Penicilium chrysogenum and Botrytis cinerea have been described and were linked to inhibition/reduction of mycelial growth, zoospore lysis and zoospore motility. Also these findings are protected/described in several patents/patent applications (Gross and Shah, 2005; Haque et al., 2017; Sachdev and Cameotra, 2013; Schofield et al., 2011; SyntheZyme, 2012; Yoo et al., 2005). The potential use of SLs as a germicide or germicide formulator, linked to reducing microbial contaminations of opportunistic pathogens, has also been described in agricultural work context or distribution centres of fruits and vegetables (de Oliveira, 2015). The agricultural industry is, besides the cleaning and cosmetic industry, already applying wild type SLs into their products. Examples are the Rewoferm ${ }^{\circledR}$ product of Evonik described above and ACS-Sophor ${ }^{\circledR}$ of Allied Carbon Solutions (Tokyo, Japan). The use of SLs in this sector is expected to grow the next few years thanks to their potential application in all stages of crop production, e.g. the use for pre-sowing soil treatment as green biostimulants for seed germination and growth (de Vasconcelos et al., 2020), treatment of soil for increased bio-availability of micronutrients (Singh, Glick, and Rathore 2018) and vegetable and fruit washing (section 5.2).

\subsection{Surfactant enhanced (bio)remediation, bioflotation and wastewater treatment}

1103 The most important environmental and health risk posing contaminants described in recent literature can be classified as poorly water-soluble organic pollutants, metals, oil fractions derived from petroleum and radionuclides (Mao et al., 2015). The readily biodegradable and non-toxic nature of SLs lends them perfect for remediation techniques in the environment, as current technologies are often inefficient and contribute to additional pollution due to the intrinsic toxicity and/or the very often low biodegradability of the compounds used (Arelli et al., 2018). This makes surfactant enhanced bioremediation (SEB) one of the most examined application topics of SLs in literature. The mode of action of (microbial) biosurfactants is often not yet fully understood, however almost always includes the increase of the contaminants' solubility and an increase in the specific surface area of a contaminant bearing matrix or the hydrophobic liquid phase. Also important, but very dependent on the structure of the used biosurfactant, is the binding of the contaminant to the biosurfactant, thus leading to contaminant-biosurfactant complexes, often resulting in inclusion into macromolecular biosurfactant structures such as micelles (Luna et al., 2016; Mao et al., 2015; Sarubbo et al., 2015). When contaminated sources are subjected to living organisms during remediation, specific non-toxic biosurfactants could aid their growth by, amongst others, increasing the bioavailability of the substrate. However, the latter mechanism is not yet fully proven and probably only accounts for specific biosurfactant-microorganism interactions (Schippers et al., 2000). For example, SLs have been shown to increase the maximal degradation rate for the microbial remediation of poly-cyclic aromatic hydrocarbons (PAHs) like anthracene, fluorene, phenanthrene and pyrene, to which the 
solubilisation effect exerted by SLs has repeatedly been attributed (Schippers et al., 2000; Song et al., 2016). This 'washing effect' has also been seen for polychlorinated biphenyls, where the removal efficiency using SLs exceeded that of traditional surfactants Tween-80 and SDS (Qi et al., 2014). Lubricating oil contaminated soils have been treated by SLs by Minucelli et al. (2017), but most of the research has been successfully conducted towards remediation and dispersion of petroleum derived hydrocarbon fractions such as 2-methylnaphthalene, hexadecane, pristane, (bio)diesel, aviation kerosene and (light) crude oil phases itself in (sea)water, beach sands and soils (Babaei and Habibi, 2018; Goswami et al., 2020; Kang et al., 2010; Saborimanesh and Mulligan, 2018). The concepts described above are also seen during biosurfactant or sophorolipid enhanced anaerobic fermentation in wastewater treatment as a consequence of increased solubility of the waste activated sludge, enhanced release of biodegradable organics and favoured growth of hydrolytic microbes and short-chain fatty acid producers over present methanogens (Huang et al., 2015; Xu et al., 2019). A lot of information is available about metal $(\mathrm{Cd}, \mathrm{Pb}, \mathrm{Cu}, \mathrm{Fe}, \mathrm{Zn}, \mathrm{Mn}, \mathrm{Ni}, \mathrm{Hg}$ and $\mathrm{Al})$ remediation for contaminated soils and secondary mining streams such as tailings using biosurfactants such as rhamnolipids and surfactin (Mulligan, 2017). Unfortunately, information on SLs is rather limited and often dates back two decades (Mulligan et al., 2001), though recent years interest seems to be restored, e.g. the remediation of contaminated soils (Basak and Das 2014; Arab and Mulligan 2016; Yang et al. 2016; Qi et al. 2018). In the context of efficient resource management, bioleaching of $\mathrm{Cu}$ out of secondary fayalite material using acidic SLs as lixiviants was reported by Castelein et al. (2021), steered by a $\mathrm{Cu}(0)$ corrosion-based and $\mathrm{CuS}$ solubilising mechanism. The use of SLs in metal mining context is also exploited by Dhar et al. (2019) in bioflotation processes, where CuS could be collected by acidic glycolipids including SLs through a chemisorption binding process between the metal ions and the carboxylic function. Independently of the affordability of SLs, the biggest concern is the selective antimicrobial activity of SLs and the negative effect it could have on the synergistic effects of the contaminant degrading and previously balanced microbiome, resulting in potential growth inhibition of certain species and the loss of degradation capacity for complex hydrocarbons (Patel et al., 2019).

\subsection{Pharmaceutics and medicine}

1149 Although SLs are not yet applied for pharmaceutical/medical purposes, a lot of literature can be found on the matter, especially related to the bio-active properties of SLs, i.e. their anti-microbial properties. Microbial contamination in wounds, e.g. after surgery and in burn wounds, and the formation of biofilms (of pathogenic microorganisms) on medical devices, such as catheters and medical implants, are a crucial problem in the medical sector (Khatoon et al., 2018). These are increasingly caused by multidrug-resistant bacteria proving the urge for alternative treatments (van Duin and Paterson, 2016). Therefore, as in other fields, the antimicrobial and antifungal activity of different SL forms against pathogenic species is a much discussed topic. It was recently reviewed in detail by Solaiman et al. 
a cream containing acidic SLs. The wound healing with the SL cream was accelerated in comparison to the control without affecting the histology of the healing wound (Lydon et al., 2017). SLs also appear to exhibit antiviral activity in combination with acceptable cytotoxicity levels suggesting their use as therapeutic agents in preventing or treating viral infections. To date, they have been described as effective antiviral agents against both the human immunodeficiency virus (HIV) (Shah et al., 2005) and the herpes virus (Borsanyiova et al., 2016; Gross and Shah, 2007). Shah et al. (2005) also showed that SLs could be used as effective spermicidal and virucidal agents. In the late 90's it was shown that SLs could induce cell differentiation instead of cell proliferation in human promyelocytic leukaemia (HL60) cell lines and could also inhibit protein kinase C activity within the HL60 cells (Isoda et al., 1997), a characteristic of an effective anti-tumour agent. Anti-cancer activities were demonstrated on human hepatoma cells of H7402 (Chen et al., 2006), and on human pancreatic (HPAC) and cervical cancer (HeLa and CaSki) cells (Fu et al., 2008; Li et al., 2017), after which the apoptotic response was further clarified (Nawale et al., 2017). However, Callaghan et al. (2016) found that lactonic SLs also reduced viability of normal human colonic and lung cell lines in vitro next to colorectal cancer cell lines. Also, an increased number of intestinal polyps was observed in Apcmin+/- mice after administration of $50 \mathrm{mg} / \mathrm{kg}$ of lactonic SLs for 70 days. Harmful effects are possibly not negligible, being an important aspect of further investigation. Next to a bio-active function, molecular selfassembly of SLs provides potential in pharmaceuticals as an encapsulation component of drugs, which can be used for controlled drug delivery purposes (Baccile et al., 2016b). Although some in depth research has been executed and some opportunities seem to exist, the application of new therapeutics in the pharma/medical sector is highly regulated (i.e. GMP and high purity/uniformity required) and associated with a lengthy registration process. This sector is also less prone to sustainability and/or bio-based claims compared to other sectors applying surfactants. Nevertheless, the formulation of drugs and especially paediatric drugs might hold some opportunities as also here some 'classic' pharmaceutical products keep expanding, leading to withdrawal from the market (Meyers et al., 2020;

1183 Siramshetty et al., 2016). Of course, as not-active agent, SLs would have to be included in the relevant 1184 pharmacopoeias for its use in a certain market(s) which should be justified by the commercial use. Biosynthesis: unravelled and bended towards the biosynthesis of novel biochemicals of novel biochemicals

1188 As described above, sophorolipids are produced as a mixture of different congeners which can in general be divided into different types of acidic, lactonic and bolaform SLs (section 2). Due to the biological nature of the production processes, these mixtures are prone to batch to batch variation, which also gives rise to variation in physiochemical and self-assembly properties (section 5.1). Although the market is looking for an increased variety of biosurfactants, the in-product variety should 
1193 be minimised to limit batch to batch variation, i.e. the uniformity should be increased. Increasing 1194 product variety and uniformity can be achieved through process and/or strain engineering. Product 1195 variety can also be increased through screening for new natural producers. In this section, advances on 1196 expanding the inter-product variety of sophorolipid/glycolipid types and on decreasing the in-product 1197 variety, are described, with a focus on the most studied SL producing organism, Starmerella 1198 bombicola.

The full SL biosynthetic pathway has been elucidated for S. bombicola (figure 5). It starts with the terminal or subterminal hydroxylation of a fatty acid (preferably oleic acid) by the CYP52M1 cytochrome P450 mono-oxygenase enzyme (Huang et al., 2014; Van Bogaert et al., 2013). This hydroxylation step is followed by two glycosylation steps performed by two distinct glycosyltransferase enzymes both utilising UDP-glucose as a glycosyl donor, finally resulting in the addition of a sophorose moiety on the hydroxylated lipophilic tail. The first glycosylation is performed by the UGTA1 glucosyltransferase enzyme (K. M. J. Saerens et al., 2011c), while the second glycosylation is performed by a second glycosyltransferase enzyme, UGTB1 (K. M. Saerens et al., 2011b). The resulting acidic or 'open form' sophorolipid can undergo acetylation on the sophorose moiety by an acetyl transferase enzyme, transferring an acetyl group from acetyl-CoA to positions 6' and/or 6" of the sophorose moiety, thus resulting in a mixture of non-, mono- and di-acetylated acidic SLs (K. M. Saerens et al., 2011b). This biosynthesis of acidic SLs takes place intracellularly and the acidic SLs are transported out of the cells by a specific SL transporter similar to multi drug transporter proteins (MDR) (Van Bogaert et al., 2013). A last enzymatic reaction takes place outside the cell, i.e. an intramolecular esterification of the free carboxylic end of the acidic SLs with the 4" position of the hydrophilic sophorose head (Roelants et al., 2016), giving rise to the so-called lactonic or 'closed form' SLs. The enzyme responsible for this reaction, the S. bombicola lactone esterase (SBLE), was identified in the exoproteome of $S$. bombicola is actively secreted (Ciesielska et al., 2016, 2014).

Figure 5: Left: Depiction of wild type sophorolipid biosynthesis in S; bombicola. A:B: A depicts fatty acyl carbon chain length while B depicts degree of unsaturation, 1: CYP52M1, 2: UGTA1, 3: UGTB1, 4: SBLE, 5: De novo fatty acid synthesis. Upper right: schematic representation of SLs depicted in figure $1 A, B$ and $C$. Bottom right: functional group legend.

The elucidation of the SL biosynthetic pathway, together with the development of molecular tools for S. bombicola, allowed multiple rational engineering strategies to solve the variety and uniformity hurdles mentioned above. To increase product uniformity, the composition of the wild type mixture was pushed towards either (100\%) acidic or either (almost 100\%) lactonic sophorolipids by the creation of an sble deletion or an sble overexpression strain, respectively (Ciesielska et al., 2016; Roelants et al., 2016). Yet, although uniformity was increased, the abundancy of different SL types in the new mixtures was still quite high, mainly due to the variation in acetylation degrees and the incorporation of different types of fatty acids into the non-, mono- or di-acetylated products. A knock 
out of the acetyltransferase gene gives rise to the production of non-acetylated molecules (K. M.

1230 Saerens et al., 2011a). Relatively simple overexpression and knock out strategies thus showed to 1231 dramatically increase the uniformity of the produced sophorolipids. Increasing the uniformity can also 1232 be achieved by specifically feeding a desired fatty acid or a substrate enriched in the desired fatty acid 1233 (e.g. pure oleic acid or an oil enriched in oleic acid, such as high oleic sunflower oil (HOSO)) (Ashby 1234 et al., 2013). The produced SLs will 'mirror' the composition of the fed substrate with a preference for $1235 \mathrm{C}_{18: 1}$ fatty substrates. Another strategy lies in modifying the substrate specificity of the responsible 1236 biosynthetic enzymes, but this has not yet been described for SL biosynthetic enzymes.

Similarly, several approaches have been applied to increase the product variety, also both genetic and process engineering approaches. Using genetic engineering to, for example, knock out the sble and at genes in $S$. bombicola, allowed the production of a specific and special type of sophorolipids with interesting properties, i.e. bolaform sophorolipids (Van Bogaert et al., 2016). Bolaform sophorolipids are produced in very low amounts in the wild type SL mixture (Price et al., 2012), but this modification allowed more uniform and increased production of these compounds, free from contaminating lactonic SLs. Still, the problem of uniformity remains, as acidic sophorolipids are co-produced. The ratio of bolaform SL/acidic SL was optimised by applying process development strategies (non-published results). Knocking out the faol gene in the former strain increased the stability of the bolaform biosurfactants, since the linking of the second sophorose moiety on the hydrophobic linker now occurs through a glycosidic bond instead of an ester bond (Roelants et al., 2018, Van Renterghem et al., 2018). Again, the choice of substrate has an important impact on the ratio of different molecules formed, as also here 'substrate mirroring' applies, grace to the higher affinity of the CYP52M1 enzyme towards long chain hydrophilic substrates (Huang et al., 2014). In another example, Takahashi et. al (2016) described improved production of alkyl polyglucosides by deletion of the faol gene, disrupting the long-chain alcohol oxidation pathway. Brakemeier et al. (1998b) were able to produce such microbial alkyl polyglucosides by feeding 2-dodecanol, showing again the crucial role of process engineering strategies to increase product variety, besides genetic engineering (Brakemeier et al., 1998b, 1995; Lang et al., 2000).

S. bombicola's tolerance towards hydrophobic substrates, due to the abundantly present (alkane inducible) cyp52 genes, represents also clear opportunities towards the production of different types of 'fatty based' molecules (Geys et al., 2018; Huang et al., 2014; Inge N.A. Van Bogaert et al., 2009). Proof of concept therefor was given by Roelants et al. (2013), who showed the production of the bioplastic polyhydroxyalkanoate (PHA) and production of cellobiose lipids. Moreover, Jezierska et al. (2019) succeeded in creating a strain capable of producing about $1 \mathrm{~g} \cdot \mathrm{L}^{-1}$ free fatty acids (mixture of $\mathrm{C}_{18: 1}, \mathrm{C}_{18: 0}$ and $\mathrm{C}_{16: 0}$ chain) by knocking out 3 genes: faal (fatty acyl-CoA synthetase), cyp52ml and $m f e 2$ (multifunctional enzyme type 2), while De Graeve et. al (2019) showed that by controlling the 
beta- and omega oxidation, by knocking out $\Delta u g t a l / \Delta p o x / \Delta f a o l$, the production of long chain hydroxy fatty acids could be obtained up to concentrations of $17.39 \mathrm{~g} \cdot \mathrm{L}^{-1}$.

Hitherto, advances in process optimisation are resulting in higher productivities and therefore lower production costs of SLs (section 4). In this perspective, genetic engineering strategies can be a valuable ally. The above described strategies to minimise product uniformity, stimulate lower DSP costs as less impurities have to be separated. Furthermore, strategies to adapt the metabolism of $S$. bombicola for increased SL production have been described. (Takahiro et al. 2017) described a KO strategy for higher SL production. Moreover, random mutagenesis in combination with highthroughput screening is described to increase production SL titres (Lin et al. 2019; Zhou et al. 2019; Ma et al. 2020). Herein, it is of utmost importance that the performance of the selected strains based on high-throughput screening methods are validated by accurate SL quantification methods. Furthermore, random mutagenesis can result in production losses by metabolism distortion caused by off-target effects and therefore thorough strain performance validation is of utmost importance (Lodens et al. 2019).

The above mentioned rational genetic engineering of $S$. bombicola required the development of a molecular toolbox, which is, till to date, under construction. The first step taken was the development of a successful transformation and selection method. Van Bogaert et al $(2008,2007)$ described the use of a chemical transformation method, where the cells are resuspended in a transformation mix containing PEG, LiAc, SS-carrier DNA, and (plasmid) DNA. Currently, the use of an electroporation protocol combined with lithium acetate and dithiothreitol is more common (K. M. Saerens et al., 2011a). Conventional yeast antibiotics based selection methods were examined but hitherto only hygromycin and nourseothricin were reported as robust selection markers for $S$. bombicola (Lodens et al., 2017; Van Bogaert et al., 2008). As for auxotrophic markers, Ura3 selection (orotidine-5'-phosphate decarboxylase) is the only one described (Lodens et al., 2017; Van Bogaert et al., 2007). Furthermore, Lodens et al. (2020) focused on the development of a reporter system for $S$. bombicola. Such a reporter system is key in the development of a molecular toolbox since it allows for screening of promotor and terminator libraries. Characterised parts for enzyme expression in turn allow for metabolic flux regulation, which aid in solving problems of titres, productivity and congeners mentioned above. Here the telomere positioning effect involved in sophorolipid synthesis was shown using the endogenous promotors $p C y p 52 m 1$ and $p$ Gapd. Finally, a huge leap forward in

1294 domesticating S. bombicola was also taken by the development of quantitative proteomics, 1295 transcriptomics and metabolomics methodologies, as well as a reverse- transcription quantitative 1296 polymerase chain reaction (RT-qPCR) platform and liquid chromatography- multireaction monitoring- mass spectrometry (LC-MRM-MS) (Lodens et al., 2019). 
1299 been taken, there is room for improvement if compared to other yeast species (e.g. Yarrowia

1300 lipolytica, Saccharomyces cerevisiae). For example, improved homologous recombination could solve 1301 the need for $1000 \mathrm{bp}$ long homologous regions. Events in which genomic integration is required could 1302 be improved by altering the non-homologous end-joining pathway and thus increasing the homologous recombination efficiency. This strategy has already been proven successful in Yarrowia lipolytica (Verbeke et al., 2013), Rhodosporidium toruloides (Koh et al., 2014), Kluyveromyces marxianus (Chen et al., 2013) and several other yeasts. By knocking out the KU70 or KU80 proteins in these yeasts, genomic integration was drastically altered in favour of homologous recombination, and the need for large homologous regions became redundant. The isolation of ARS/CEN sequences in several exotic yeast species allowed the use of plasmids and as such the use of more "complex" molecular tools like Cre-Lox or CRISPR-CAS9 (Wagner and Alper, 2016). The development of CRIPSPRCAS9 can also eliminate the need for selection markers due to the high efficiency of the technique.

1311 This would obviate the need for marker recovery in S. bombicola, which is quite laborious and 1312 frequently required, as only three markers are available. CRISPR-CAS9 has been developed in numerous non-conventional yeasts, e.g. Yarrowia lipolytica (Schwartz et al., 2016) and

1314 Kluyveromyces lactis (Spohner et al., 2016). Also, if the tailor-made biomolecules are to achieve 1315 industrial relevance, a (much) more extended library of characterised regulatory parts will be required 1316 (both for transcription and translation). Taken together, this will allow more efficient metabolic 1317 engineering and might open the door to further counteract the issue with SLs produced in mixtures.

\section{$1318 \quad 7$ Industrial perspectives}

1319 The interesting surfactant and antimicrobial properties of sophorolipids in combination with high 1320 natural productivities and sustainable nature (biological process based on biobased feedstock, good 1321 biodegradability) has resulted in their application in a range of commercialised B2C products and 1322 other applications, as discussed in section 5. Although the industrial interest in biobased surfactants is 1323 clearly on the rise, the production volumes of sophorolipids remain modest (two-digit tonne scale in 1324 Europe). This is mainly because of the high costs of sophorolipids (20-30 euro $\mathrm{kg}^{-1}$ in Europe) in 1325 comparison with classic surfactants (bulk surfactants typically cost around 1 euro/kg, while chemically 1326 produced biobased surfactants, such as APGs, are typically sold at between 3-6 euro $\mathrm{kg}^{-1}$ ). The main 1327 two reasons for these high costs of sophorolipids are 1) the low scale combined with the fact that 2) 1328 industrial microbiology for the large-scale production of biochemicals, such as microbial 1329 biosurfactants, is still a relatively 'young' technology compared to mature and fully optimised 1330 chemical production technologies. Clearly this is a catch-22 situation, where the high costs of sophorolipids prevent an increase in the production volumes and vice versa. When the production scale and volumes would be increased to let's say the production of a few thousand tonnes of SLs per year, the prices could drop below 10 euro $\mathrm{kg}^{-1}$ depending on substrates, set ups, type of SL molecule, 
purification method(s) etc. (Roelants et al., 2018). This drop in price would result in an increase of the demand and subsequent increase of the production volumes and further decrease of the price, as such creating a clear growth of the market and escaping the catch-22 situation. capital investments. Although the productivities of the SL production process are typically quite high (an average volumetric productivity of about $2 \mathrm{~g} \cdot \mathrm{L}^{-1} \cdot \mathrm{h}^{-1}$ can be easily reached), a production volume of about 10000 tonnes of SLs per year would still require an estimated (conservative) bioreactor capacity order of magnitude of $1000 \mathrm{~m}^{3}$ plus the required associated equipment for the purification/downstream processing. Such capacity increase would require substantial CAPEX investments, which should be substantiated and backed up by a clear market pull for these volumes at the projected price and requires substantial ambition from the industry. This pivoting point and shift in ambitions from the industry might have been reached, seen Unilever's recent statements towards their ambition to completely eliminate fossil feedstocks for the production of cleaning products by 2030 and their budget reservation of 1 billion euro to do so (Macmillan, 2020). Their aim, together with that of Evonik, to build a multi thousand tonne scale microbial biosurfactant (rhamnolipid) production plant in Europe (Evonik, 2019; Roelants and Soetaert, 2021) clearly substantiates that ambition. Now that SLs have been available on the B2B market (commercialised by Evonik) for about 5 years, several B2C companies have had the chance to test sophorolipids in their applications.

To our knowledge, industrial interest is there, but price is still a crucial issue. Once large scale procurance can be guaranteed, investments in large scale production capacity should not be too far off. This could be done by existing or new players in the field as several industrial parties have expressed their will to invest in this field and some new players such as Locus, Holiferm and Croda (Snaith, UK) have expressed their ambitions towards large scale SL production. We thus expect the world to look quite different in five years from now and predict a bright future for microbial biosurfactants. Whether sophorolipids will take the same flight as rhamnolipids depends on their (combination of) functionalities and the will of B2C companies to formulate these compounds in their products because, besides being green, biobased and mild, the products also need to do the job.

\section{Conclusive remarks}

1362 The interest in and impact of sophorolipids is increasing exponentially. Therefore, this review 1363 provides academic and industrial stakeholders the necessary critical assessment to look back at and 1364 extend the sophorolipid tale, from beehive to bioeconomy. Take home messages are:

1365 - The genuine SL producing organisms are located in the genera of Starmerella and Pseudohyphozyma. 
- As for the Starmerella species in their natural habitat, it has been postulated that SLs are produced as extracellular storage compound ('personal hoard') in combination with antimicrobial activity.

- Qualitative strain and structure identification are of utmost importance as previous inadequacies led to questionable reports.

- To utilise SLs to their full extend, process optimisation has been performed to increase production performance. Hitherto, in-situ product recovery in combination with high biomass concentrations showed promising results. For further process optimisation reports, it is advised to use correct and standardised terminology. Moreover, production processes should be optimised for overall production cost and environmental impact. An increase in production process performance alongside an increase in production capacity will decrease the production cost and result in an increased application potential. In this perspective, the personal care and cleaning sector are playing a pioneering role as they already have sophorolipids in their formulations. Subsequently, the economy of scale will make the production price accessible for crop protection and food applications. If the necessary investments for production scale-up are performed, we expect a bright future for sophorolipids and other microbial biosurfactants.

- The strength of SLs lies in their function as both (bio-)active component and formulating agent. Additionally, the 'green nature' (high biodegradability, biological production) and mild properties

\section{Acknowledgements}

No acknowledgements are necessary as the work provided to create this manuscript was fully performed by the authors themselves.

\section{Research funding}

Funding: This work was supported by the 'Fonds Wetenschappelijk Onderzoek' [grant numbers 1S37420N, 1S37920N, 1S58817N]; Flemish Vlaio VIS project APPLISURF [HBC.2017.0704]

\section{References}

Abdel-Mawgoud, A.M., Lépine, F., Déziel, E., 2010. Rhamnolipids: diversity of structures, microbial origins and roles. Appl. Microbiol. Biotechnol. 86, 1323-1336. https://doi.org/10.1007/s00253$010-2498-2$

Akemi, V., Silveira, I., Urzedo, C.A., Freitas, Q., Pedrine, M.A., Celligoi, C., 2018. Antimicrobial applications of sophorolipid from Candida bombicola: A promising alternative to conventional drugs. https://doi.org/10.7324/JABB.2018.60614

Albrecht, A., Rau, U., Wagner, F., 1996. Initial steps of sophoroselipid biosynthesis by Candida 
bombicola ATCC 22214 grown on glucose. Appl. Microbiol. Biotechnol. 46, 67-73. https://doi.org/10.1007/s002530050784

Allef, P., Hartung, C., Schilling, M., 2012. Aqueous hair and skin cleaning compositions comprising biotensides. WO2013098066A2.

Andersen, K.K., Vad, B.S., Roelants, S., van Bogaert, I.N.A., Otzen, D.E., 2016. Weak and saturable protein-surfactant interactions in the denaturation of apo-a-lactalbumin by acidic and lactonic sophorolipid. Front. Microbiol. 7, 1-9. https://doi.org/10.3389/fmicb.2016.01711

Arab, F., Mulligan, C.N., 2016. Efficiency of sophorolipids for arsenic removal from mine tailings. Environ. Geotech. jenge.15.00016. https://doi.org/10.1680/jenge.15.00016

Arelli, A., Nuzzo, A., Sabia, C., Banat, I.M., Zanaroli, G., Fava, F., 2018. Optimization of washing conditions with biogenic mobilizing agents for marine fuel-contaminated beach sands. $\mathrm{N}$. Biotechnol. 43, 13-22. https://doi.org/10.1016/j.nbt.2017.12.007

Ashby, R.D., McAloon, A.J., Solaiman, D.K.Y., Yee, W.C., Reed, M., 2013. A Process Model for Approximating the Production Costs of the Fermentative Synthesis of Sophorolipids. J. Surfactants Deterg. 16, 683-691. https://doi.org/10.1007/s11743-013-1466-0

Ashby, R.D., Solaiman, D.K.Y., Foglia, T.A., 2008. Property control of sophorolipids: influence of fatty acid substrate and blending. Biotechnol. Lett. 30, 1093-1100. https://doi.org/10.1007/s10529-008-9653-1

Ba, A.A., Everaert, J., Poirier, A., Le Griel, P., Soetaert, W., Roelants, S.L.K.W., Hermida-Merino, D., Stevens, C. V., Baccile, N., 2020. Synthesis and self-assembly of aminyl and alkynyl substituted sophorolipids. Green Chem. 22, 8323-8336. https://doi.org/10.1039/d0gc03053h

Babaei, F., Habibi, A., 2018. Fast Biodegradation of Diesel Hydrocarbons at High Concentration by the Sophorolipid-Producing Yeast Candida catenulata KP324968. J. Mol. Microbiol. Biotechnol. 28, 240-254. https://doi.org/10.1159/000496797

Babazadeh, R., Lahtvee, P.J., Adiels, C.B., Goksör, M., Nielsen, J.B., Hohmann, S., 2017. The yeast osmostress response is carbon source dependent. Sci. Rep. 7, 1-11. https://doi.org/10.1038/s41598-017-01141-4

Baccile, N., Babonneau, F., Banat, I.M., Ciesielska, K., Cuvier, A.-S., Devreese, B., Everaert, B., Lydon, H., Marchant, R., Mitchell, C.A., Roelants, S., Six, L., Theeuwes, E., Tsatsos, G., Tsotsou, G.E., Vanlerberghe, B., Van Bogaert, I.N.A., Soetaert, W., 2017. Development of a Cradle-to-Grave Approach for Acetylated Acidic Sophorolipid Biosurfactants. ACS Sustain. Chem. Eng. 5, 1186-1198. https://doi.org/10.1021/acssuschemeng.6b02570 
Baccile, N., Babonneau, F., Jestin, J., Pehau-Arnaudet, G., Van Bogaert, I., 2012. Unusual, pHInduced, Self-Assembly Of Sophorolipid Biosurfactants. ACS Nano 6, 4763-4776. https://doi.org/10.1021/nn204911k

Baccile, Niki, Ben Messaoud, G., Zinn, T., Fernandes, F.M., 2019b. Soft lamellar solid foams from ice-templating of self-assembled lipid hydrogels: organization drives the mechanical properties. Mater. Horizons 6, 2073-2086. https://doi.org/10.1039/c9mh00371a

Baccile, N., Cuvier, A.-S., Prévost, S., Stevens, C. V., Delbeke, E., Berton, J., Soetaert, W., Van Bogaert, I.N.A., Roelants, S., 2016a. Self-Assembly Mechanism of pH-Responsive Glycolipids: Micelles, Fibers, Vesicles, and Bilayers. Langmuir 32, 10881-10894. https://doi.org/10.1021/acs.langmuir.6b02337

Baccile, N., Cuvier, A.-S., Valotteau, C., Van Bogaert, I.N.A., 2013. Practical methods to reduce impurities for gram-scale amounts of acidic sophorolipid biosurfactants. Eur. J. Lipid Sci. Technol. 115, 1404-1412. https://doi.org/10.1002/ejlt.201300131

Baccile, N., Delbeke, E.I.P., Brennich, M., Seyrig, C., Everaert, J., Roelants, S.L.K.W., Soetaert, W., Van Bogaert, I.N.A., Van Geem, K.M., Stevens, C. V., 2019a. Asymmetrical, Symmetrical, Divalent, and Y-Shaped (Bola)amphiphiles: The Relationship between the Molecular Structure and Self-Assembly in Amino Derivatives of Sophorolipid Biosurfactants. J. Phys. Chem. B 123, 3841-3858. https://doi.org/10.1021/acs.jpcb.9b01013

Baccile, N., Le Griel, P., Prévost, S., Everaert, B., Van Bogaert, I.N.A., Roelants, S., Soetaert, W., 2017b. Glucosomes: Glycosylated Vesicle-in-Vesicle Aggregates in Water from pH-Responsive Microbial Glycolipid. ChemistryOpen 6, 526-533. https://doi.org/10.1002/open.201700101

Baccile, N., Messaoud, G. Ben, Griel, P. Le, Cowieson, N., Perez, J., Geys, R., Graeve, M. De, Roelants, S.L.K.W., Soetaert, W., 2021a. Palmitic Acid Sophorolipid Biosurfactant: From SelfAssembled Fibrillar Network (SAFiN) To Hydrogels with Fast Recovery. Philos. Trans. A 10.1098/rsta.2020.0343. https://doi.org/10.1098/rsta.2020.0343

Baccile, N., Nassif, N., Malfatti, L., Van Bogaert, I.N.A., Soetaert, W., Pehau-Arnaudet, G., Babonneau, F., 2011. Sophorolipids: a yeast-derived glycolipid as greener structure directing agents for self-assembled nanomaterials. Green Chem. 12, 1564-1567. https://doi.org/10.1039/c0gc00163e

Baccile, N., Selmane, M., Le Griel, P., Prévost, S., Perez, J., Stevens, C. V., Delbeke, E., Zibek, S., Guenther, M., Soetaert, W., Van Bogaert, I.N.A., Roelants, S., 2016b. pH-Driven Self-Assembly of Acidic Microbial Glycolipids. Langmuir 32, 6343-6359. https://doi.org/10.1021/acs.langmuir.6b00488 
Baccile, N., Seyrig, C., Poirier, A., Castro, S.A., Roelants, S.L.K.W., Abel, S., 2021b. Self-Assembly, Interfacial Properties, Interactions with Macromolecules and Numerical Modelling of Microbial Bio-based Amphiphiles (Biosurfactants). A Tutorial Review. Green Chem. DOI: 10.1039/d1gc00097g. https://doi.org/10.1039/d1gc00097g

Baccile, N., Van Renterghem, L., Le Griel, P., Ducouret, G., Brennich, M., Cristiglio, V., Roelants, S.L.K.W., Soetaert, W., 2018. Bio-based glyco-bolaamphiphile forms a temperature-responsive hydrogel with tunable elastic properties. Soft Matter 14, 7859-7872. https://doi.org/10.1039/C8SM01167B

Barclay, T.G., Constantopoulos, K., Matisons, J., 2014. Nanotubes self-assembled from amphiphilic molecules via helical intermediates. Chem. Rev. 114, 10217-10291. https://doi.org/10.1021/cr400085m

Basak, G., Das, D., Das, N., 2014. Dual role of acidic diacetate sophorolipid as biostabilizer for ZnO nanoparticle synthesis and biofunctionalizing agent against Salmonella enterica and Candida albicans. J. Microbiol. Biotechnol. 24, 87-96. https://doi.org/10.4014/jmb.1307.07081

Basak, G., Das, N., 2014. Characterization of sophorolipid biosurfactant produced by Cryptococcus sp. VITGBN2 and its application on Zn(II) removal from electroplating wastewater. J. Environ. Biol. 35, 485-489.

Ben Messaoud, G., Le Griel, P., Hermida-Merino, D., Roelants, S.L.K.W., Soetaert, W., Stevens, C.V., Baccile, N., 2019. pH-Controlled Self-Assembled Fibrillar Network Hydrogels: Evidence of Kinetic Control of the Mechanical Properties. Chem. Mater. 31, 4817-4830. https://doi.org/10.1021/acs.chemmater.9b01230

Ben Messaoud, G., Promeneur, L., Brennich, M., Roelants, S.L.K.W., Le Griel, P., Baccile, N., 2018. Complex coacervation of natural sophorolipid bolaamphiphile micelles with cationic polyelectrolytes. Green Chem. 20, 3371-3385. https://doi.org/10.1039/c8gc01531g

Bergström, M., 2000a. Thermodynamics of anisotropic surfactant micelles. I. The influence of curvature free energy on the micellar size and shape. J. Chem. Phys. 113, 5559-5568. https://doi.org/10.1063/1.1289884

Bergström, M., 2000b. Thermodynamics of anisotropic surfactant micelles. II. A molecular interpretation of the micellar curvature free energy. J. Chem. Phys. 113, 5569-5579. https://doi.org/10.1063/1.1289885

Bhangale, A.P., Wadekar, S.D., Kale, S.B., Pratap, A.P., 2014. Sophorolipids synthesized using nontraditional oils with glycerol and studies on their surfactant properties with synthetic surfactant. Tenside, Surfactants, Deterg. 51, 387-396. https://doi.org/10.3139/113.110320 
Borsanyiova, M., Patil, A., Mukherji, R., Prabhune, A., Bopegamage, S., 2016. Biological activity of sophorolipids and their possible use as antiviral agents. Folia Microbiol. (Praha). 61, 85-89. https://doi.org/10.1007/s12223-015-0413-z

Brakemeier, A., Lang, S., Wullbrandt, D., Merschel, L., Benninghoven, A., Buschmann, N., Wagner, F., 1995. Novel sophorose lipids from microbial conversion of 2-alkanols. Biotechnol. Lett. 17, 1183-1188. https://doi.org/10.1007/BF00128383

Brakemeier, A., Wullbrandt, D., Lang, S., 1998a. Microbial alkyl-sophorosides based on 1-dodecanol or 2-, 3- or 4-dodecanones. Biotechnol. Lett. 20, 215-218.

Brakemeier, A., Wullbrandt, D., Lang, S., 1998b. Candida bombicola, production of novel alkyl glycosides based on glucose/2-dodecanol. Appl. Microbiol. Biotechnol. 50, 161-166. https://doi.org/10.1007/s002530051271

Brysch-Herzberg, M., 2004. Ecology of yeasts in plant-bumblebee mutualism in Central Europe. FEMS Microbiol. Ecol. 50, 87-100. https://doi.org/10.1016/j.femsec.2004.06.003

Bucholtz, M.L., Light, R.J., 1976. Hydrolysis of 13-sophorosyloxydocosanoic acid esters by acetyland carboxylesterases isolated from Candida bogoriensis. J. Biol. Chem. 251, 431-437.

Cajka, T., Garay, L.A., Sitepu, I.R., Boundy-Mills, K.L., Fiehn, O., 2016. Multiplatform Mass Spectrometry-Based Approach Identifies Extracellular Glycolipids of the Yeast Rhodotorula babjevae UCDFST 04-877. J. Nat. Prod. 79, 2580-2589. https://doi.org/10.1021/acs.jnatprod.6b00497

Callaghan, B., Lydon, H., Roelants, S.L.K.W., Van Bogaert, I.N.A., Marchant, R., Banat, I.M., Mitchell, C.A., 2016. Lactonic sophorolipids increase tumor burden in Apcmin+/- mice. PLoS One 11. https://doi.org/10.1371/journal.pone.0156845

Cambia, 2020. Lens version 7.2.1. (https://www.lens.org/, accessed on 23/12/2020) [WWW Document]. URL https://www.lens.org/ (accessed 12.23.20).

Campos, J.M., Montenegro Stamford, T.L., Sarubbo, L.A., de Luna, J.M., Rufino, R.D., Banat, I.M., 2013. Microbial biosurfactants as additives for food industries. Biotechnol. Prog. 29, 1097-1108. https://doi.org/10.1002/btpr.1796

Cardinale, B.J., Duffy, J.E., Gonzalez, A., Hooper, D.U., Perrings, C., Venail, P., Narwani, A., MacE, G.M., Tilman, D., Wardle, D.A., Kinzig, A.P., Daily, G.C., Loreau, M., Grace, J.B., Larigauderie, A., Srivastava, D.S., Naeem, S., 2012. Biodiversity loss and its impact on humanity. Nature. https://doi.org/10.1038/nature11148

Casas, J.A., Garcia-Ochoa, F., 1999. Sophorolipid production by Candida bombicola: Medium 
composition and culture methods. J. Biosci. Bioeng. 88, 488-494. https://doi.org/http://dx.doi.org/10.1016/S1389-1723(00)87664-1

1532

Castelein, M., van Renterghem, L., Verbruggen, F., Spooren, J., Yurramendi, L., Laing, G. Du, Boon, N., Soetaert, W., Hennebel, T., Roelants, S., Williamson, A., 2020. Bioleaching of metals from secondary materials using glycolipid biosurfactants (ready for submission).

Cavalero, D.A., Cooper, D.G., 2003. The effect of medium composition on the structure and physical state of sophorolipids produced by Candida bombicola ATCC 22214. J. Biotechnol. 103, 31-41. https://doi.org/http://dx.doi.org/10.1016/S0168-1656(03)00067-1

Centraal bureau voor Schimmelculturen, 2020. CBS strain database (https://wi.knaw.nl/, accessed on 23/12/2020) [WWW Document]. URL https://wi.knaw.nl/ (accessed 12.23.20).

Chandran, P., Das, N., 2012. Role of sophorolipid biosurfactant in degradation of diesel oil by Candida tropicalis. Bioremediat. J. 16, 19-30. https://doi.org/10.1080/10889868.2011.628351

Chandran, P., Das, N., 2011. Characterization of sophorolipid biosurfactant produced by yeast species grown on diesel oil. Int. J. Sci. Nat. 2, 63-71.

Chen, J., Song, X., Zhang, H., Qu, Y.B., Miao, J.Y., 2006. Sophorolipid produced from the new yeast strain Wickerhamiella domercqiae induces apoptosis in H7402 human liver cancer cells. Appl. Microbiol. Biotechnol. 72, 52-59. https://doi.org/10.1007/s00253-005-0243-z

Chen, J., Zhang, H., 2014. Method for selectively producing sophorolipid. (CN104178538A).

Chen, J., Zhang, H., Liu, Y., Fu, S., Liu, X., 2014. Metal ions can affect the composition and production of sophorolipids by Wickerhamiella domercqiae Y2A CGMCC 3798. Eur. J. Lipid Sci. Technol. 116, 1505-1512.

Chen, Z., Sun, H., Li, P., He, N., Zhu, T., Li, Y., Schacherer, J., 2013. Enhancement of the Gene Targeting Efficiency of Non-Conventional Yeasts by Increasing Genetic Redundancy. https://doi.org/10.1371/journal.pone.0057952

Ciesielska, K., Li, B., Groeneboer, S., Van Bogaert, I., Lin, Y.C., Soetaert, W., Van de Peer, Y., Devreese, B., 2013. SILAC-Based Proteome Analysis of Starmerella bombicola Sophorolipid Production. J. Proteome Res. 12, 4376-4392. https://doi.org/10.1021/pr400392a

Ciesielska, K., Roelants, S.L.K.W., Van Bogaert, I.N.A., De Waele, S., Vandenberghe, I., Groeneboer, S., Soetaert, W., Devreese, B., 2016. Characterization of a novel enzyme-Starmerella bombicola lactone esterase (SBLE) - responsible for sophorolipid lactonization. Appl. Microbiol. Biotechnol. 100, 9529-9541. https://doi.org/10.1007/s00253-016-7633-2

Ciesielska, K., Van Bogaert, I.N., Chevineau, S., Li, B., Groeneboer, S., Soetaert, W., Van de Peer, Y., 
Devreese, B., 2014. Exoproteome analysis of Starmerella bombicola results in the discovery of an esterase required for lactonization of sophorolipids. J. Proteomics 98, 159-174. https://doi.org/http://dx.doi.org/10.1016/j.jprot.2013.12.026

1565

Claus, S., Van Bogaert, I.N.A., 2017. Sophorolipid production by yeasts: a critical review of the literature and suggestions for future research. Appl. Microbiol. Biotechnol. 101, 7811-7821. https://doi.org/10.1007/s00253-017-8519-7

Cox, T.F., Crawford, R.J., Gregory, L.G., Hosking, S.L., Kotsakis, P., 2011. Mild to the skin, foaming detergent composition (WO2011120776A1). WO2011120776A1.

Cuvier, A.-S., Berton, J., Stevens, C. V., Fadda, G.C., Babonneau, F., Van Bogaert, I.N.A., Soetaert, W., Pehau-Arnaudet, G., Baccile, N., 2014. pH-triggered formation of nanoribbons from yeastderived glycolipid biosurfactants. Soft Matter 10, 3950-3959. https://doi.org/10.1039/C4SM00111G

Cuvier, A.S., Babonneau, F., Berton, J., Stevens, C. V., Fadda, G.C., Genois, I., Le Griel, P., P HauArnaudet, G., Baccile, N., 2015a. Synthesis of Uniform, Monodisperse, Sophorolipid Twisted Ribbons. Chem. - An Asian J. 10, 2419-2426. https://doi.org/10.1002/asia.201500693

Cuvier, A.S., Babonneau, F., Berton, J., Stevens, C. V., Fadda, G.C., Péhau-Arnaudet, G., Le Griel, P., Prévost, S., Perez, J., Baccile, N., 2015b. Nanoscale Platelet Formation by Monounsaturated and Saturated Sophorolipids under Basic pH Conditions. Chem. - A Eur. J. 21, 19265-19277. https://doi.org/10.1002/chem.201502933

Daniel, Hans-J., Otto, R.T., Reuss, M., Syldatk, C., 1998. Sophorolipid Production with High Yields on Whey Concentrate and Rapeseed Oil without Consumption of Lactose. Biotechnol. Lett. 20, 805-807.

Daniel, Hans-Joachim, Reuss, M., Syldatk, C., 1998. Production of sophorolipids in high concentration from deproteinized whey and rapeseed oil in a two stage fed batch process using Candida bombicola ATCC 22214 and Cryptococcus curvatus ATCC 20509. Biotechnol. Lett. 20, 1153-1156. https://doi.org/10.1023/A:1005332605003

Daverey, A., Pakshirajan, K., 2010. Sophorolipids from Candida bombicola using mixed hydrophilic substrates: Production, purification and characterization. Colloids Surfaces B Biointerfaces 79, 246-253. https://doi.org/http://dx.doi.org/10.1016/j.colsurfb.2010.04.002

Daverey, A., Pakshirajan, K., 2009. Production of sophorolipids by the yeast Candida bombicola using simple and low cost fermentative media. Food Res. Int. 42, 499-504.

Davila, A.-M., Marchal, R., Vandecasteele, J.-P., 1997. Sophorose lipid fermentation with differentiated substrate supply for growth and production phases. Appl. Microbiol. Biotechnol. 
47, 496-501.

Davila, A.-M., Marchal, R., Vandecasteele, J.-P., 1992. Kinetics and balance of a fermentation free from product inhibition: sophorose lipid production by Candida bombicola. Appl. Microbiol. Biotechnol. 38, 6-11. https://doi.org/10.1007/BF00169410

De Graeve, M., Van de Velde, I., Saey, L., Chys, M., Oorts, H., Kahriman, H., Mincke, S., Stevens, C., De Maeseneire, S.L., Roelants, S.L.K.W., Soetaert, W.K.G., 2019. Production of long-chain hydroxy fatty acids by Starmerella bombicola. FEMS Yeast Res. 19. https://doi.org/10.1093/femsyr/foz067

de Bruyn, J.W., Van Keulen, H.A., Ferguson, J.H.A., 1968. Rapid method for the simultaneous determination of glucose and fructose using anthrone reagent. J. Sci. Food Agric. 19, 597-601. https://doi.org/10.1002/jsfa.2740191009

De Clercq, V., Roelants, S.L.K.W., Castelein, M.G., De Maeseneire, S.L., Soetaert, W.K., 2021. Elucidation of the natural function of sophorolipids produced by Starmerella bombicola. J. Fungi (submission ongoing).s

De Graeve, M., De Maeseneire, S.L., Roelants, S.L.K.W., Soetaert, W., 2018. Starmerella bombicola, an industrially relevant, yet fundamentally underexplored yeast. FEMS Yeast Res. 18. https://doi.org/10.1093/femsyr/foy072

de Oliveira, M.R. et al., 2015. Sophorolipids: a promising biosurfactant and it's applications. Adv. Biotechnol. Res. 16, 161-174.

de Vasconcelos, G.M.D., Mulinari, J., Schmidt, V.K. de O., Matosinhos, R.D., José Vladimir de Oliveira, Oliveira, D. de, De Andrade, C.J., 2020. Biosurfactants as Green Biostimulants for Seed Germination and Growth. Int. J. Res. Stud. Microbiol. Biotechnol. 6. https://doi.org/10.20431/2454-9428.0601001

Deinema, M., 1961. Intra- and extra-cellular lipid production by yeasts. Meded. Landb-Hoogesch. wageningen 61 .

Develter, D.; Fleurackers, S., 2012. Sophorolactone production (US10287615B2). US10287615B2.

Develter, D., Fleurackers, S., 2012. Improved sophorolactone production (EP2718454A1).

Develter, D., Fleurackers, S., 2007. A method for the production of short chained glycolipids (EP1953237).

Develter, D., Jacobs, I., Renkin, M., 2003. Detergent compositions (EP1445302A1). EP1445302A1.

Develter, D.W.G., Lauryssen, L.M.L., 2010. Properties and industrial applications of sophorolipids. 
Dhar, P., Chernyshova, I. V., Thornhill, M., Roelants, S., Soetaert, W., Kota, H.R., 2019. Floatability of Chalcopyrite by Glycolipid Biosurfactants as Compared to Traditional Thiol Surfactants. Tenside Surfactants Deterg. 56, 429-435. https://doi.org/10.3139/113.110639

Dhasaiyan, P., Banerjee, A., Visaveliya, N., Prasad, B.L. V, 2013. Influence of the sophorolipid molecular geometry on their self-assembled structures. Chem. Asian J. 8, 369-372. https://doi.org/10.1002/asia.201200935

Dhasaiyan, P., Le Griel, P., Roelants, S., Redant, E., Van Bogaert, I.N.A., Prevost, S., Prasad, B.L. V., Baccile, N., 2017. Micelles versus Ribbons: How Congeners Drive the Self-Assembly of Acidic Sophorolipid Biosurfactants.

ChemPhysChem

18 ,

643-652. https://doi.org/10.1002/cphc.201601323

Dhasaiyan, P., Pandey, P.R., Visaveliya, N., Roy, S., Prasad, B.L. V, 2014. Vesicle structures from bolaamphiphilic biosurfactants: Experimental and molecular dynamics simulation studies on the effect of unsaturation on sophorolipid self-assemblies. Chem. - A Eur. J. 20, 6246-6250. https://doi.org/10.1002/chem.201304719

Dhasaiyan, P., Prévost, S., Baccile, N., Prasad, B.L. V, 2018. pH- and time-resolved in-situ SAXS study of self-assembled twisted ribbons formed by elaidic acid sophorolipids. Langmuir 34, 2121-2131. https://doi.org/10.1021/acs.langmuir.7b03164

Díaz De Rienzo, M.A., Stevenson, P., Marchant, R., Banat, I.M., 2016. Antibacterial properties of biosurfactants against selected Gram-positive and -negative bacteria. FEMS Microbiol. Lett. 363. https://doi.org/10.1093/femsle/fnv224

Dolman, B.M., Kaisermann, C., Martin, P.J., Winterburn, J.B., 2017. Integrated sophorolipid production and gravity separation. Process Biochem. 54, 162-171. https://doi.org/10.1016/J.PROCBIO.2016.12.021

Duran, A.L., 2015. Sophorolipid-containing compositions having reduced pour point temperature. WO2015164327A1.

Elshafie, A.E., Joshi, S.J., Al-Wahaibi, Y.M., Al-Bemani, A.S., Al-Bahry, S.N., Al-Maqbali, D., Banat, I.M., 2015. Sophorolipids Production by Candida bombicola ATCC 22214 and its Potential Application in Microbial Enhanced Oil Recovery. Front. Microbiol. 6, 1324. https://doi.org/10.3389/fmicb.2015.01324

Ernenwein, C., Reynaud, R., Guilleret, A., Podevin, L., Lafosse, A., Rannou, F., 2013. Biosolubilizer (WO2013182759A1). WO2013182759A1. 
Esders, T.W., Light, R.J., 1972. Characterization and in-vivo production of three glycolipids from Candida bogoriensis - 13-glucopyranosylglucopyranosyloxydocosanoic acid and its monoacetylated and diacetylated derivatives. J. Lipid Res. 13, 663--.

Evonik, 2019. Evonik and Unilever team up for large-scale production of world's first "green" biosurfactant. (https://household-care.evonik.com/product/householdcare/en/pages/article.aspx?articleId=121470, accessed on 23/12/2020) [WWW Document]. URL https://household-care.evonik.com/product/householdcare/en/pages/article.aspx ?articleId=121470 (accessed 12.23.20).

Felse, P.A., Shah, V., Chan, J., Rao, K.J., Gross, R.A., 2007. Sophorolipid biosynthesis by Candida bombicola from industrial fatty acid residues. Enzyme Microb. Technol. 40, 316-323. https://doi.org/10.1016/j.enzmictec.2006.04.013

Fleurackers, S.J.J., 2013. Commentary regarding "Practical methods to reduce impurities in gramscale amounts of acidic sophorolipid biosurfactants.” Eur. J. Lipid Sci. Technol. 115, 1402-1403. https://doi.org/10.1002/ejlt.201300235

Fu, S.L., Wallner, S.R., Bowne, W.B., Hagler, M.D., Zenilman, M.E., Gross, R., Bluth, M.H., 2008. Sophorolipids and their derivatives are lethal against human pancreatic cancer cells. J. Surg. Res. 148, 77-82. https://doi.org/10.1016/j.jss.2008.03.005

Gao, R., Falkeborg, M., Xu, X., Guo, Z., 2013. Production of sophorolipids with enhanced volumetric productivity by means of high cell density fermentation. Appl. Microbiol. Biotechnol. 97, 11031111. https://doi.org/10.1007/s00253-012-4399-z

Garay, L.A., Sitepu, I.R., Cajka, T., Cathcart, E., Fiehn, O., German, J.B., Block, D.E., Boundy-Mills, K.L., 2017. Simultaneous production of intracellular triacylglycerols and extracellular polyol esters of fatty acids by Rhodotorula babjevae and Rhodotorula aff. paludigena. J. Ind. Microbiol. Biotechnol. 44, 1397-1413. https://doi.org/10.1007/s10295-017-1964-6

Garcia-Ochoa, F., Casas, J.A., 1996. Process for the production of sophorose by Candida bombicola (ES2103688A1).

Geetha, S.J., Banat, I.M., Joshi, S.J., 2018. Biosurfactants: Production and potential applications in microbial enhanced oil recovery (MEOR). Biocatal. Agric. Biotechnol. 14, 23-32. https://doi.org/10.1016/j.bcab.2018.01.010

Geys, R., De Graeve, M., Lodens, S., Van Malderen, J., Lemmens, C., De Smet, M., Mincke, S., Van Bogaert, I., Stevens, C., De Maeseneire, S., Roelants, S., Soetaert, W., 2018. Increasing Uniformity of Biosurfactant Production in Starmerella bombicola via the Expression of Chimeric Cytochrome P450s. Colloids and Interfaces 2, 42. https://doi.org/10.3390/colloids2040042 
Giessler-Blank, S., Schilling, M., Thum, O., Sieverding, E., 2010. Use of sophorolipids and derivatives thereof in combination with pesticides as adjuvant/additive for plant protection and the industrial non-crop field. WO2011039014A1.

Gietz, R.D., Woods, R.A., 2002. Transformation of yeast by lithium acetate/single-stranded carrier DNA/polyethylene glycol method. Methods Enzymol. 350, 87-96. https://doi.org/10.1016/S0076-6879(02)50957-5

Göbbert, U., Lang, S., Wagner, F., 1984. Sophorose lipid formation by resting cells of Torulopsis bombicola. Biotechnol. Lett. 6, 225-230. https://doi.org/10.1007/BF00140041

Gonçalves, C., Wisecaver, J.H., Kominek, J., Salema Oom, M., Leandro, M.J., Shen, X.X., Opulente, D.A., Zhou, X., Peris, D., Kurtzman, C.P., Hittinger, C.T., Rokas, A., Gonçalves, P., 2018. Evidence for loss and reacquisition of alcoholic fermentation in a fructophilic yeast lineage. Elife 7. https://doi.org/10.7554/eLife.33034

Gonçalves, P., Gonçalves, C., Brito, P.H., Sampaio, J.P., 2020. The Wickerhamiella/Starmerella clade-A treasure trove for the study of the evolution of yeast metabolism. Yeast 37, 313-320. https://doi.org/10.1002/yea.3463

Gorin, P.A.J., Spencer, J.F.T., Tulloch, A.P., 1961. Hydroxy Fatty Acid Glycosides of Sophorose from Torulopsis magnoliae. Can. J. Chem. 39, 846-855. https://doi.org/10.1139/v61-104

Goswami, T., Tack, F.M.G., McGachy, L., Šír, M., 2020. Remediation of Aviation KeroseneContaminated Soil by Sophorolipids from Candida bombicola CB 2107. Appl. Sci. 10, 1981. https://doi.org/10.3390/app10061981

Gross, R., Shah, V., 2005. Antifungal properties of various forms of sophorolipids (WO2006069175A2).

Gross, R.A., Peng, Y., Thavasi, R., Koh, A., 2013. Modified sophorolipids as oil solubilizing agents (US9650405B2). US9650405B2.

Gross, R.A., Shah, V., 2007. Anti-herpes virus properties of various forms of sophorolipids (WO2007130738A1). WO2007130738A1.

Gross, R.A., Shah, V., 2003. Antimicrobial properties of various forms of sophorolipids (WO2004044216A1). WO2004044216A1.

Grossman, A.D., 1995. GENETIC NETWORKS CONTROLLING THE INITIATION OF SPORULATION AND THE DEVELOPMENT OF GENETIC COMPETENCE IN BACILLUS SUBTILIS, A/Ill u. Rev. Genetics.

Gunawan, S., Vorderbruggen, M.A., Armstrong, C.D., 2017. Method of using sophorolipids or 
mannosylerythritol lipids as acid corrosion inhibitors in well treatment operations. US9683164B2.

Haas, L.O.C., Cregg, J.M., Gleeson, M.A.G., 1990. Development of an integrative DNA transformation system for the yeast Candida tropicalis. J. Bacteriol. 172, 4571-4577. https://doi.org/10.1128/jb.172.8.4571-4577.1990

Haque, F., Alfatah, M., Ganesan, K., Bhattacharyya, M.S., 2016. Inhibitory Effect of Sophorolipid on Candida albicans Biofilm Formation and Hyphal Growth. Sci. Rep. 6, 1-11. https://doi.org/10.1038/srep23575

Haque, F., Sajid, M., Cameotra, S.S., Battacharyya, M.S., 2017. Anti-biofilm activity of a sophorolipid-amphotericin B niosomal formulation against Candida albicans. Biofouling 33, 768-779. https://doi.org/10.1080/08927014.2017.1363191

Hayes, D.G., Solaiman, D.K.., Ashby, R.D., 2019. Biobased Surfactants, in: Biobased Surfactants Synthesis, Properties, and Applications. Elsevier, p. 541.

Heike, S., Maria, T., Brigitte, L., 2016. Cleansing agents containing biosurfactants and having prebiotic activity (GB2544166A). GB2544166A.

Hillion, G., Marchal, R., Stoltz, C., Borzeix, F., 1995. Use of a sophorolipid to provide free radical formation inhibiting activity or elastase inhibiting activity (US5756471A). US5756471A.

Hillion, G., Marchal, R., Stoltz, C., Borzeix, F., 1994. Use of sophorolipids and cosmetic and dermatological compositions (FR2720941B1). FR2720941B1.

Hirata, Y., Ryu, M., Igarashi, K., Nagatsuka, A., Furuta, T., Kanaya, S., Sugiura, M., 2009. Natural synergism of acid and lactone type mixed sophorolipids in interfacial activities and cytotoxicities. J. Oleo Sci. 58, 565-572.

Holmberg, K., Jönsson, B., Kronberg, B., Lindman, B., 2002. Ch. 2 - Surfactant Micellization, in: Surfactants and Polymers in Aqueous Solutions. John Wiley \& Sons, Ltd., pp. 39-66.

Hommel, R., Ratledge, C., 1993. Biosynthetic mechanisms of low molecular weight surfactants and their precursor molecules, in: Kosaric, N. (Ed.), Biosurfactants: Production: Properties: Applications. Marcel Dekker, INC, pp. 3-63.

Hommel, R. K., Stegner, S., Kleber, H.-P., Weber, L., 1994. Effect of ammonium ions on glycolipid production by Candida (Torulopsis)apicola. Appl. Microbiol. Biotechnol. 42, 192-197. https://doi.org/10.1007/BF00902716

Hommel, R K, Weber, L., Weiss, A., Himmelreich, U., Rilke, O., Kleber, H.-P., 1994. Production of sophorose lipid by Candida (Torulopsis) apicola grown on glucose. J. Biotechnol. 33, 147-155. 
Hu, Y., 2000. Production, purification and enzymatic polymerization of sophorolipids. Dep. Chem. Eng. University of Akron, Akron.

Hu, Y., Ju, L., 2001. Purification of lactonic sophorolipids by crystallization. J. Biotechnol. 87, 263272.

Huang, F.-C., Peter, A., Schwab, W., 2014. Expression and Characterization of CYP52 Genes Involved in the Biosynthesis of Sophorolipid and Alkane Metabolism from Starmerella bombicola. Appl. Environ. Microbiol. 80, 766-776. https://doi.org/10.1128/AEM.02886-13

Huang, X., Shen, C., Liu, J., Lu, L., 2015. Improved volatile fatty acid production during waste activated sludge anaerobic fermentation by different bio-surfactants. Chem. Eng. J. 264, 280290. https://doi.org/10.1016/j.cej.2014.11.078

Imura, T., Masuda, Y., Minamikawa, H., Fukuoka, T., Konishi, M., Morita, T., Sakai, H., Abe, M., Kitamoto, D., 2010. Enzymatic Conversion of Diacetylated Sophoroselipid into Acetylated Glucoselipid: Surface-Active Properties of Novel Bolaform Biosurfactants. J. Oleo Sci. J. Oleo Sci 59, 495-501.

Imura, T., Morita, T., Fukuoka, T., Ryu, M., Igarashi, K., Hirata, Y., Kitamoto, D., 2014. Spontaneous Vesicle Formation from Sodium Salt of Acidic Sophorolipid and Its Application as a Skin Penetration Enhancer 147, 141-147.

Ishii, N., Kobayashi, T., Matsumiya, K., Ryu, M., Hirata, Y., Matsumura, Y., Suzuki, Y.A., 2012. Transdermal administration of lactoferrin with sophorolipid. Biochem. Cell Biol. 90, 504-512. https://doi.org/10.1139/o11-065

Isoda, H., Shinmoto, H., Kitamoto, D., Matsumura, M., Nakahara, T., 1997. Differentiation of human promyelocytic leukemia cell line HL60 by microbial extracellular glycolipids. Lipids 32, 263271. https://doi.org/10.1007/s11745-997-0033-0

Israelachvili, J.N., Mitchell, D.J., Ninham, B.W., 1976. Theory of self-assembly of hydrocarbon amphiphiles into micelles and bilayers. J. Chem. Soc. Faraday Trans. 2 72, 1525. https://doi.org/10.1039/f29767201525

Ito, S., Inoue, S., 1982. Sophorolipids from Torulopsis bombicola: possible relation to alkane uptake. Appl. Environ. Microbiol. 43, 1278-83.

Ito, S., Kinta, M., Inoue, S., 1980. Growth of yeasts on n-alkanes: Inhibition by a lactonic sophorolipid produced by Torulopsis bombicola. Agric. Biol. Chem. 44, 2221-2223. https://doi.org/10.1271/bbb1961.44.2221

Jessop, P.G., 2011. Searching for green solvents. Green Chem. 13, 1391-1398. 
1788

1789

1790

1791

1792

1793

1794

1795

1796

1797

1798

1799

1800

1801

1802

1803

1804

1805

1806

1807

1808

1809

1810

1811

1812

1813

1814

1815

1816

1817

1818

Jezierska, S., Claus, S., Ledesma-Amaro, R., Van Bogaert, I., 2019. Redirecting the lipid metabolism of the yeast Starmerella bombicola from glycolipid to fatty acid production. J Ind Microbiol Biotechnol 46, 1697-1706. https://doi.org/10.1007/s10295-019-02234-x

Jiménez-Peñalver, P., Castillejos, M., Koh, A., Gross, R., Sánchez, A., Font, X., Gea, T., 2018. Production and characterization of sophorolipids from stearic acid by solid-state fermentation, a cleaner alternative to chemical surfactants. J. Clean. Prod. 172, 2735-2747. https://doi.org/10.1016/j.jclepro.2017.11.138

Jiménez-Peñalver, P., Gea, T., Sánchez, A., Font, X., 2016. Production of sophorolipids from winterization oil cake by solid-state fermentation: Optimization, monitoring and effect of mixing. Biochem. Eng. J. https://doi.org/10.1016/j.bej.2016.08.006

Jiménez-Peñalver, P., Rodríguez, A., Daverey, A., Font, X., Gea, T., 2019. Use of wastes for sophorolipids production as a transition to circular economy: state of the art and perspectives. Rev. Environ. Sci. Biotechnol. https://doi.org/10.1007/s11157-019-09502-3

Joshi, S.J., Al-Wahaibi, Y., Al-Bahry, S., Al-Rawahi, K., Elshafie, A., Al-Bemani, A., Banat, I.M., 2019. Biosurfactant Production from Waste Frying Oil and its Utilization in Microbial Enhanced Oil Recovery. Arab Gulf J. Sci. Res. Vol. 37, p22-23. 2p.

Jules, M., Beltran, G., François, J., Parrou, J.L., 2008. New insights into trehalose metabolism by Saccharomyces cerevisiae: NTH2 encodes a functional cytosolic trehalase, and deletion of TPS1 reveals Ath1p-dependent trehalose mobilization. Appl. Environ. Microbiol. 74, 605-614. https://doi.org/10.1128/AEM.00557-07

Kang, S.-W., Kim, Y.-B., Shin, J.-D., Kim, E.-K., 2010. Enhanced Biodegradation of Hydrocarbons in Soil by Microbial Biosurfactant, Sophorolipid. Appl. Biochem. Biotechnol. 160, 780-790. https://doi.org/10.1007/s12010-009-8580-5

Karsten, S., Dreja, M., Noglich, J., 2010. Low-residue detergent for hard surfaces. WO2011051161A1.

Kaur, G., Wang, H., To, M.H., Roelants, S.L.K.W., Soetaert, W., Lin, C.S.K., 2019. Efficient sophorolipids production using food waste. J. Clean. Prod. 232, 1-11. https://doi.org/10.1016/J.JCLEPRO.2019.05.326

Khatoon, Z., McTiernan, C.D., Suuronen, E.J., Mah, T.F., Alarcon, E.I., 2018. Bacterial biofilm formation on implantable devices and approaches to its treatment and prevention. Heliyon 4 , e01067. https://doi.org/10.1016/j.heliyon.2018.e01067 
Khoo, H.H., Ee, W.L., Isoni, V., 2016. Bio-chemicals from lignocellulose feedstock: Sustainability, LCA and the green conundrum. Green Chem. 18, 1912-1922. https://doi.org/10.1039/c5gc02065d

Kim, H.S., Kim, Y.B., Lee, B.S., Kim, E.K., 2005. Sophorolipid production by Candida bombicola ATCC 22214 from a corn-oil processing byproduct. J. Microbiol. Biotechnol. 15, 55-58.

Kim, K., Yoo, D., Kim, Y., Lee, B., Shin, D., Kim, E.K., 2002. Characteristics of sophorolipid as an antimicrobial agent. J. Microbiol. Biotechnol. 12, 235-241.

Kitamoto, D., Isoda, H., Nakahara, T., 2002. Functions and potential applications of glycolipid biosurfactants - from energy-saving materials to gene delivery carriers —. J. Biosci. Bioeng. 94, 187-201. https://doi.org/10.1016/s1389-1723(02)80149-9

Klekner, V., Kosaric, N., Zhou, Q.H., 1991. Sophorose lipids produced from sucrose. Biotechnol. Lett. 13, 345-348. https://doi.org/10.1007/bf01027680

Koh, A., Gross, R., 2016a. A versatile family of sophorolipid esters: Engineering surfactant structure for stabilization of lemon oil-water interfaces. Colloids Surfaces A Physicochem. Eng. Asp. 507, 152-163. https://doi.org/10.1016/j.colsurfa.2016.07.089

Koh, A., Gross, R., 2016b. Molecular editing of sophorolipids by esterification of lipid moieties: Effects on interfacial properties at paraffin and synthetic crude oil-water interfaces. Colloids $\begin{array}{lllll}\text { Surfaces A } & \text { Physicochem. } & \text { Eng. } & \text { Asp. }\end{array}$ https://doi.org/10.1016/j.colsurfa.2016.07.084

Koh, A., Linhardt, R.J., Gross, R., 2016. Effect of Sophorolipid n -Alkyl Ester Chain Length on Its Interfacial Properties at the Almond Oil-Water Interface. Langmuir 32, 5562-5572. https://doi.org/10.1021/acs.langmuir.6b01008

Koh, A., Todd, K., Sherbourne, E., Gross, R.A., 2017a. Fundamental Characterization of the Micellar Self-Assembly of Sophorolipid Esters. Langmuir 33, 5760-5768. https://doi.org/10.1021/acs.langmuir.7b00480

Koh, A., Wong, A., Quinteros, A., Desplat, C., Gross, R., 2017b. Influence of Sophorolipid Structure on Interfacial Properties of Aqueous-Arabian Light Crude and Related Constituent Emulsions. J. Am. Oil Chem. Soc. 94, 107-119. https://doi.org/10.1007/s11746-016-2913-7

Koh, C.M.J., Liu, Y., Moehninsi, Du, M., Ji, L., 2014. Molecular characterization of KU70 and KU80 homologues and exploitation of a KU70-deficient mutant for improving gene deletion frequency in Rhodosporidium toruloides. BMC Microbiol. 14, 1-10. https://doi.org/10.1186/1471-2180-1450 
Konishi, M., Fujita, M., Ishibane, Y., Shimizu, Y., Tsukiyama, Y., Ishida, M., 2016. Isolation of yeast candidates for efficient sophorolipids production: Their production potentials associate to their lineage. Biosci. Biotechnol. Biochem. 80, 2058-2064. https://doi.org/10.1080/09168451.2016.1191332

Konishi, M., Fukuoka, T., Morita, T., Imura, T., Kitamoto, D., 2008. Production of new types of sophorolipids by Candida batistae. J. Oleo Sci. 57, 359-369.

Konishi, M., Morita, T., Fukuoka, T., Imura, T., Uemura, S., Iwabuchi, H., Kitamoto, D., 2018. Efficient Production of Acid-Form Sophorolipids from Waste Glycerol and Fatty Acid Methyl Esters by \&lt;i\&gt;Candida floricola\&lt;/i\&gt; J. Oleo Sci. 67, 489-496. https://doi.org/10.5650/jos.ess17219

Konishi, M., Morita, T., Fukuoka, T., Imura, T., Uemura, S., Iwabuchi, H., Kitamoto, D., 2017. Selective Production of Acid-form Sophorolipids from Glycerol by Candida floricola. J. Oleo Sci 66, 1365-1373. https://doi.org/10.5650/jos.ess17116

Konishi, M., Yoshida, Y., Horiuchi, J., 2015. Efficient production of sophorolipids by Starmerella bombicola using a corncob hydrolysate medium. J. Biosci. Bioeng. 119, 317-322. https://doi.org/10.1016/j.jbiosc.2014.08.007

Koral, B., Weers, L., Campbell, J.J., 2014. Methods and compositions for decreasing the viscosity of hydrocarbon-based fluids during refining. US9550937B2.

Kralova, I., Sjoblom, J., 2009. Surfactants used in food industry: a review. J. Dispers. Sci. Technol. $30,1363-1383$.

Kurtzman, C P, 2012. Candida kuoi sp. nov., an anamorphic species of the Starmerella yeast clade that synthesizes sophorolipids. Int. J. Syst. Evol. Microbiol. 62, 2307-2311. https://doi.org/10.1099/ijs.0.039479-0

Kurtzman, C.P., Price, N.P.J., Ray, K.J., Kuo, T.-M., 2011. Fermentative production of sophorolipids from soybean and other vegetable oils. (US9382566B1). US9382566B1.

Kurtzman, Cletus P., Price, N.P.J., Ray, K.J., Kuo, T.M., 2010. Production of sophorolipid biosurfactants by multiple species of the Starmerella (Candida) bombicola yeast clade. FEMS Microbiol. Lett. 311, 140-146. https://doi.org/10.1111/j.1574-6968.2010.02082.x

Lang, S., Brakemeier, A., Heckmann, R., Spockner, S., Rau, U., 2000. Production of native and modified sophorose lipids. Chim. OGGI-CHEMISTRY TODAY 18, 76-79.

Lang, S., Wagner, F., 1993. Biological activities of biosurfactants, in: Kosaric, N. (Ed.), Biosurfactants: Production-Properties-Applications, Surfactants Science Series. Marcel Dekker, 
pp. 251-268.

1884

1885

1886

1887

1888

1889

1890

1891

1892

1893

1894

1895

1896

1897

1898

1899

1900

1901

1902

1903

1904

1905

1906

1907

1908

1909

1910

1911

1912

1913

1914

1915

Laquerbe, S., Carvalho, A., Schmutz, M., Poirier, A., Baccile, N., Ben Messaoud, G., 2021. pHSwitchable Pickering Emulsions Stabilized by Biosurfactant-Polyelectrolyte Complex Coacervate Colloids. J. Colloid Interface Sci. DOI: 10.1016/j.jcis.2021.04.135. https://doi.org/10.1016/j.jcis.2021.04.135

Li, H., Guo, W., Ma, X. jing, Li, J. shan, Song, X., 2017. In Vitro and in Vivo Anticancer Activity of Sophorolipids to Human Cervical Cancer. Appl. Biochem. Biotechnol. 181, 1372-1387. https://doi.org/10.1007/s12010-016-2290-6

Li, H., Ma, X., Shao, L., Shen, J., Song, X., 2012. Enhancement of Sophorolipid Production of Wickerhamiella domercqiae var. sophorolipid CGMCC 1576 by Low-Energy Ion Beam Implantation. Appl. Biochem. Biotechnol. 167, 510-523. https://doi.org/10.1007/s12010-0129664-1

Li, H., Ma, X., Wang, S., Song, X., 2013. Production of sophorolipids with eicosapentaenoic acid and docosahexaenoic acid from Wickerhamiella domercqiae var. sophorolipid using fish oil as a hydrophobic carbon source. Biotechnol. Lett. 35, 901-908. https://doi.org/10.1007/s10529-013$1151-4$

Li, J., Li, H., Li, W., Xia, C., Song, X., 2016. Identification and characterization of a flavin-containing monooxygenase MoA and its function in a specific sophorolipid molecule metabolism in Starmerella bombicola. Appl. Microbiol. Biotechnol. 100, 1307-1318. https://doi.org/10.1007/s00253-015-7091-2

Lin, Y., Chen, Y., Li, Q., Tian, X., Chu, J., 2019. Rational high-throughput screening system for high sophorolipids production in Candida bombicola by co-utilizing glycerol and glucose capacity. Bioresour. Bioprocess. 6, 1-9. https://doi.org/10.1186/s40643-019-0252-x

Lindow, S.E., Brandl, M.T., 2003. Microbiology of the phyllosphere. Appl. Environ. Microbiol. https://doi.org/10.1128/AEM.69.4.1875-1883.2003

Linton, J.D., 1991. Metabolite production and growth efficiency. Antonie Van Leeuwenhoek 60, $293-$ 311. https://doi.org/10.1007/BF00430371

Liu, X. ge, Ma, X. jing, Yao, R. sheng, Pan, C. yu, He, H. bing, 2016. Sophorolipids production from rice straw via SO3 micro-thermal explosion by Wickerhamiella domercqiae var. sophorolipid CGMCC 1576. AMB Express 6, 60. https://doi.org/10.1186/s13568-016-0227-7

Liu, Z., Tian, X., Chen, Y., Lin, Y., Mohsin, A., Chu, J., 2019. Efficient sophorolipids production via a novel in situ separation technology by Starmerella bombicola. Process Biochem. 81, 1-10. https://doi.org/10.1016/j.procbio.2018.12.005 
Lo, C.-M., Ju, L.-K., 2009. Sophorolipids-induced cellulase production in cocultures of Hypocrea jecorina Rut C30 and Candida bombicola. Enzyme Microb. Technol. 44, 107-111. https://doi.org/10.1016/j.enzmictec.2008.10.006

Lodens, S., De Graeve, M., Roelants, S.L.K.W., De Maeseneire, S.L., Soetaert, W., 2017. Transformation of an exotic yeast species into a platform organism: a case study for engineering glycolipid production in the yeast Starmerella bombicola., in: Braman, J. (Ed.), Synthetic Biology. Springer Publishing Co. series "Methods in Molecular Biology.” https://doi.org/in press

Lodens, S., Roelants, S.L.K.W., Ciesielska, K., Geys, R., Derynck, E., Maes, K., Pattyn, F., Van Renterghem, L., Mottet, L., Dierickx, S., Vanhaecke, L., Devreese, B., De Maeseneire, S.L., Soetaert, W., 2019. Unraveling and resolving inefficient glucolipid biosurfactants production through quantitative multiomics analyses of Starmerella bombicola strains. Biotechnol. Bioeng. bit.27191. https://doi.org/10.1002/bit.27191

Lodens, S., Roelants, S.L.K.W., Luyten, G., Geys, R., Coussement, P., De Maeseneire, S.L., Soetaert, W., 2020. Unraveling the regulation of sophorolipid biosynthesis in Starmerella bombicola. FEMS Yeast Res. https://doi.org/10.1093/femsyr/foaa021

Luna, J.M., Rufino, R.D., Sarubbo, L.A., 2016. Biosurfactant from Candida sphaerica UCP0995 exhibiting heavy metal remediation properties. Process Saf. Environ. Prot. 102, 558-566. https://doi.org/10.1016/j.psep.2016.05.010

Lydon, H.L., Baccile, N., Callaghan, B., Marchant, R., Mitchell, C.A., Banat, I.M., 2017. Adjuvant antibiotic activity of acidic sophorolipids with potential for facilitating wound healing. Antimicrob. Agents Chemother. 61. https://doi.org/10.1128/AAC.02547-16

Ma, X., Li, H., Shao, L., Shen, J., Song, X., 2011. Effects of nitrogen sources on production and composition of sophorolipids by Wickerhamiella domercqiae var. sophorolipid CGMCC 1576. Appl. Microbiol. Biotechnol. 91, 1623-1632. https://doi.org/10.1007/s00253-011-3327-y

Ma, X., Li, H., Song, X., 2012. Surface and biological activity of sophorolipid molecules produced by Wickerhamiella domercqiae var. sophorolipid CGMCC 1576. J. Colloid Interface Sci. 376, 165172. https://doi.org/10.1016/j.jcis.2012.03.007

Ma, X., Meng, L., Zhang, H., Zhou, L., Yue, J., Zhu, H., Yao, R., 2020. Sophorolipid biosynthesis and production from diverse hydrophilic and hydrophobic carbon substrates. Appl. Microbiol. Biotechnol. https://doi.org/10.1007/s00253-019-10247-w

Macmillan, S., 2020. Unilever to eliminate fossil fuels in cleaning products by 2030 (https://www.unilever.com/news/press-releases/2020/unilever-to-invest-1-billion-to-eliminatefossil-fuels-in-cleaning-products-by-2030.html, accessed on 23/12/2020) [WWW Document]. 
URL https://www.unilever.com/news/press-releases/2020/unilever-to-invest-1-billion-toeliminate-fossil-fuels-in-cleaning-products-by-2030.html (accessed 12.23.20).

Madsen, J.K., Kaspersen, J.D., Andersen, C.B., Nedergaard Pedersen, J., Andersen, K.K., Pedersen, J.S., Otzen, D.E., 2017. Glycolipid Biosurfactants Activate, Dimerize, and Stabilize Thermomyces lanuginosus Lipase in a pH-Dependent Fashion. Biochemistry 56, 4256-4268. https://doi.org/10.1021/acs.biochem.7b00420

Maingault, M., 1996. Utilization of sophorolipids as therapeutically active substances or cosmetic products, in particular for the treatment of the skin (WO1997001343A3). WO1997001343A3.

Manet, S., Cuvier, A.S., Valotteau, C., Fadda, G.C., Perez, J., Karakas, E., Abel, S., Baccile, N., 2015. Structure of Bolaamphiphile Sophorolipid Micelles Characterized with SAXS, SANS, and MD Simulations. J. Phys. Chem. B 119, 13113-13133. https://doi.org/10.1021/acs.jpcb.5b05374

Mao, X., Jiang, R., Xiao, W., Yu, J., 2015. Use of surfactants for the remediation of contaminated soils: A review. J. Hazard. Mater. 285, 419-435. https://doi.org/10.1016/j.jhazmat.2014.12.009

Markets, M. and, 2016. Surfactant market by type (anionic, non-ionic, cationic, and amphoteric), substrate (synthetic, and bio- based) and application (detergents, personal care, textile, elastomers \& plastics, crop protection) - Global Forecast to 2021 food \& beverage), in: Markets and Markets. p. 170.

Masson-Delmotte, V., Zhai, P., Pörtner, H.O., Roberts, D., Skea, J., Shukla, P.R., Pirani, A., Moufouma-Okia, W., Péan, C., Pidcock, R., Connors, S., Matthews, J.B.R., Chen, Y., Zhou, X., Gomis, M.I., Lonnoy, E., Maycock, T., Tignor, M., Waterfield, T., 2019. IPCC, 2018: Global Warming of $1.5^{\circ} \mathrm{C}$. An IPCC Special Report on the impacts of global warming of $1.5^{\circ} \mathrm{C}$ above pre-industrial levels and related global greenhouse gas emission pathways, in the context of strengthening the global response to the threat of $\mathrm{cl}$.

Matsumiya, K., Suzuki, Y.A., Hirata, Y., Nambu, Y., Matsumura, Y., 2017. Protein-surfactant interactions between bovine lactoferrin and sophorolipids under neutral and acidic conditions. Biochem. Cell Biol. 95, 126-132. https://doi.org/10.1139/bcb-2016-0057

Mekala, S., Peters, K.C., Singer, K.D., Gross, R.A., 2018. Biosurfactant-functionalized porphyrin chromophore that forms: J-aggregates. Org. Biomol. Chem. 16, 7178-7190. https://doi.org/10.1039/c8ob01655k

Meyers, R.S., Thackray, J., Matson, K.L., McPherson, C., Lubsch, L., Hellinga, R.C., Hoff, D.S., 2020. Key Potentially Inappropriate Drugs in Pediatrics: The KIDs List. J. Pediatr. Pharmacol. Ther. 25, 175-191. https://doi.org/10.5863/1551-6776-25.3.175 
produced by Pseudozyma

flocculosa.

Glycobiology

19, 995-1001. https://doi.org/10.1093/glycob/cwp078

Minucelli, T., Ribeiro-Viana, R.M., Borsato, D., Andrade, G., Cely, M.V.T., de Oliveira, M.R., Baldo, C., Celligoi, M.A.P.C., 2017. Sophorolipids Production by Candida bombicola ATCC 22214 and Its Potential Application in Soil Bioremediation. Waste and Biomass Valorization 8, 743-753. https://doi.org/10.1007/s12649-016-9592-3

Mnif, I., Ellouz-Chaabouni, S., Ghribi, D., 2018. Glycolipid Biosurfactants, Main Classes, Functional Properties and Related Potential Applications in Environmental Biotechnology. J. Polym. Environ. 26, 2192-2206. https://doi.org/10.1007/s10924-017-1076-4

Mnif, I., Ghribi, D., 2016. Glycolipid biosurfactants: main properties and potential applications in agriculture and food industry. J. Sci. Food Agric. 96, 4310-4320. https://doi.org/10.1002/jsfa.7759

Mousavi, F., Beheshti-Maal, K., Massah, A., 2015. Production of Sophorolipid from an Identified Current Yeast, Lachancea thermotolerans BBMCZ7FA20, Isolated from Honey Bee. Curr. Microbiol. 71, 303-310. https://doi.org/10.1007/s00284-015-0841-7

Mulligan, C.N., 2017. Biosurfactants for the remediation of metal contamination, in: Das, S., Dash, H.R. (Eds.), Handbook of Metal-Microbe Interactions and Bioremediation. CRC Press: Boca Raton, FL, USA, pp. 299-316.

Mulligan, C.N., Yong, R.N., Gibbs, B.F., 2001. Heavy metal removal from sediments by biosurfactants. J. Hazard. Mater. 85, 111-125. https://doi.org/http://dx.doi.org/10.1016/S03043894(01)00224-2

Naik, N.J., Abhyankar, I., Darne, P., Prabhune, A., Madhusudhan, B., 2019. Sustained Transdermal Release of Lignans Facilitated by Sophorolipid based Transferosomal Hydrogel for Cosmetic Application. Int. J. Curr. Microbiol. Appl. Sci. 8, 1783-1791. https://doi.org/10.20546/ijcmas.2019.802.210

Nawale, L., Dubey, P., Chaudhari, B., Sarkar, D., Prabhune, A., 2017. Anti-proliferative effect of novel primary cetyl alcohol derived sophorolipids against human cervical cancer cells HeLa. PLoS One 12, e0174241. https://doi.org/10.1371/journal.pone.0174241

Nooman, M.U., Mahmoud, M.H., Al-kashef, A.S., Rashad, M.M., Rashad, M.M., 2017. Hypocholesterolemic impact of newly isolated sophorolipids produced by microbial conversion of safflower oil cake in rats fed high-fat and cholesterol diet. Grasas y Aceites 68, 212. https://doi.org/10.3989/gya.0219171

Nuñez, A., Ashby, R., Foglia, T.A., Solaiman, D.K.Y., 2004. LC/MS analysis and lipase modification 
of the sophorolipids produced by Rhodotorula bogoriensis. Biotechnol. Lett. 26, 1087-93. https://doi.org/10.1023/B:BILE.0000032970.95603.6d

Olanya, O.M., Ukuku, D.O., Solaiman, D.K.Y., Ashby, R.D., Niemira, B.A., Mukhopadhyay, S., 2018. Reductionin Listeria monocytogenes, Salmonella enterica and Escherichia coli O157:H7 in vitro and on tomato by sophorolipid and sanitiser as affected by temperature and storage time. Int. J. Food Sci. Technol. 53, 1303-1315. https://doi.org/10.1111/ijfs.13711

Ozdener, M.H., Ashby, R.D., Jyotaki, M., Elkaddi, N., Spielman, A.I., Bachmanov, A.A., Solaiman, D.K.Y., 2019. Sophorolipid Biosurfactants Activate Taste Receptor Type 1 Member 3- Mediated Taste Responses and Block Responses to Bitter Taste In Vitro and In Vivo. J. Surfactants Deterg. 22, 441-449. https://doi.org/10.1002/jsde.12246

Palme, O., Comanescu, G., Stoineva, I., Radel, S., Benes, E., Develter, D., Wray, V., Lang, S., 2010. Sophorolipids from Candida bombicola: Cell separation by ultrasonic particle manipulation. Eur. J. Lipid Sci. Technol. 112, 663-673. https://doi.org/10.1002/ejlt.200900163

Parekh, V.J., Patravale, V.B., Pandit, A.B., n.d. Mango kernel fat: A novel lipid source for the fermentative production of sophorolipid biosurfactant using Starmerella Bombicola NRRL-Y 17069. Sch. Res. Libr. Ann. Biol. Res. 2012, 1798-1803.

Patel, S., Homaei, A., Patil, S., Daverey, A., 2019. Microbial biosurfactants for oil spill remediation: pitfalls and potentials. Appl. Microbiol. Biotechnol. https://doi.org/10.1007/s00253-018-9434-2

Pekin, G., Vardar-Sukan, F., Kosaric, N., 2005. Production of Sophorolipids from Candida bombicola ATCC 22214 Using Turkish Corn Oil and Honey. Eng. Life Sci. 5, 357-362.

Pellicier, F., Andre, P., 2004. Cosmetic use of sophorolipids as subcutaneous adipose cushion regulating agents and slimming application. WO2004108063.

Penfold, J., Chen, M., Thomas, R.K., Dong, C., Smyth, T.J.P., Perfumo, A., Marchant, R., Banat, I.M., Stevenson, P., Parry, A., Tucker, I., Grillo, I., 2011. Solution self-assembly of the sophorolipid biosurfactant and its mixture with anionic surfactant sodium dodecyl benzene sulfonate. Langmuir 27, 8867-8877. https://doi.org/10.1021/la201661y

Peters, K.C., Mekala, S., Gross, R.A., Singer, K.D., 2020. Chiral inversion and enhanced cooperative self-assembly of biosurfactant-functionalized porphyrin chromophores. J. Mater. Chem. C 8, 4675-4679. https://doi.org/10.1039/c9tc06829e

Peters, K.C., Mekala, S., Gross, R.A., Singer, K.D., 2019. Cooperative Self-Assembly of Helical Exciton-Coupled Biosurfactant-Functionalized Porphyrin Chromophores. ACS Appl. Bio Mater. 2, 1703-1713. https://doi.org/10.1021/acsabm.9b00086 
Pimentel, M., ANTONINI, Y., MARTINS, R., LACHANCE, M., ROSA, C., Y., A., R.P., M., 2005. Candida riodocensis and Candida cellae, two new yeast species from the clade associated with solitary bees in the Atlantic rain forest of Brazil. FEMS Yeast Res. 5, 875-879. https://doi.org/10.1016/j.femsyr.2005.03.006

Poomtien, J., Thaniyavarn, J., Pinphanichakarn, P., Jindamorakot, S., Morikawa, M., 2013. Production and Characterization of a Biosurfactant from Cyberlindnera samutprakarnensis JP52 T. Biosci. Biotechnol. Biochem. 77, 2362-2370. https://doi.org/10.1271/bbb.130434

Price, Neil P J, Ray, K.J., Vermillion, K.E., Dunlap, C.A., Kurtzman, C.P., 2012. Structural characterization of novel sophorolipid biosurfactants from a newly identified species of Candida yeast. Carbohydr. Res. 348, 33-41. https://doi.org/10.1016/j.carres.2011.07.016

Punrata, T., Thaniyavarn, J., Chanprateep Napathorn, S., Anuntagool, J., Thaniyavarn, S., 2020. Production of a sophorolipid biosurfactant by Wickerhamomyces anomalus MUE24 and its use for modification of rice flour properties. ScienceAsia 46, 11. https://doi.org/10.2306/scienceasia1513-1874.2020.003

Qi, X., Xu, X., Zhong, C., Jiang, T., Wei, W., Song, X., 2018. Removal of Cadmium and Lead from Contaminated Soils Using Sophorolipids from Fermentation Culture of Starmerella bombicola CGMCC 1576 Fermentation. Int. J. Environ. Res. Public Health 15, 2334. https://doi.org/10.3390/ijerph15112334

Qi, X.Y., Song, X., Sun, Y.M., 2014. Enhanced Soil Washing of PCB by Sophorolipids from Transformer Oil Contaminated Soil. Appl. Mech. Mater. 694, 450-454. https://doi.org/10.4028/www.scientific.net/AMM.694.450

Ranji, H., Babajanzadeh, B., Sherizadeh, S., 2019. Detergents and surfactants: a brief review. Open Access J. Sci. 3, 94-99. https://doi.org/10.15406/oajs.2019.03.00138

Rashad, M.M., Al-kashef, A.S., Nooman, M.U., Mahmoud, A.E.E.D., 2014. Co-utilization of motor oil waste and sunflower oil cake on the production of new sophorolipids by Candida bombicola NRRL Y-17069. Res. J. Pharm. Biol. Chem. Sci. 5, 1515-1528.

Ribeiro, I.A., Bronze, M.R., Castro, M.F., Ribeiro, M.H.L., 2012a. Design of selective production of sophorolipids by Rhodotorula bogoriensis through nutritional requirements. J. Mol. Recognit. 25, 630-640. https://doi.org/10.1002/jmr.2188

Ribeiro, I.A., Bronze, M.R., Castro, M.F., Ribeiro, M.H.L., 2012b. Sophorolipids: improvement of the selective production by Starmerella bombicola through the design of nutritional requirements. Appl. Microbiol. Biotechnol. 97, 1875-1887. https://doi.org/10.1007/s00253-012-4437-x

Rispoli, F.J., Badia, D., Shah, V., 2010. Optimization of the fermentation media for sophorolipid 
production from Candida bombicola ATCC 22214 using a simplex centroid design. Biotechnol.

Roberto De Oliveira, M., Camilios-Neto, D., Baldo, C., Magri, A., Pedrine, M.A., Celligoi, C., 2014. Biosynthesis And Production Of Sophorolipids. Int. J. Sci. Technol. Res. 3.

Roelants, S., Solaiman, D.K.Y., Ashby, R.D., Lodens, S., Van Renterghem, L., Soetaert, W., 2019. Production and application of sophorolipids, in: Douglas, H.G., K, S.D., Ashby, R.D. (Eds.), Biobased Surfactants: Synthesis, Properties and Applications. Elsevier Academic Press ; AOCS Press, pp. 65-119.

Roelants, S.L.K.W., Ciesielska, K., De Maeseneire, S.L., Moens, H., Everaert, B., Verweire, S.,

Roelants, S.L.K.W., Saerens, K.M.J., Derycke, T., Li, B., Lin, Y.-C., de Peer, Y., De Maeseneire, Denon, Q., Vanlerberghe, B., Van Bogaert, I.N.A., Van der Meeren, P., Devreese, B., Soetaert, W., 2016. Towards the industrialization of new biosurfactants: Biotechnological opportunities for the lactone esterase gene from Starmerella bombicola. Biotechnol. Bioeng. 113, 550-559. https://doi.org/10.1002/bit.25815

S.L., Van Bogaert, I.N.A., Soetaert, W., 2013. Candida bombicola as a platform organism for the production of tailor-made biomolecules. Biotechnol. Bioeng. 110, 2494-2503. https://doi.org/10.1002/bit.24895

Roelants, S.L.K.W., Soetaert, W., 2021. Industrial perspectives for microbial biosurfactants in "Biosurfactants for the Biobased Economy", in: Hausmann, R., Henkel, M. (Eds.), Series Advances in Biochemical Engineering/Biotechnology. Springer.

Roelants, S.L.K.W., Van Renterghem, L., Maes, K., Everaert, B., Redant, E., Vanlerberghe, B., De Maeseneire, S.L., Soetaert, W.K., 2018. Microbial biosurfactants: from lab to market, in: Banat, I.M., Thavasi, R. (Eds.), Microbial Biosurfactants and Their Environmental and Industrial Applications. CRC Press, Boca Raton. https://doi.org/10.1201/b21950-13

Ron, E.Z., Rosenberg, E., 2001. Natural roles of biosurfactants. Environ. Microbiol. 3, 229-236. https://doi.org/10.1046/j.1462-2920.2001.00190.x

Rosa, C.A., Lachance, M.A., Silva, J.O.C., Teixeira, A.C.P., Marini, M.M., Antonini, Y., Martins, R.P., 2003. Yeast communities associated with stingless bees. FEMS Yeast Res. 4, 271-275. https://doi.org/10.1016/S1567-1356(03)00173-9

Rosa, C.A.C.A., Viana, E.M.E.M., Martins, R.P.R.P., Antonini, Y., Lachance, M.-A.M.-A., 1999. Candida batistae, a New Yeast Species Associated with Solitary Digger Nesting Bees in Brazil. Mycologia 91, 428. https://doi.org/10.2307/3761343

Ruinen, J., 1963. The phyllosphere II. Yeasts from the phyllosphere of tropical foliage. Antonie Van 
Saborimanesh, N., Mulligan, C.N., 2018. Dispersion of Weathered Biodiesel, Diesel, and Light Crude Oil in the Presence of Sophorolipid Biosurfactant in Seawater. J. Environ. Eng. (United States) 144, 1-9. https://doi.org/10.1061/(ASCE)EE.1943-7870.0001369

Sachdev, D.P., Cameotra, S.S., 2013. Biosurfactants in agriculture. Appl. Microbiol. Biotechnol. https://doi.org/10.1007/s00253-012-4641-8

Saerens, K., Soetaert, W., Van Bogaert, I.N.A., 2010. Producing unacetylated sophorolipids by fermentation. (WO 2012080116 A1).

Saerens, K.M., Saey, L., Soetaert, W., 2011a. One-step production of unacetylated sophorolipids by an acetyltransferase negative Candida bombicola. Biotechnol. Bioeng. 108, 2923-2931.

Saerens, K.M., Zhang, J., Saey, L., Van Bogaert, I.N., Soetaert, W., 2011b. Cloning and functional characterization of the UDP-glucosyltransferase UgtB1 involved in sophorolipid production by Candida bombicola and creation of a glucolipid-producing yeast strain. Yeast 28, 279-292.

Saerens, K.M., Roelants, S.L.K.W., Van Bogaert, I.N.A., Soetaert, W., 2011c. Identification of the UDP-glucosyltransferase gene UGTA1, responsible for the first glucosylation step in the sophorolipid biosynthetic pathway of Candida bombicola ATCC 22214. FEMS Yeast Res. 11, 123-132. https://doi.org/10.1111/j.1567-1364.2010.00695.x

Sałek, K., Euston, S.R., 2019. Sustainable microbial biosurfactants and bioemulsifiers for commercial exploitation. Process Biochem. 85, 143-155. https://doi.org/10.1016/j.procbio.2019.06.027

Sanada, H., Nakagami, G., Takehara, K., Goto, T., Ishii, N., Yoshida, S., Ryu, M., Tsunemi, Y., 2014. Antifungal Effect of Non-Woven Textiles Containing Polyhexamethylene Biguanide with Sophorolipid: A Potential Method for Tinea Pedis Prevention. Healthcare 2, 183-191. https://doi.org/10.3390/healthcare2020183

Santos, A.R.O., Leon, M.P., Barros, K.O., Freitas, L.F.D., Hughes, A.F.S., Morais, P.B., Lachance, M.A., Rosa, C.A., 2018. Starmerella camargoi f.A., sp. nov., starmerella ilheusensis f.a., sp. nov., Starmerella litoralis f.a., sp. nov., starmerella opuntiae f.a., sp. nov., Starmerella roubikii f.a., sp. nov. and Starmerella vitae f.a., sp. nov., isolated from flowers and bees, and transfer of related candida species to the genus Starmerella as new combinations. Int. J. Syst. Evol. Microbiol. 68, 1333-1343. https://doi.org/10.1099/ijsem.0.002675

Santos, D.K.F., Rufino, R.D., Luna, J.M., Santos, V.A., Sarubbo, L.A., 2016. Biosurfactants: Multifunctional biomolecules of the 21 st century. Int. J. Mol. Sci. https://doi.org/10.3390/ijms17030401 
Sarubbo, L.A., Rocha, R.B., Luna, J.M., Rufino, R.D., Santos, V.A., Banat, I.M., 2015. Some aspects of heavy metals contamination remediation and role of biosurfactants. Chem. Ecol. 7540, 1-17. https://doi.org/10.1080/02757540.2015.1095293

Schippers, C., Geßner, K., Müller, T., Scheper, T., 2000. Microbial degradation of phenanthrene by addition of a sophorolipid mixture. J. Biotechnol. 83, 189-198. https://doi.org/10.1016/S01681656(00)00304-7

Schofield, M.H., Thavasi, R.T., Gross, R.A., 2011. Modified sophorolipids for the inhibition of plant pathogens. WO 2013052615.

Schönherr, J., Baur, P., Uhlig, B.A., Obstbau, G.-, Obstbau, A., Hannover, U., Steinberg, A., Sarstedt, D., 2000. Rates of cuticular penetration of 1-naphthylacetic acid ( NAA ) as affected by adjuvants , temperature, humidity and water quality $61-74$.

Schwartz, C.M., Hussain, M.S., Blenner, M., Wheeldon, I., 2016. Synthetic RNA Polymerase III Promoters Facilitate High-Efficiency CRISPR-Cas9-Mediated Genome Editing in Yarrowia lipolytica. ACS Synth. Biol. 5, 356-359. https://doi.org/10.1021/acssynbio.5b00162

Sean, F., Ken, A., Tyler, D., 2020. Method And Apparatus For Continuous Production Of Sophorolipids.(WO 2020006194 A1)

Sen, S., Borah, S.N., Bora, A., Deka, S., 2017. Production, characterization, and antifungal activity of a biosurfactant produced by Rhodotorula babjevae YS3. Microb. Cell Fact. 16, 95. https://doi.org/10.1186/s12934-017-0711-z

Seyrig, C., Kignelman, G., Thielemans, W., Griel, P. Le, Cowieson, N., Perez, J., Baccile, N., 2020. Stimuli-induced non-equilibrium phase transitions in polyelectrolyte-surfactant complex coacervates. Langmuir 36, 8839-8857. https://doi.org/10.1021/acs.langmuir.0c01177

Shah, V., Doncel, G.F., Seyoum, T., Eaton, K.M., Zalenskaya, I., Hagver, R., Azim, A., Gross, R., 2005. Sophorolipids, microbial glycolipids with anti-human immunodeficiency virus and spermimmobilizing activities. Antimicrob. Agents Chemother. 49, 4093-4100.

Shah, M.U.H., Sivapragasam, M., Moniruzzaman, M., Talukder, M.M.R., Yusup, S.B., Goto, M., 2017. Production of sophorolipids by Starmerella bombicola yeast using new hydrophobic substrates. Biochem. Eng. J. 127, 60-67. https://doi.org/10.1016/J.BEJ.2017.08.005

Sharma, D., 2016. Biosurfactants in Food, Surfactant Science Series. https://doi.org/10.1007/978-3319-39415-2

Shen, X.X., Opulente, D.A., Kominek, J., Zhou, X., Steenwyk, J.L., Buh, K. V., Haase, M.A.B., Wisecaver, J.H., Wang, M., Doering, D.T., Boudouris, J.T., Schneider, R.M., Langdon, Q.K., 

C.A., DeVirgilio, J., Hulfachor, A.B., Groenewald, M., Kurtzman, C.P., Hittinger, C.T., Rokas, A., 2018. Tempo and Mode of Genome Evolution in the Budding Yeast Subphylum. Cell 175, 1533-1545.e20. https://doi.org/10.1016/j.cell.2018.10.023

Shin, J.D., Lee, J., Kim, Y.B., Han, I. sun, Kim, E.K., 2010. Production and characterization of methyl ester sophorolipids with 22-carbon-fatty acids. Bioresour. Technol. 101, 3170-3174. https://doi.org/10.1016/j.biortech.2009.12.019

Sieverding, E., 2015. Increasing yields by the use of sophorolipids (WO2015172964A1). WO2015172964A1.

SINGH, R., GLICK, B.R., RATHORE, D., 2018. Biosurfactants as a Biological Tool to Increase Micronutrient Availability in Soil: A Review. Pedosphere 28, 170-189. https://doi.org/10.1016/S1002-0160(18)60018-9

Siramshetty, V.B., Nickel, J., Omieczynski, C., Gohlke, B.-O., Drwal, M.N., Preissner, R., 2016. WITHDRAWN-a resource for withdrawn and discontinued drugs. Nucleic Acids Res. 44,

Sleator, R.D., Hill, C., 2002. Bacterial osmoadaptation: the role of osmolytes in bacterial stress and virulence. FEMS Microbiol. Rev. 26, 49-71. https://doi.org/10.1111/j.1574-6976.2002.tb00598.x

Smyth, T.J.P., Rudden, M., Tsaousi, K., Marchant, R., Banat, I.M., 2014. Protocols for the Detection and Chemical Characterisation of Microbial Glycolipids. Springer, Berlin, Heidelberg, pp. 2960. https://doi.org/10.1007/8623_2014_25

Soden, A., Francis, I.L., Oakey, H., Henschke, P.A., 2000. Effects of co-fermentation with Candida

Solaiman, D.K.Y., Ashby, R.D., Crocker, N. V., 2015. High-titer production and strong antimicrobial activity of sophorolipids from Rhodotorula bogoriensis. Biotechnol. Prog. 31, 867-874. https://doi.org/10.1002/btpr.2101

Solaiman, D.K.Y., Ashby, R.D., Nuñez, A., Foglia, T.A., 2004. Production of sophorolipids by Candida bombicola grown on soy molasses as substrate. Biotechnol. Lett. 26, 1241-1245. https://doi.org/10.1023/B:BILE.0000036605.80577.30 bitter tastant and at least one sophorolipid, and methods of reducing bitter taste attributed to a bitter tastant in an edible composition. 16/174570. 
Solaiman, D.K.Y., Roelants, S.L.K.W., Ashby, R.., Van Renterghem, L., Lodens, S., Soetaert, W., 2018. Chapter 3: Production and application of sophorolipids. Biobased surfactants Synth. Prop. Appl. Second Ed. 84.

Song, D., Liang, S., Yan, L., Shang, Y., Wang, X., 2016. Solubilization of Polycyclic Aromatic Hydrocarbons by Single and Binary Mixed Rhamnolipid-Sophorolipid Biosurfactants. J. Environ. Qual. 45, 1405-1412. https://doi.org/10.2134/jeq2015.08.0443

Song, X., 2013. Method for producing sophorolipid through fermentation by taking cottonseed molasses and cottonseed oil as substrates. (CN103540631A).

Souza, K.S.T., Gud Na, E.J., Azevedo, Z., De Freitas, V., Schwan, R.F., Rodrigues, L.R., Dias, D.R., Teixeira, J.A., 2017. New glycolipid biosurfactants produced by the yeast strain Wickerhamomyces anomalus CCMA 0358. Colloids Surfaces B Biointerfaces 154, 373-382. https://doi.org/10.1016/j.colsurfb.2017.03.041

Spencer, J.F.T., Gorin, P.A.J., Tulloch, A.P., 1970. Torulopsis bombicola sp. n. Antonie Van Leeuwenhoek 36, 129-133. https://doi.org/10.1007/BF02069014

Spohner, S.C., Schaum, V., Quitmann, H., Czermak, P., 2016. Kluyveromyces lactis: An emerging tool in biotechnology. J. Biotechnol. https://doi.org/10.1016/j.jbiotec.2016.02.023

SyntheZyme, 2012. synthezyme's fungicides and antimicrobials [WWW Document]. URL https://greenchemicalsblog.com/wpcontent/uploads/2012/09/synthezyme_fungicides_and_antimicrobials.pdf (accessed 3.24.21).

Szenk, M., Dill, K.A., de Graff, A.M.R., 2017. Why Do Fast-Growing Bacteria Enter Overflow Metabolism? Testing the Membrane Real Estate Hypothesis. Cell Syst. https://doi.org/10.1016/j.cels.2017.06.005

Tadros, T., 2013. Food Surfactants. In: Encyclopedia of Colloid and Interface Science. Springer Berlin Heidelberg, Berlin, Heidelberg. https://doi.org/10.1007/978-3-642-20665-8

Takahashi, M., Morita, T., Wada, K., Hirose, N., Fukuoka, T., Imura, T., Kitamoto, D., 2011. Production of Sophorolipid Glycolipid Biosurfactants from Sugarcane Molasses Using Starmerella bombicola NBRC 10243. J. Oleo Sci. 60, 267-273.

Tanford, C., 1973. The hydrophobic effect: Formation of micelles and biological membranes. WileyInterscience.

Teichmann, B., Linne, U., Hewald, S., Marahiel, M.A., Bolker, M., 2007. A biosynthetic gene cluster for a secreted cellobiose lipid with antifungal activity from Ustilago maydis. Mol. Microbiol. 66, 525-533. https://doi.org/10.1111/j.1365-2958.2007.05941.x 
Thaniyavarn, J., Chianguthai, T., Sangvanich, P., Roongsawang, N., Washio, K., Morikawa, M., Thaniyavarn, S., 2008. Production of Sophorolipid Biosurfactant by Pichia anomala. Biosci. Biotechnol. Biochem. 72, 2061-2068. https://doi.org/10.1271/bbb.80166

Thavasi, R., Banat, I.M., 2018. Downstream processing of Microbial Biosurfactants, in: Thavasi, R., Banat, I.M. (Eds.), Microbial Biosurfactants and Their Environmental and Industrial Applications. CRC Press, Boca Raton, p. 12.

Thomas, L., Larroche, C., Pandey, A., 2013. Current developments in solid-state fermentation. Biochem. Eng. J. 81, 146-161. https://doi.org/10.1016/J.BEJ.2013.10.013

Tokuoka, K., Ishitani, T., Goto, S., Komagata, K., 1987. Four new yeast species beloning to the genus Candida. J. Gen. Appl. Microbiol. 33, 1-10.

Tran, H.G., 2012. Improving the glycosylation activity of cellobiose/cellodextrin phosphorylase through enzyme engineering. Ghent, Belgium: Ghent University.

Tulloch, A.P., Hill, A., Spencer, J.F.T., 1967. A new type of macrocyclic lactone from Torulopsis apicola. Chem. Commun. 0, 584. https://doi.org/10.1039/c19670000584

Tulloch, A.P., Spencer, J.F.T., 1968. Fermentation of long-chain compounds by Torulopsis apicola . IV. Products from esters and hydrocarbons with 14 and 15 carbon atoms and from methyl palmitoleate. Can. J. Chem. 46, 1523-1528. https://doi.org/10.1139/v68-249

Tulloch, A.P., Spencer, J.F.T., Deinema, M.H., 1968. A new hydroxy fatty acid sophoroside from Candida bogoriensis. Can. J. Chem. 46, 345-348. https://doi.org/10.1139/v68-057

Tulloch, A.P., Spencer, J.F.T., Gorin, P.A.J., 1962. The fermentation of long-chain compounds by Torulopsis magnoliae. I. Structures of the hydroxy fatty acids obtained by the fermentation of fatty acids and hydrocarbons. Can. J. Chem. 40, 1326-1338. https://doi.org/10.1139/v62-203

Twigg, M.S., Baccile, N., Banat, I.M., Déziel, E., Marchant, R., Roelants, S., Van Bogaert, I.N.A., 2020. Microbial biosurfactant research: time to improve the rigour in the reporting of synthesis, functional characterization and process development. Microb. Biotechnol. 1751-7915.13704. https://doi.org/10.1111/1751-7915.13704

Van Bogaert, I.N.A., Buyst, D., Martins, J.C., Roelants, S.L.K.W., Soetaert, W.K., 2016. Synthesis of bolaform biosurfactants by an engineered Starmerella bombicola yeast. Biotechnol. Bioeng. 113, 2644-2651. https://doi.org/10.1002/bit.26032

Van Bogaert, I.N.A., Ciesielska, K., Devreese, B., Soetaert, W., 2015. Sophorolipids: Microbial synthesis and application, in: Biosurfactants: Production and Utilization - Processes, Technologies, and Economics. pp. 19-37. 
Van Bogaert, I.N.A., De Maeseneire, S.L., De Schamphelaire, W., Develter, D., Soetaert, W., Vandamme, E.J., 2007. Cloning, characterization and functionality of the orotidine-5 '-phosphate decarboxylase gene (URA3) of the glycolipid-producing yeast Candida bombicola. Yeast 24, 201-208. https://doi.org/10.1002/yea.1448

Van Bogaert, I.N.A., De Maeseneire, S.L., Develter, D., Soetaert, W., Vandamme, E.J., 2008. Cloning and characterization of the glyceraldehyde 3-phosphate dehydrogenase gene of Candida bombicola and use of its promotor. J. Ind. Microbiol. Biotechnol. 35, 1085-1092.

Van Bogaert, Inge N.A., Demey, M., Develter, D., Soetaert, W., Vandamme, E.J., 2009. Importance of the cytochrome P450 monooxygenase CYP52 family for the sophorolipid-producing yeast Candida bombicola. FEMS Yeast Res. 9, 87-94. https://doi.org/10.1111/j.15671364.2008.00454.x

Van Bogaert, Inge N A, Develter, D., Fleurackers, S., 2009. A method for the production of mediumchain sophorolipids (WO2009141407A2). WO2009141407A2.

Van Bogaert, I.N.A., Holvoet, K., Roelants, S.L.K.W., Li, B., Lin, Y.C., Van de Peer, Y., Soetaert, W., 2013. The biosynthetic gene cluster for sophorolipids: A biotechnological interesting biosurfactant produced by Starmerella bombicola. Mol. Microbiol. 88, 501-509. https://doi.org/10.1111/mmi.12200

Van Bogaert, I.N.A., Saerens, K., De Muynck, C., Develter, D., Soetaert, W., Vandamme, E.J., 2007. Microbial production and application of sophorolipids. Appl. Microbiol. Biotechnol. 76, 23-34.

Van Bogaert, I.N.A., Soetaert, W., 2015. Final Report Summary - BIOSURFING (New-to-nature biosurfactants by metabolic engineering: production and application; FP7 ID:289219).

Van Bogaert, I.N.A., Soetaert, W., 2011. Sophorolipids, in: Soberón-Chávez, G. (Ed.), Biosurfactants : From Genes to Applications, Microbiology Monographs. Springer, pp. 179-210.

Van Bogaert, I.N.A., Zhang, J., Soetaert, W., 2011. Microbial synthesis of sophorolipids. Process Biochem. 46, 821-833. https://doi.org/http://dx.doi.org/10.1016/j.procbio.2011.01.010

van Duin, D., Paterson, D.L., 2016. Multidrug-Resistant Bacteria in the Community. Infect. Dis. Clin. North Am. 30, 377-390. https://doi.org/10.1016/j.idc.2016.02.004

Van Hamme, J.D., Singh, A., Ward, O.P., 2006. Physiological aspects. Part 1 in a series of papers devoted to surfactants in microbiology and biotechnology. Biotechnol. Adv. https://doi.org/10.1016/j.biotechadv.2006.08.001

Van Renterghem, L., Clicque, H., Huyst, A., Roelants, S.L.K.W., Soetaert, W., 2019. Miniaturization of Starmerella bombicola fermentation for evaluation and increasing (novel) glycolipid 
production. Appl. Microbiol. Biotechnol. 103, 4347-4362. https://doi.org/10.1007/s00253-01909766-3

Van Renterghem, L., Roelants, S.L.K.W., Baccile, N., Uyttersprot, K., Taelman, M.C., Everaert, B., Mincke, S., Ledegen, S., Debrouwer, S., Scholtens, K., Stevens, C., Soetaert, W., 2018. From lab to market: An integrated bioprocess design approach for new-to-nature biosurfactants produced by Starmerella bombicola. Biotechnol. Bioeng. 115, 1195-1206. https://doi.org/10.1002/bit.26539

Vaughn, S.F., Behle, R.W., Skory, C.D., Kurtzman, C.P., Price, N.P.J., 2014. Utilization of sophorolipids as biosurfactants for postemergence herbicides q. Crop Prot. 59, 29-34. https://doi.org/10.1016/j.cropro.2014.01.014

Vedaraman, N., Venkatesh, N.M., 2010. The effect of medium composition on the production of sophorolipids and the tensiometric properties by Starmerella bombicola MTCC 1910. Polish J. Chem. Technol. 12, 9-13. https://doi.org/10.2478/v10026-010-0011-4

Verbeke, J., Beopoulos, A., Nicaud, J.-M., 2013. Efficient homologous recombination with short length flanking fragments in Ku70 deficient Yarrowia lipolytica strains. Biotechnol. Lett. 35, 571-576. https://doi.org/10.1007/s10529-012-1107-0

Wagner, J.M., Alper, H.S., 2016. Synthetic biology and molecular genetics in non-conventional yeasts: Current tools and future advances. Fungal Genet. Biol. 89, 126-136. https://doi.org/10.1016/j.fgb.2015.12.001

Wang, H., Kaur, G., To, M.H., Roelants, S.L.K.W., Patria, R.D., Soetaert, W., Lin, C.S.K., 2020a. Efficient in-situ separation design for long-term sophorolipids fermentation with high productivity. J. Clean. Prod. 246, 118995. https://doi.org/10.1016/j.jclepro.2019.118995

Wang, H., Roelants, S.L., To, M.H., Patria, R.D., Kaur, G., Lau, N.S., Lau, C.Y., Van Bogaert, I.N., Soetaert, W., Lin, C.S., 2019. Starmerella bombicola: recent advances on sophorolipid production and prospects of waste stream utilization. J. Chem. Technol. Biotechnol. 94, 9991007. https://doi.org/10.1002/jctb.5847

Wang, H., Tsang, C.W., To, M.H., Kaur, G., Roelants, S.L.K.W., Stevens, C. V., Soetaert, W., Lin, C.S.K., 2020b. Techno-economic evaluation of a biorefinery applying food waste for sophorolipid production - A case study for Hong Kong. Bioresour. Technol. 303, 122852. https://doi.org/10.1016/j.biortech.2020.122852

Wang, Q.-M., Yurkov, A.M., Göker, M., Lumbsch, H.T., Leavitt, S.D., Groenewald, M., Theelen, B., Liu, X.-Z., Boekhout, T., Bai, F.-Y., 2015. Phylogenetic classification of yeasts and related taxa within Pucciniomycotina.

Stud.

Mycol.

81 , 149-189. 
Xiaoming, W., Jing, H., Wenxiong, C., 2005. Biological degreasing agent used in metal processing pretreatment of oil removing and degreasing, and method for processing metal surface greasy dirt.

Xu, Q., Liu, X., Wang, D., Liu, Y., Wang, Q., Ni, B.-J., Li, X., Yang, Q., Li, H., 2019. Enhanced

Xue, C.L., Solaiman, D.K.Y., Ashby, R.D., Zerkowski, J., Lee, J.H., Hong, S.T., Yang, D., Shin, J.A.,

Yang, X., Zhu, L., Xue, C., Chen, Y., Qu, L., Lu, W., 2012. Recovery of purified lactonic sophorolipid fermentation using a novel bioreactor with dual ventilation pipes and dual sieveplates coupled with a novel separation system. Microb. Biotechnol. 11, 455-464. https://doi.org/10.1111/1751-7915.13028 
2371 Zhou, G., Tian, X., Lin, Y., Zhang, S., Chu, J., 2019. Rational high-throughput system for screening of 2372 high sophorolipids-producing strains of Candida bombicola. Bioprocess Biosyst. Eng. 42, 575582. https://doi.org/10.1007/s00449-018-02062-w

2374 Zhou, S.Q., Xu, C., Wang, J., Gao, W., Akhverdiyeva, R., Shah, V., Gross, R., 2004. Supramolecular assemblies of a naturally derived sophorolipid. Langmuir 20, 7926-7932. https://doi.org/10.1021/la048590s 


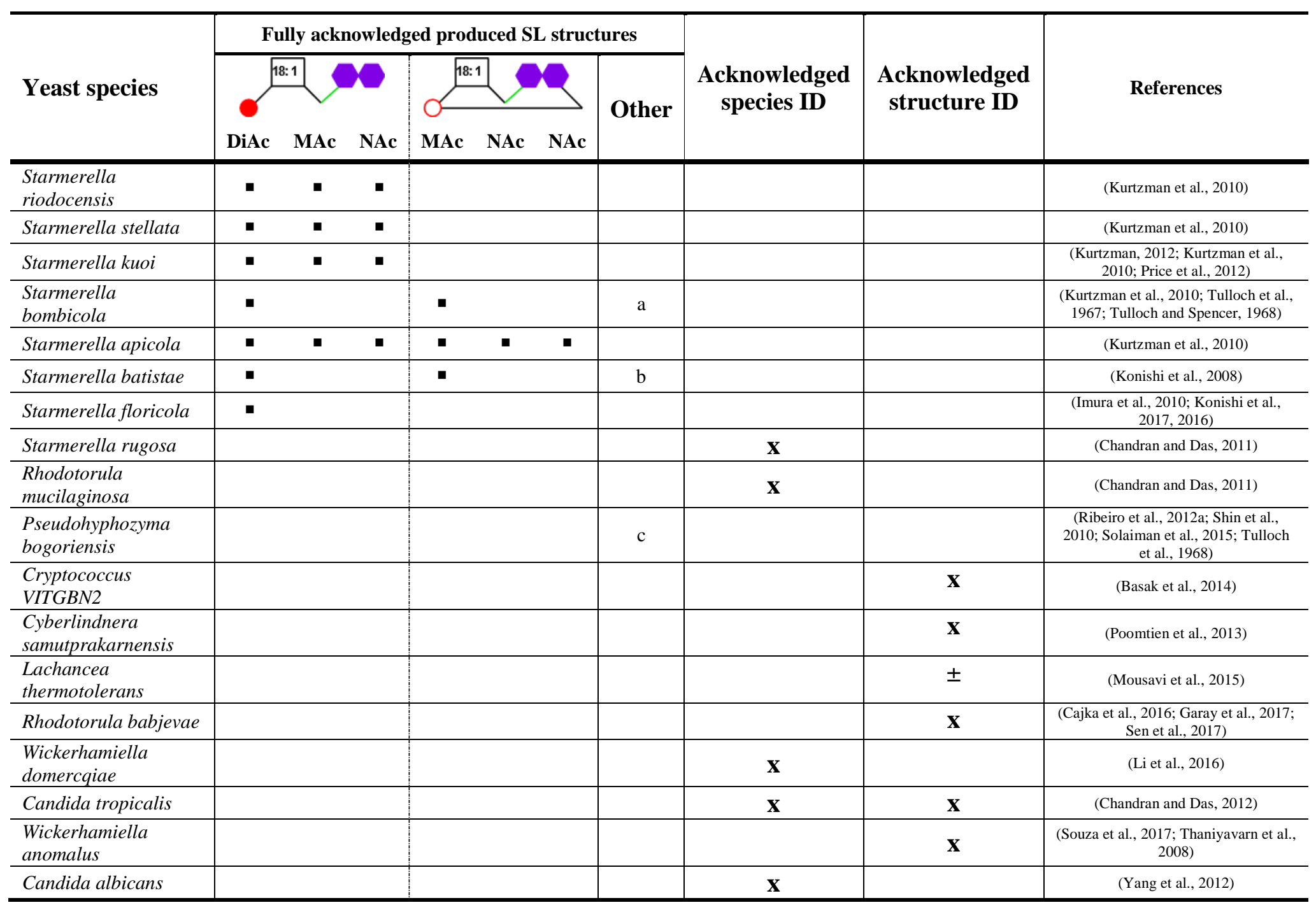


Table 2

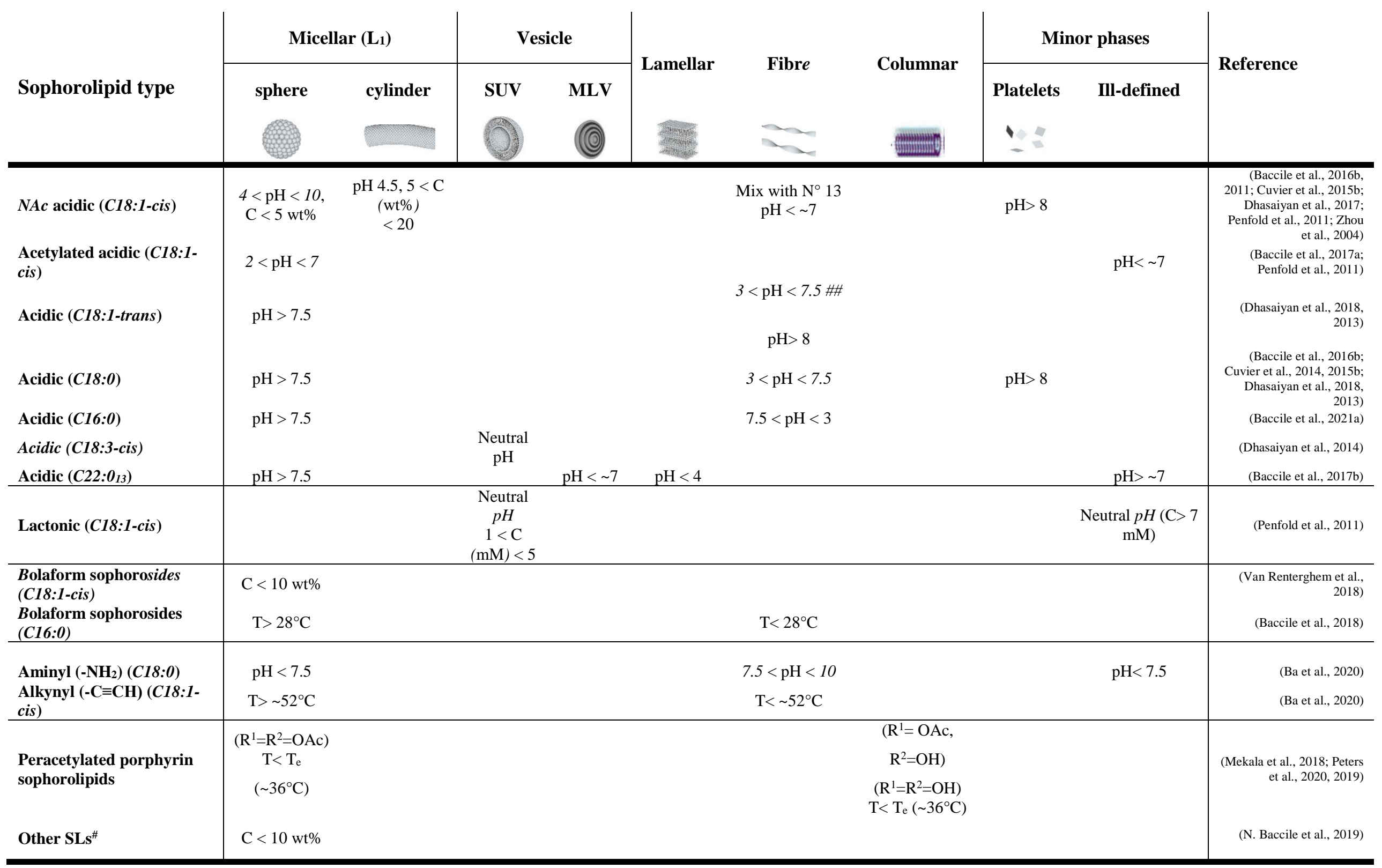





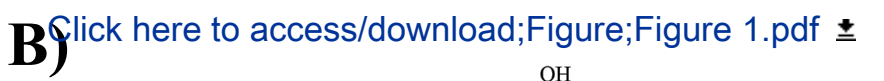

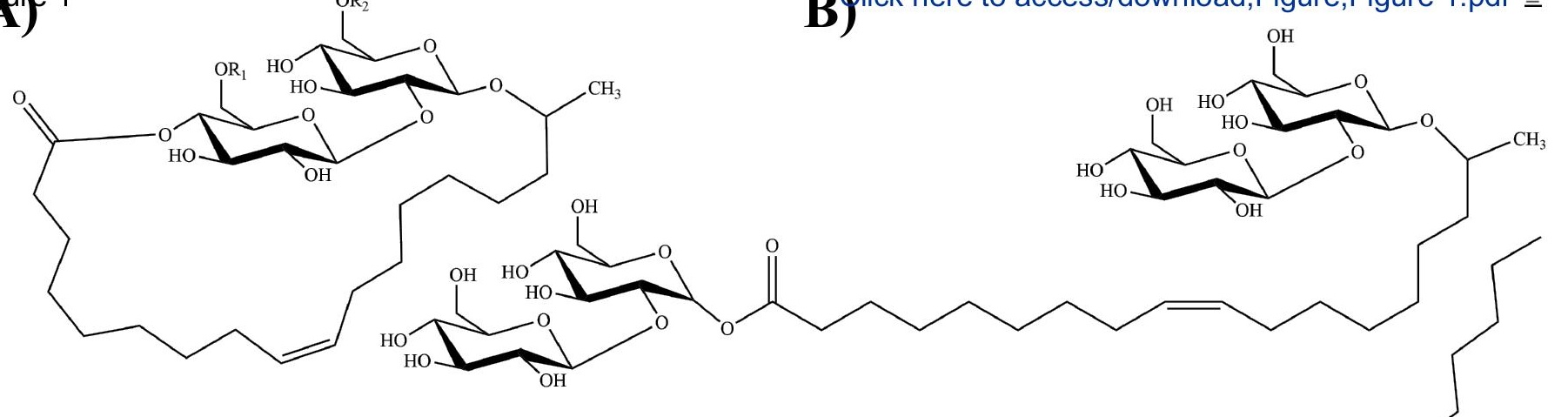

C)

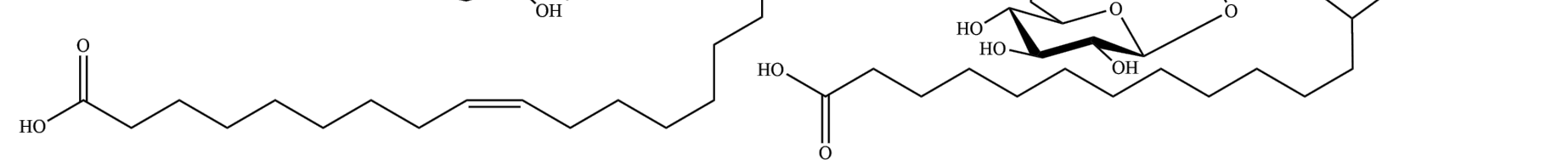


Click here to access/download;Figure;Figure 2.pdf $\underline{\underline{\boldsymbol{}}}$
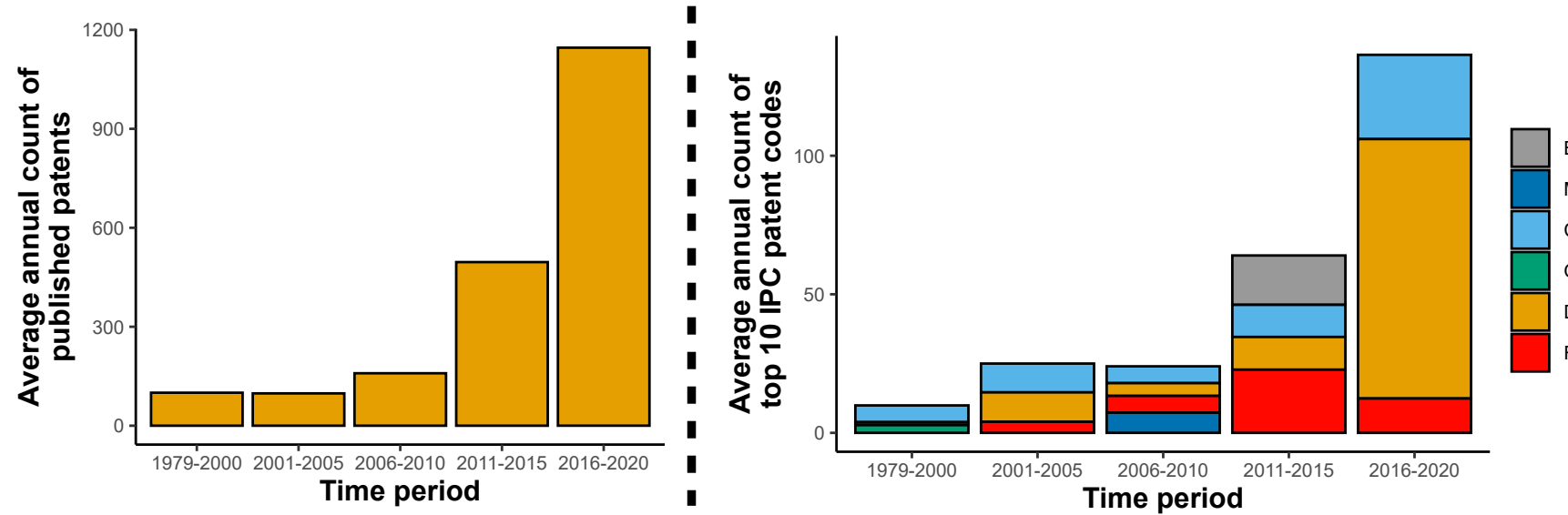

Biocide application

Medical application

Cosmetic application

Organic chemistry

Detergent application

Fermentation process 
Figure 4
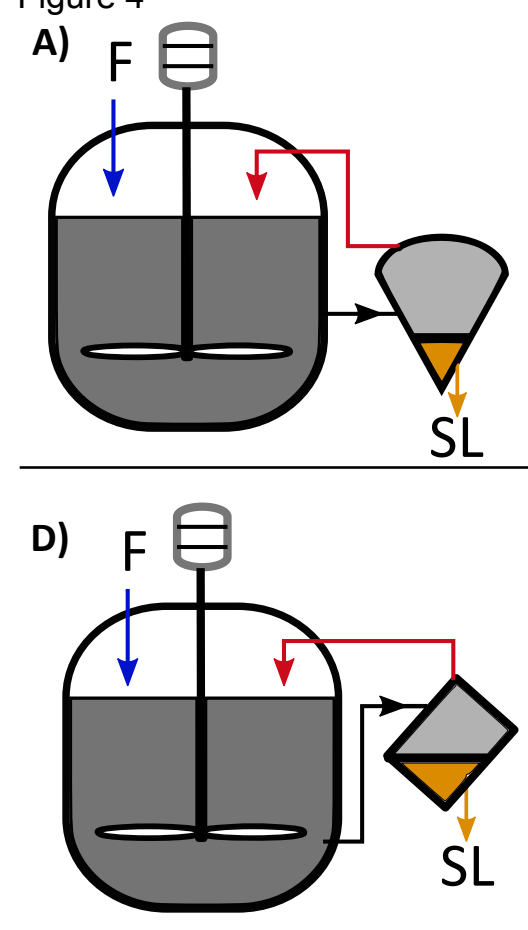

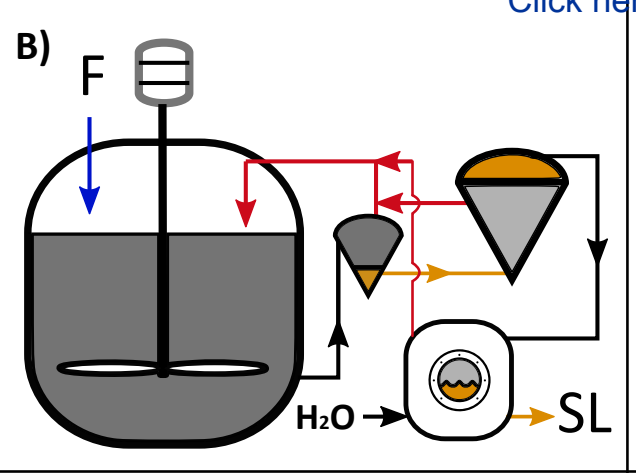

E)

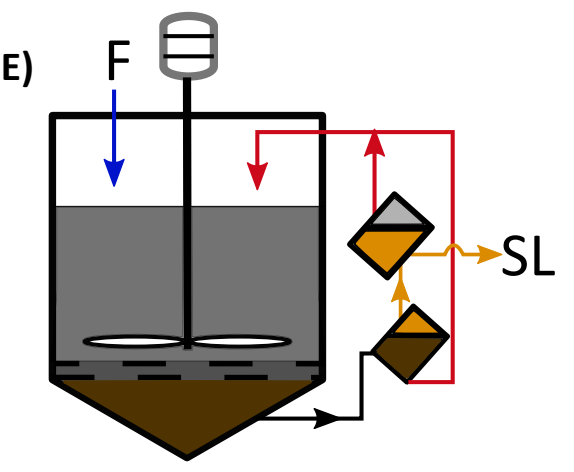

c) $\mathrm{F} \theta \mathrm{SL}$

I)

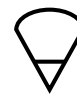

II)

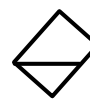

F)

SL

III)

$\triangle$

IV) 
Figure 5

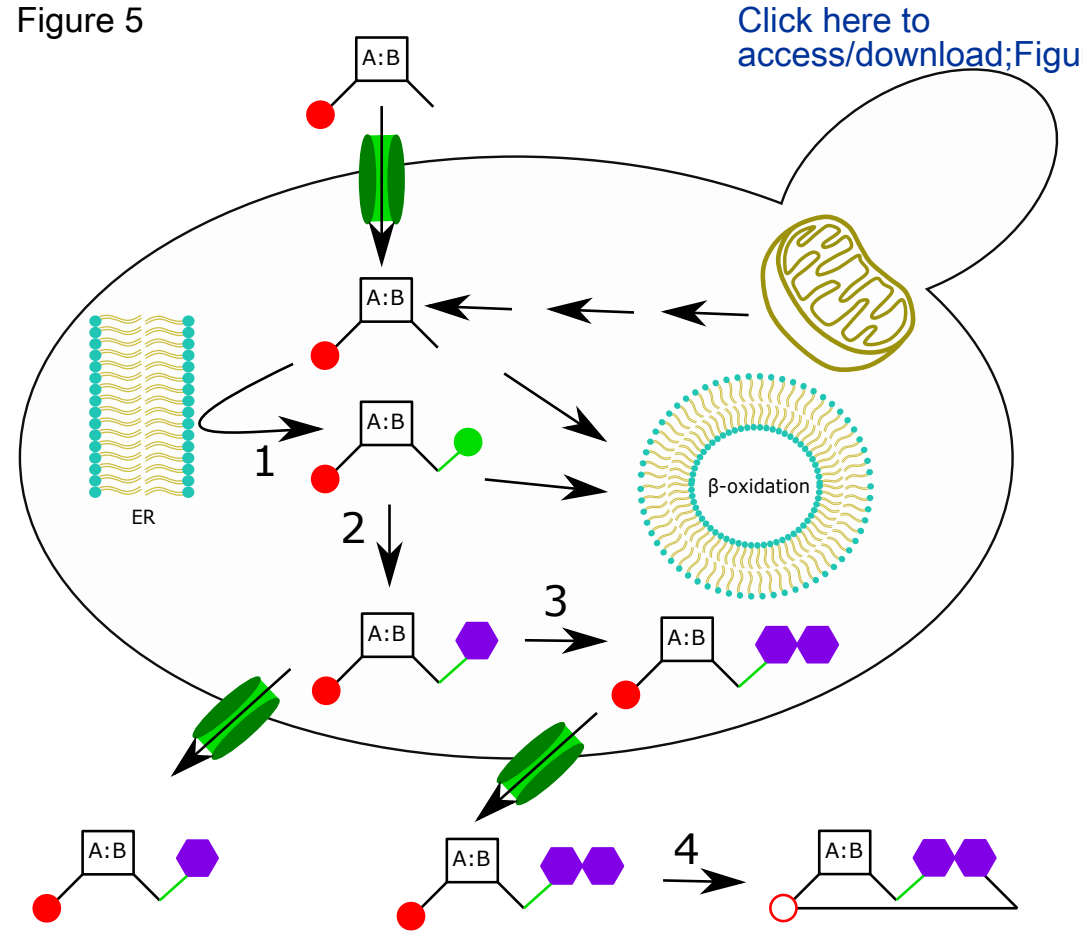

$11 \mathrm{~A}$

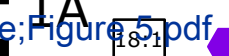

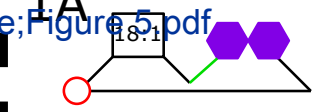

1B

12

$1 \mathrm{C}$

$18: 1$

\ $\mathrm{COOH}$ group

I hydroxyl group

glucose group

COO group 